\title{
Conception, Synthesis and Biological Evaluation of Original Discodermolide Analogues
}

\author{
Elsa de Lemos, ${ }^{[\mathrm{a}]}$ Evangelos Agouridas, ${ }^{[\mathrm{a}]}$ Geoffroy Sorin, ${ }^{[\mathrm{a}]}$ Antonio Guerreiro, ${ }^{[\mathrm{b}]}$ Alain \\ Commerçon, ${ }^{[b]}$ Ange Pancrazi, ${ }^{[a]}$ Jean-François Betzer, ${ }^{[a]}$ Marie-Isabelle Lannou, ${ }^{[a]}$ Janick \\ Ardisson $^{[a]}$
}

\begin{abstract}
Due to its intriguing biological activity profile and potential chemotherapeutic application discodermolide (DDM) proved to be an attractive target. Therefore, notable efforts have been carried out directed toward its total synthesis as well as toward the production and evaluation of synthetic analogues. Recently, we
\end{abstract}

achieved the total synthesis of DDM. At the present, guided by the knowledge gained during our DDM total synthesis and by the requirement of keeping the bioactive " $U$ " shape conformation, we report the convergent preparation of five original analogues. Three types of changes were realized through modification of the terminal
(Z)-diene moiety, of the methyl group in the $\mathrm{C} 14$ position, and the lactone region. All analogues were active in the nanomolar range and two of them turned out to be equipotent to DDM.

\section{Keywords: anticancer agents • polyketides $\bullet$ discodermolide analogues $\bullet$ cross-coupling $\bullet$ nickel}

\section{Introduction}

(+)-Discodermolide (DDM) $\mathbf{1}$ is a polypropionate natural product originally isolated from the marine sponge Discodermia dissoluta. ${ }^{[1]}$ It was found to be a potent microtubule stabilizer that binds with remarkable affinity to the taxoid site on $\beta$-tubulin in microtubules. ${ }^{[2]}$ Further studies, however, revealed clear differences between the two drugs. In vitro, DDM exhibits greater tubulin polymerization potency than Taxol, and formed microtubules are much shorter. Additionally, DDM is a poor substrate of the P-glycoprotein pump and retains antiproliferative potency against $\beta$-tubulin mutant cell lines that are resistant to taxanes and epothilones. ${ }^{[2]]}$ Interestingly, discodermolide can induce accelerated cell senescence, which is not a typical characteristic of Taxol. ${ }^{[3]}$ Of particular relevance are the findings that DDM and Taxol act synergistically, both in in vitro and in vivo tumor models, something that is not observed with taxanes and epothilones. ${ }^{[4]}$

These exciting activities resulted in a Phase I clinical trial initiated by Novartis which was suspended due to pulmonary

Dr. E. de Lemos, Dr. E. Agouridas, Dr. G. Sorin, Dr. A. Pancrazi, Dr. J.-F. Betzer, Dr. M.-I. Lannou, Prof. J. Ardisson Université Paris Descartes

Faculté de Pharmacie, CNRS UMR 8638

4 avenue de l'Observatoire

75270 Paris Cedex (France)

Fax: (+33)143291403

E-mail: jean-francois.betzer@icsn-gif.fr

marie-isabelle.lannou@parisdescartes.fr

janick.ardisson@parisdescartes.fr

[b] Dr. A. Guerreiro, Dr. A. Commerçon

Chemical \& Analytical Sciences

Natural Product Chemistry, Sanofi-Aventis

Centre de Recherche de Vitry-Alfortville

13 Quai Jules Guesde

94403 Vitry-sur-Seine Cedex (France) toxiticy, despite encouraging results. ${ }^{[5]}$ However, investigation work towards non toxic and active DDM analogues is still ongoing. ${ }^{[6]}$

(+)-DDM 1 comprises a linear polypropionate backbone, punctuated by 13 stereogenic centers, $Z$-olefinic linkages at C8-C9 and $\mathrm{C} 13-\mathrm{C} 14$, a terminal Z-diene substituent at $\mathrm{C} 21-\mathrm{C} 24$, and a $\delta$ lactone (Figure 1). Reported solid-state, solution and protein-bound DDM conformations reveal the unusual result that a common hairpin conformational motif exists in all three microenvironments. ${ }^{[7]}$ No other flexible microtubule binding agents exhibits such constancy of conformation. The stability of this strongly preferred form with respect to the central sector of the molecule, is due to steric factors (i. e. $\mathrm{A}^{1,3}$ and $\mathrm{A}^{1,2}$ strains and synpentane interactions) arising from repeated modular segments, composed of the $\mathrm{C}(\mathrm{Me})-\mathrm{CHX}-\mathrm{C}(\mathrm{Me})$ fragment as well as the $\mathrm{C} 8-\mathrm{C} 9$ and $\mathrm{C} 13-\mathrm{C} 14(Z)$ double bonds.

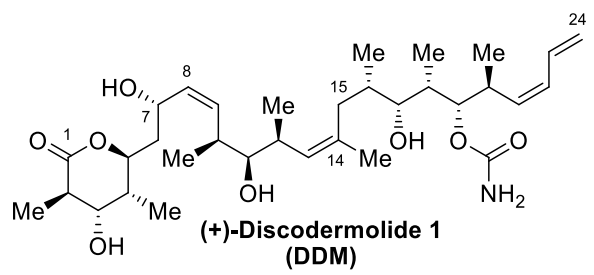

Figure 1. Discodermolide structure.

The natural product was only isolated in low yields, and no biosynthesis allowed to produce DDM to date; therefore the material necessary for biological studies must be generated synthetically. The unique profile of this medicinally relevant product has incited a number of efforts directed toward the total synthesis of (+)-DDM ${ }^{[8,9,10]}$ as well as toward the production of synthetic analogues. ${ }^{[10,11]}$ These studies have helped to define critical requirements for activity. Changes in the C15-C24 fragment of DDM were some of the first modifications investigated. The configuration of the $\mathrm{C} 16$ and $\mathrm{C} 17$ stereocentres and the geometry of the C21-C22 double bond seem 
crucial for activity. In the $\mathrm{C} 8$-C14 region of the molecule, only scarce variations have been reported. This can be attributed to the crucial importance of the middle part on the spatial orientation of the molecule. On the contrary, this is by modifying the $\delta$-lactone fragment that most of the analogues have been generated. Thus, while the carbon backbone is required to set the overall conformation of the molecule, the diene and lactone regions provide opportunities to develop analogues with improved potency, pharmacokinetic properties or simplified structure.

Recently, we achieved the total synthesis of DDM 1 using a straightforward and highly convergent route. ${ }^{[8 \mathrm{~m}-\mathrm{n}]}$ The modulable character of our approach allowing specific structural modifications, we report here the elaboration of five original DDM analogues and their biological evaluation.

\section{Results and Discussion}

The design of the analogues was guided by the chemical knowledge gained during the total synthesis and by the strong constraint of keeping the essential "U"-shaped conformation of DDM. Therefore, computational conformational analysis was performed on the focused analogues in order to check if the hairpin conformation is still favored. ${ }^{[12]}$

We envisioned modifying or replacing the terminal C21-C24 diene, the lactone region and the methyl group at the $\mathrm{C} 14$ position of DDM. Therefore, we focused on the synthesis of five analogues, 2 (including a C24 gem-di-Me group), 3 and 4 (encompassing a phenyl or a benzyl group at the C22 position), $\mathbf{5}$ (substituted by an isopropyl group at $\mathrm{C} 14$ ) and $\mathbf{6}$ (in which an aromatic group replaced the $\delta$-lactone) (Figure 2).

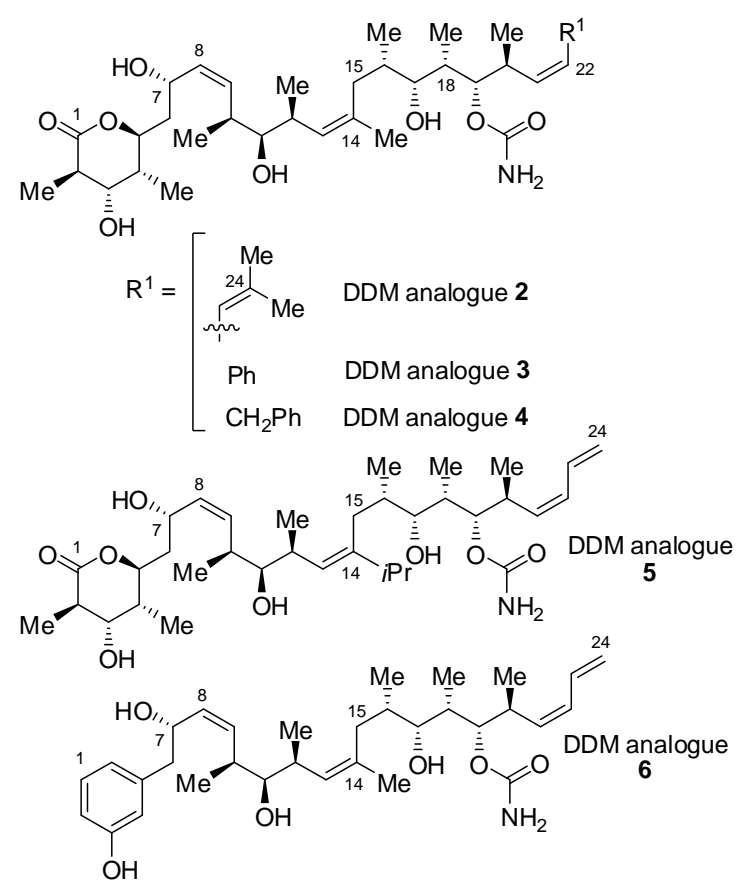

Figure 2. Focused DDM analogues.

The strategy for the preparation of the five analogues 2-6 patterned after the synthesis of DDM 1, is summarized in Scheme 1. The same disconnections were made to provide $\mathbf{A}, \mathbf{B}$ and $\mathbf{C}$ fragments. The linkage of these subunits will rely on acetylide addition to Weinreb amide [B-C] and Suzuki Pd-catalyzed $\mathrm{sp}^{2}-\mathrm{sp}^{3}$ coupling reaction $[\mathbf{A}-\mathbf{B C}]$.

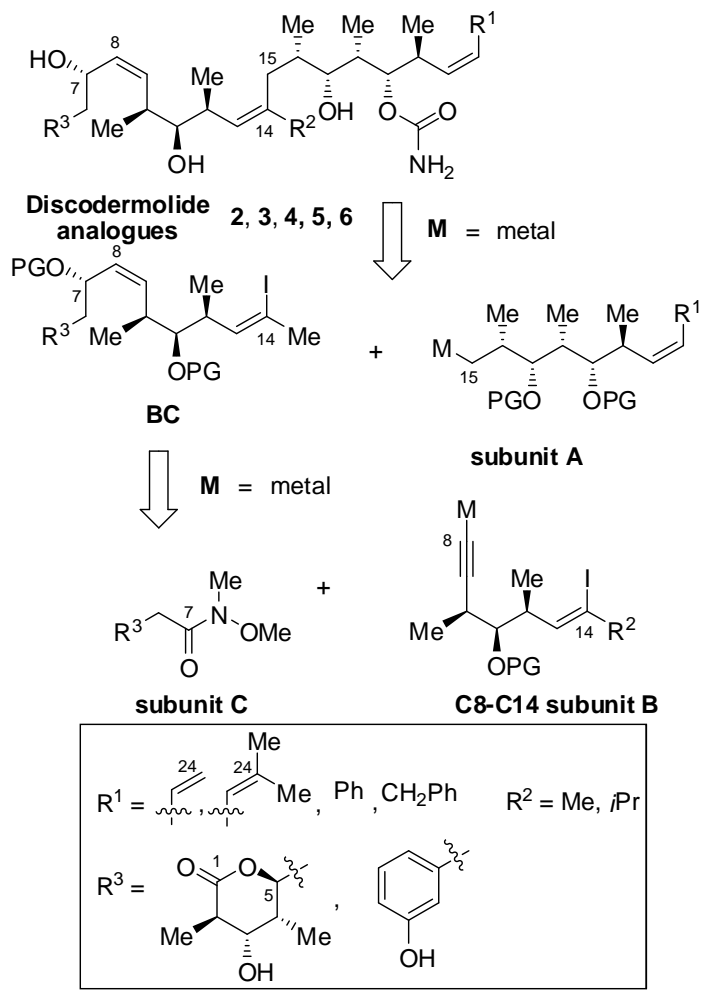

Scheme 1. DDM analogues: retrosynthetic analysis.

A central feature of our DDM 1 total synthesis was the repeated addition of the chiral $(R)$-crotyltitanium reagent 9 to a $(S)$-methyl aldehyde $\mathbf{7}$ to yield homoallylic adducts $\mathbf{1 0}$ encompassing a syn-anti methyl-hydroxy-methyl triad linked to a (Z)-O-enecarbamate group, with excellent diastereoselectivity (Scheme 2 ). The enantioenriched (R)- $\alpha$-(N,N-diisopropylcarbamoyloxy) crotyltitanium (9) was readily prepared in situ from crotyl diisopropylcarbamate $\mathbf{8}$, an equimolar mixture of $n \mathrm{BuLi} /(-)$-sparteine, and tetra(isopropoxy)titanium. ${ }^{[13,14]}$

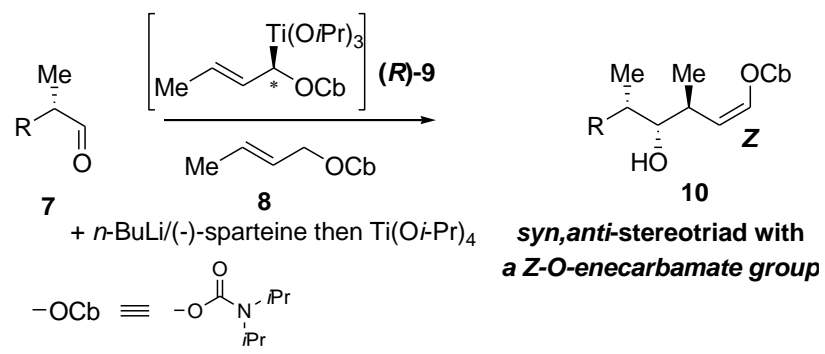

Scheme 2. DDM total synthesis: crotyltitanation of aldehyde 7 .

Furthermore, reactivity of the $(\mathrm{Z})-O$-enecarbamate moiety was critical in the preparation of the $\mathrm{C} 21-\mathrm{C} 24$ terminal (Z)-diene $\mathbf{1 2}$ of DDM. The direct vinylation of vinylcarbamate $\mathbf{1 1}$ was performed through nickel-catalyzed cross-coupling reaction in the presence of $\mathrm{Ni}(\mathrm{acac})_{2}$ with vinyllithium (Scheme 3). ${ }^{[8 \mathrm{~m}-\mathrm{n}, 15,16]}$ 


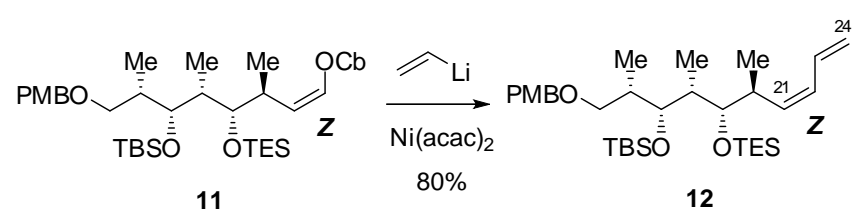

Scheme 3. DDM total synthesis: formation of the terminal (Z)-diene $\mathbf{1 2 .}$

This approach could allow us to modify the (Z) C21-C24 diene core through an extension of the nickel-catalyzed cross-coupling reaction from the terminal (Z)-O-enecarbamate compound $\mathbf{1 1}$. Hence, the elaboration of three original and more lipophilic DDM analogues was considered, one including a (Z)-diene unit with a C24 gem-di-Me group (13) and two non-diene derivatives with a phenyl or a benzyl core (14 and 15) (Scheme 4).
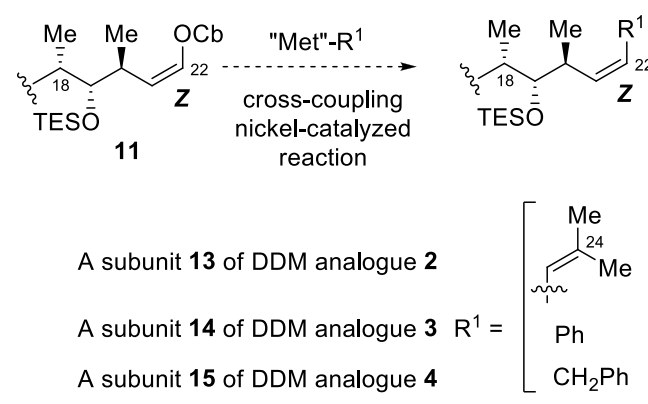

Scheme 4. Synthetic analysis of DDM analogues: set-up of the analogous terminal $(Z)$ dienes through nickel-catalyzed cross-coupling reaction.

The replacement of the methyl group at the $\mathrm{C} 14$ position by a more sterically demanding isopropyl group was very original and innovative. Although such a variation has never been reported so far, we were convinced it could enhance the specific active conformation of DDM 1. For the building of the corresponding analogue 5, we studied an improvement of the dyotropic rearrangement developed for our DDM total synthesis, ${ }^{[8 \mathrm{~m}-\mathrm{n}, 17]}$ involving an isopropyl cuprate instead of a methylcuprate, from dihydrofuran 16, to lead to olefin 17 (Scheme 5).

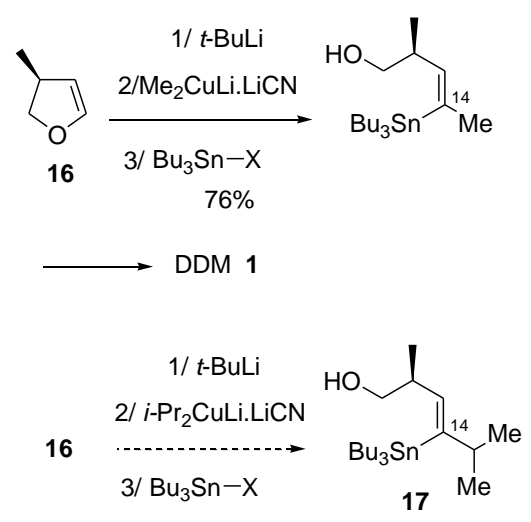

\section{DDM analogue 5}

Scheme 5. Synthetic analysis of DDM analogues: installation of an isopropyl group at the $\mathrm{C} 14$ position through dyotropic rearrangement.
Replacing the $\delta$-lactone fragment by a phenol group suggested great promise even if such already reported analogues were characterized by a slightly lower activity. ${ }^{[1 \mathrm{k}, 18]}$ However, this loss of activity was not clearly linked to $\delta$-lactone modification, since literature compounds were, at the same time, desoxygenated at the C7 position; structure-activity investigation addressing this point showed that the hydroxyl function at $\mathrm{C} 7$ could play a significant role in the biological activity (possibility of hydrogen bonding in the binding site). Therefore, we investigated the simplification of DDM backbone with a phenol core to afford analogue $\mathbf{6}$ while keeping DDM C7-hydroxyl function.

The synthesis of the DDM analogue 2 bearing a C24 gem-di-Me group started with the construction of the $(Z)$ C21-C24 diene unit (Scheme 6). It was planned by a Ni-mediated Grignard coupling reaction between the $\mathrm{C} 15-\mathrm{C} 22$ vinylcarbamate $\mathbf{1 1}$ previously prepared by us during the total synthesis of DDM ${ }^{[8 \mathrm{~m}-\mathrm{n}]}$ and 2methylpropenylmagnesium bromide. The required diene 13 was delivered in very high yield (94\%) and the geometric control was total. This compound was then smoothly transformed into the corresponding C15-C24 sub-unit $\mathbf{1 8}$ in two steps. The second key step involved an $\mathrm{sp}^{2}-\mathrm{sp}^{3}$ Suzuki coupling reaction ${ }^{[19]}$ by using Balkyl organoborane species prepared from alkyl iodide 18 and $\mathrm{C} 1-$ C14 vinyl iodide 19 already described in our DDM synthesis, ${ }^{[8 \mathrm{~m}-\mathrm{n}]}$ to afford adduct $\mathbf{2 0}$ in non optimized $51 \%$ yield.
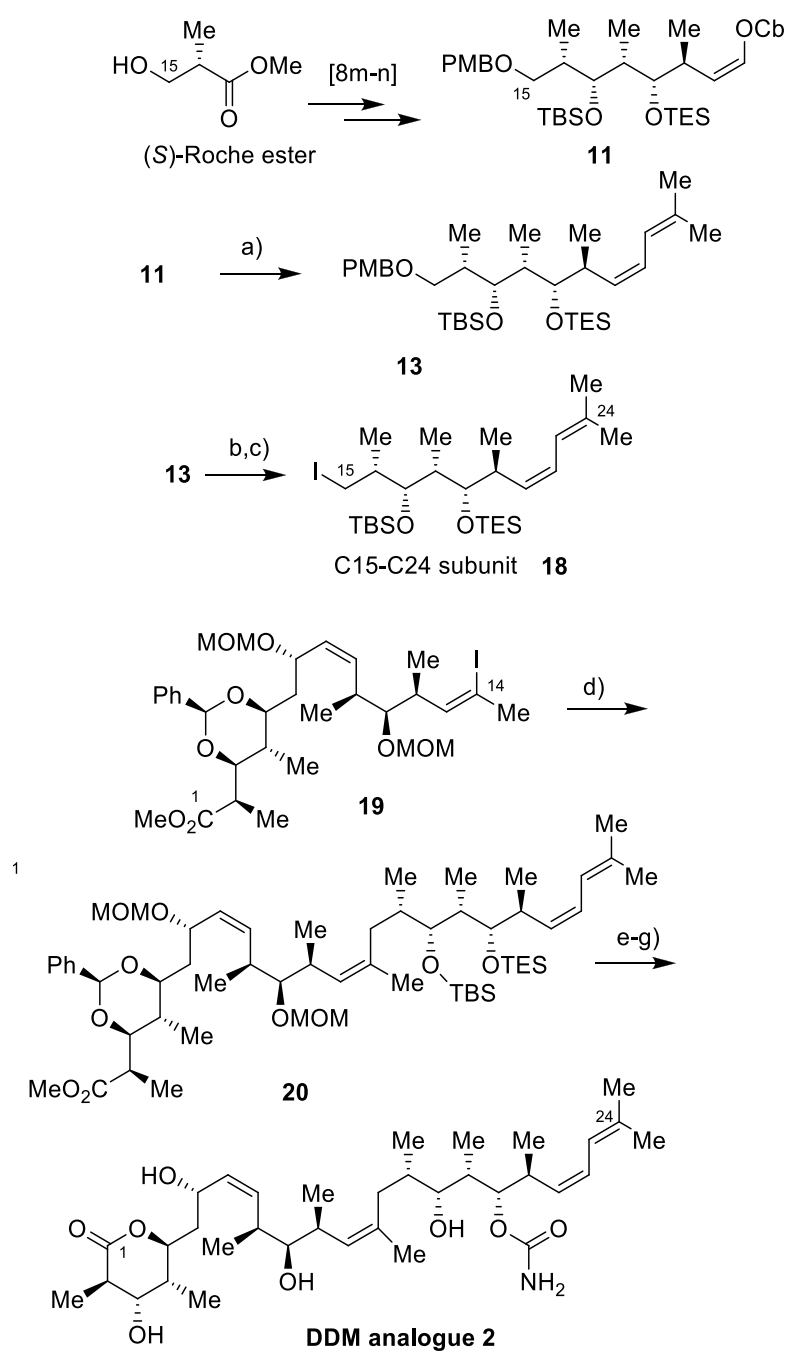

Scheme 6. Synthesis of DDM analogue 2. a) $\mathrm{Ni}(\mathrm{acac})_{2}, \mathrm{Et}_{2} \mathrm{O}, 0{ }^{\circ} \mathrm{C}, \quad 2$ methylpropenylmagnesium bromide, $16 \mathrm{~h}, 94 \%$; b) DDQ, $\mathrm{CH}_{2} \mathrm{Cl}_{2} / \mathrm{H}_{2} \mathrm{O} 95: 5,0{ }^{\circ} \mathrm{C} \rightarrow \mathrm{RT}$, 
$3 \mathrm{~h} 30,83 \%$; c) $\mathrm{I}_{2}, \mathrm{PPh}_{3}$, imid, $\mathrm{C}_{6} \mathrm{H}_{6} / \mathrm{Et}_{2} \mathrm{O}, 0{ }^{\circ} \mathrm{C} \rightarrow \mathrm{RT}, 2 \mathrm{~h}, 61 \%$; d) 18, $t \mathrm{BuLi}, \mathrm{Et}_{2} \mathrm{O}$, $78{ }^{\circ} \mathrm{C}$, 5 min, $B$-methoxy-9-BBN, THF, $-78{ }^{\circ} \mathrm{C} \rightarrow \mathrm{RT}$, then $19, \mathrm{Cs}_{2} \mathrm{CO}_{3}, \mathrm{PdCl}_{2} \mathrm{dppf}$, $\mathrm{AsPh}_{3}, \mathrm{DMF}, \mathrm{H}_{2} \mathrm{O}, 16 \mathrm{~h}, 51 \%$; e) PTSA, $\mathrm{MeOH}, 0{ }^{\circ} \mathrm{C}, 1 \mathrm{~h}, 70 \%$; f) $\mathrm{Cl}_{3} \mathrm{CC}(\mathrm{O}) \mathrm{NCO}$ $\mathrm{CH}_{2} \mathrm{Cl}_{2}$, RT, 15 min, then $\mathrm{K}_{2} \mathrm{CO}_{3}, \mathrm{MeOH}, \mathrm{RT}, 1.15 \mathrm{~h}, 78 \%$; g) $\mathrm{HCl} 4 \mathrm{~N}$, THF, RT, $72 \mathrm{~h}$, 47\%. acac=acetylacetonate, $\mathrm{DDQ}=2,3$-dichloro-5,6-dicyano-1,4-benzoquinone imid=imidazole, $\mathrm{BBN}=$ borabicyclo[3,3,1]nonane, $\mathrm{dppf}=($ diphenylphosphino)ferrocene.

Selective cleavage of the C19-TES ether followed by carbamate moiety installation and final total deprotection with concomitant lactonisation provided DDM analogue 2.

The elaboration of the non-diene analogue $\mathbf{3}$ possessing a phenyl group followed a similar sequence from vinylcarbamate $\mathbf{1 1}$ (Scheme 7). Thus, nickel-catalyzed cross-coupling reaction involving phenylmagnesium bromide ensured the construction of the C15-C24 sub-unit 21 with high selectivity. Then, $\mathrm{sp}^{2}-\mathrm{sp}^{3}$ Suzuki coupling reaction (formation of 22), carbamate function set-up and deprotection delivered desired DDM analogue $\mathbf{3}$.
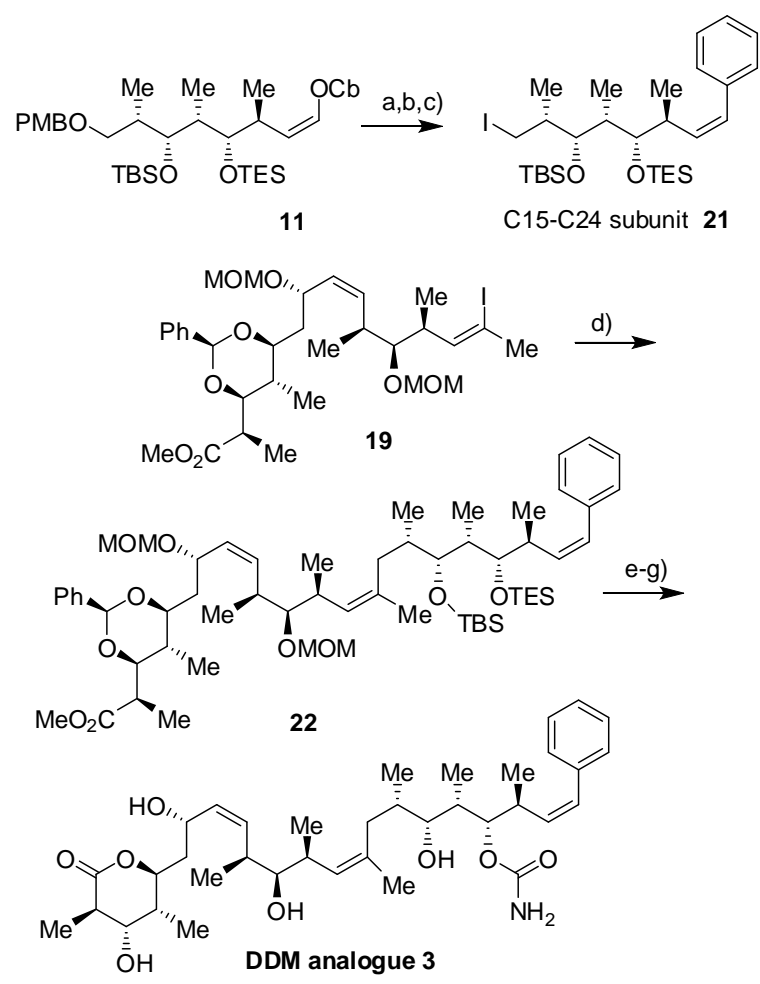

Scheme 7. Synthesis of DDM analogue 3. a) 14: $\mathrm{Ni}(\mathrm{acac})_{2}, \mathrm{Et}_{2} \mathrm{O}, 0{ }^{\circ} \mathrm{C}$ phenylmagnesium bromide, 16h; b) DDQ, $\mathrm{CH}_{2} \mathrm{Cl}_{2} / \mathrm{H}_{2} \mathrm{O} 95: 5,0{ }^{\circ} \mathrm{C} \rightarrow \mathrm{RT}, 3 \mathrm{~h} 30,59 \%$ over 2 steps; c) $\mathrm{I}_{2}, \mathrm{PPh}_{3}$, imid, $\mathrm{C}_{6} \mathrm{H}_{6} / \mathrm{Et}_{2} \mathrm{O}, 0{ }^{\circ} \mathrm{C} \rightarrow \mathrm{RT}, 3 \mathrm{~h}, 86 \%$; d) $21, t \mathrm{BuLi}^{\circ} \mathrm{Et}_{2} \mathrm{O}$, $78{ }^{\circ} \mathrm{C}, 5 \mathrm{~min}, B$-methoxy-9-BBN, THF, $-78{ }^{\circ} \mathrm{C} \rightarrow \mathrm{RT}$, then $19, \mathrm{Cs}_{2} \mathrm{CO}_{3}, \mathrm{PdCl}_{2} \mathrm{dppf}$ $\mathrm{AsPh}_{3}, \mathrm{DMF}, \mathrm{H}_{2} \mathrm{O}, 16 \mathrm{~h}, 10 \%$; e) PTSA, $\mathrm{MeOH}, 0{ }^{\circ} \mathrm{C}, 1 \mathrm{~h}, 69 \%$; f) $\mathrm{Cl}_{3} \mathrm{CC}(\mathrm{O}) \mathrm{NCO}$, $\mathrm{CH}_{2} \mathrm{Cl}_{2}, \mathrm{RT}, 15 \mathrm{~min}$, then $\mathrm{K}_{2} \mathrm{CO}_{3}, \mathrm{MeOH}, \mathrm{RT}, 1.15 \mathrm{~h}, 58 \%$; g) $\mathrm{HCl} 4 \mathrm{~N}, \mathrm{THF}, \mathrm{RT}, 72 \mathrm{~h}$, $91 \%$. acac=acetylacetonate, $\mathrm{DDQ}=2,3$-dichloro-5,6-dicyano-1,4-benzoquinone, imid= imidazole, $\mathrm{BBN}=$ borabicyclo[3,3,1]nonane, $\mathrm{dppf}=($ diphenylphosphino $)$ ferrocene.

For the synthesis of the second non-diene analogue 4 bearing a benzyl group, DDQ cleavage of the PMB ether at the C15 position did not proceed in the presence of the benzyl function. Therefore, we inverted the order of the first two steps, DDQ deprotection and $\mathrm{Ni}$-mediated coupling reaction (Scheme 8). Except this minor modification, completion of the synthesis following the established route (Suzuki reaction between alkyl iodide 23 and vinyl iodide 19 to yield 24, selective carbamate installation and final deprotection) allowed the preparation of DDM analogue 4.

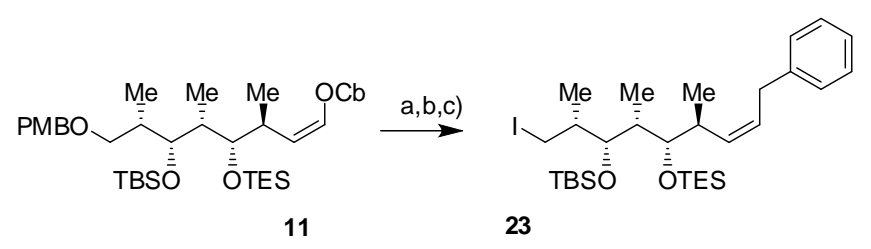

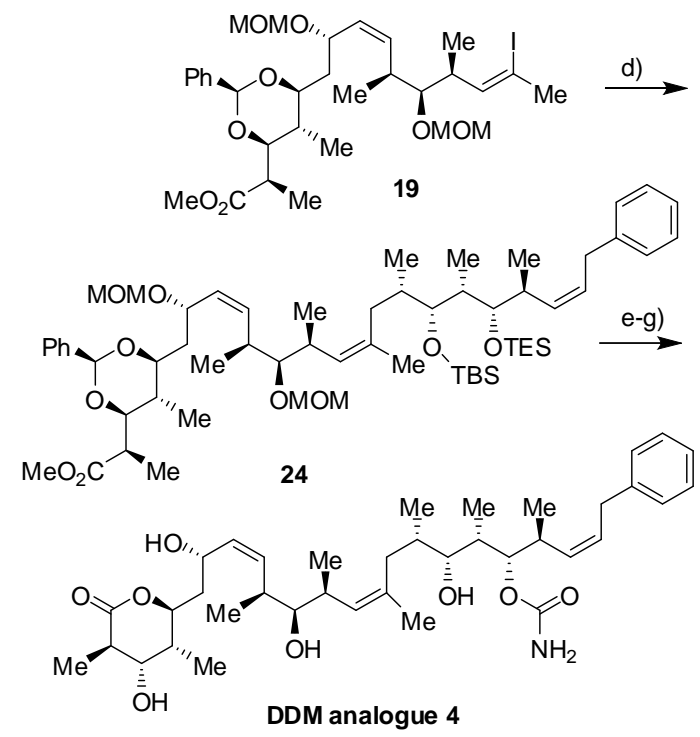

Scheme 8. Synthesis of DDM analogue 4. a) DDQ, $\mathrm{CH}_{2} \mathrm{Cl}_{2} / \mathrm{H}_{2} \mathrm{O} 95: 5,0{ }^{\circ} \mathrm{C} \rightarrow \mathrm{RT}, 30$ min, $60 \%$ b) 15: Ni(acac) 2 , Et $2 \mathrm{O}$, rt, benzylmagnesium chloride, $3 \mathrm{~h} ; 73 \%$; c) $\mathrm{I}_{2}, \mathrm{PPh}_{3}$, imid, $\mathrm{C}_{6} \mathrm{H}_{6} / \mathrm{Et}_{2} \mathrm{O}, 0{ }^{\circ} \mathrm{C} \rightarrow \mathrm{RT}, 2 \mathrm{~h}, 77 \%$; d) $23, t \mathrm{BuLi}, \mathrm{Et}_{2} \mathrm{O},-78{ }^{\circ} \mathrm{C}, 2 \mathrm{~min}, B$-methoxy9-BBN, THF, $-78{ }^{\circ} \mathrm{C} \rightarrow$ RT, then 19, $\mathrm{Cs}_{2} \mathrm{CO}_{3}, \mathrm{PdCl}_{2} \mathrm{dppf}, \mathrm{AsPh}_{3}, \mathrm{DMF}, \mathrm{H}_{2} \mathrm{O}, 16 \mathrm{~h}$, $30 \%$; e) PTSA, $\mathrm{MeOH}, 0{ }^{\circ} \mathrm{C}, 1 \mathrm{~h}, 80 \%$; f) $\mathrm{Cl}_{3} \mathrm{CC}(\mathrm{O}) \mathrm{NCO}, \mathrm{CH}_{2} \mathrm{Cl}_{2}, \mathrm{RT}, 15 \mathrm{~min}$, then $\mathrm{K}_{2} \mathrm{CO}_{3}, \mathrm{MeOH}, \mathrm{RT}, 1.15 \mathrm{~h}, 27 \%$; g) $\mathrm{HCl} 4 \mathrm{~N}, \mathrm{THF}, \mathrm{RT}, 72 \mathrm{~h}, 56 \%$. acac=acetylacetonate, $\quad \mathrm{DDQ}=2,3$-dichloro-5,6-dicyano-1,4-benzoquinone, imid =imidazole, $\mathrm{BBN}=$ borabicyclo[3,3,1]nonane, $\mathrm{dpp} f=($ diphenylphosphino $)$ ferrocene.

The synthesis of the fourth analogue $\mathbf{5}$, substituted at the C14 position by an isopropyl group, was then investigated. DHF (+/-)-16 ${ }^{[8 \mathrm{~m}-\mathrm{n}]}$ was subjected to metallate rearrangement under the previously developed optimized laboratory conditions with a cyano-Gilman isopropylcuprate to lead to the expected $(Z)$-alkene $(+/-)-17$ in a satisfactory $72 \%$ yield and total diastereoselectivity (Scheme 9 ). A two-step sequence, oxidation and crotyltitanation with the inherently chiral secondary organometallic reagent $(R)-\mathbf{9}$, delivered the required homoallylic alcohol $\mathbf{2 5}$ as main product in $41 \%$ yield along with its diastereomer $\mathbf{2 6}$ in $25 \%$ yield. To confirm the configuration of the $(S)$-C11 secondary hydroxy centre, secondary alcohol $\mathbf{2 5}$ was derivatized to give the $(R)$ - and $(S)$ - $\alpha$-methoxy-phenylacetic acid (MPA) esters. ${ }^{[20,21]}$ From vinylcarbamate 25, $\alpha$-elimination reaction upon a $t \mathrm{BuLi}$ treatment and subsequent $\mathrm{C} 11$ alcohol protection furnished alkyne 27. 


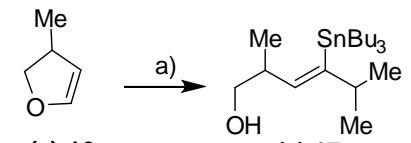

$( \pm)-16$ $( \pm)-17$

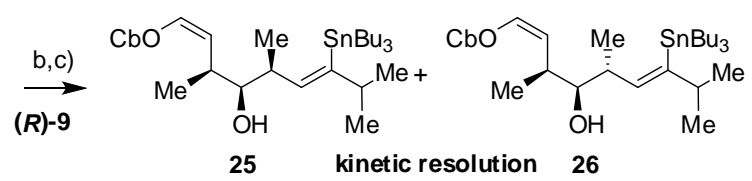<smiles>C#C[C@H](C)[C@H](OC)[C@@H](C)/C=C(\SCCCC)C(C)C</smiles>

27

Scheme 9. Synthesis of alkyne 27. a) $t \mathrm{BuLi}, i \mathrm{Pr}_{2} \mathrm{CuLi}$.LiCN, Et $2 \mathrm{O} / \mathrm{DMS} 4: 1,0{ }^{\circ} \mathrm{C} \rightarrow$ $\mathrm{RT}, 12 \mathrm{~h}$, then $n$-Bu $\mathrm{SnCl},-30{ }^{\circ} \mathrm{C} \rightarrow \mathrm{RT}, 5 \mathrm{~h}, 72 \%$; b) TEMPO (10 mol\%), BAIB, $\mathrm{CH}_{2} \mathrm{Cl}_{2}, \mathrm{RT}, 2 \mathrm{~h}$; c) $(R)-9$, cyclohexane/pentane $1: 7,-78{ }^{\circ} \mathrm{C}, 3 \mathrm{~h}$, compound $2541 \%$ over 2 steps and compound $2625 \%$ over 2 steps; d) $t \mathrm{BuLi}$, THF, $-40{ }^{\circ} \mathrm{C} \rightarrow-20{ }^{\circ} \mathrm{C}, 20$ min, 62\%; e) $\mathrm{MOMCl}$, TBAI, Hunig's base, $\mathrm{CH}_{2} \mathrm{Cl}_{2}$, RT, 24 h, 88\%. TEMPO=2,2,6,6tetramethyl-1-piperidinyloxy free radical, $\mathrm{BAIB}=[\mathrm{bis}($ acetoxy)iodo]benzene, MOM=methoxymethyl, TBAI=tetra- $n$-butylammonium iodide, Hunig's base $=$ diisopropylethylamine.

Coupling of the compound 27 with the amide $28^{[8 \mathrm{~m}-\mathrm{n}]}$ delivered the ketone 29 (Scheme 10). Diastereoselective reduction of this intermediate under CBS conditions ${ }^{[22]}$ led, after protection of the alcohol at $\mathrm{C} 11$, to alkyne 30. Oxidation followed by partial hydrogenation with $\mathrm{PtO}_{2}$ (catalyst of choice for this congested alkyne) and iodine-tin exchange then completed the formation of vinyliodide 31. The convergent coupling of $\mathbf{3 1}$ with alkyliodide $\mathbf{3 2}$ [8m-n] was carried out under Suzuki conditions. ${ }^{[23]}$ Deprotection of the $\mathrm{C} 1-\mathrm{C} 24$ fragment $\mathbf{3 3}$ and carbamate formation at $\mathrm{C} 19$ then furnished DDM analogue 5 .

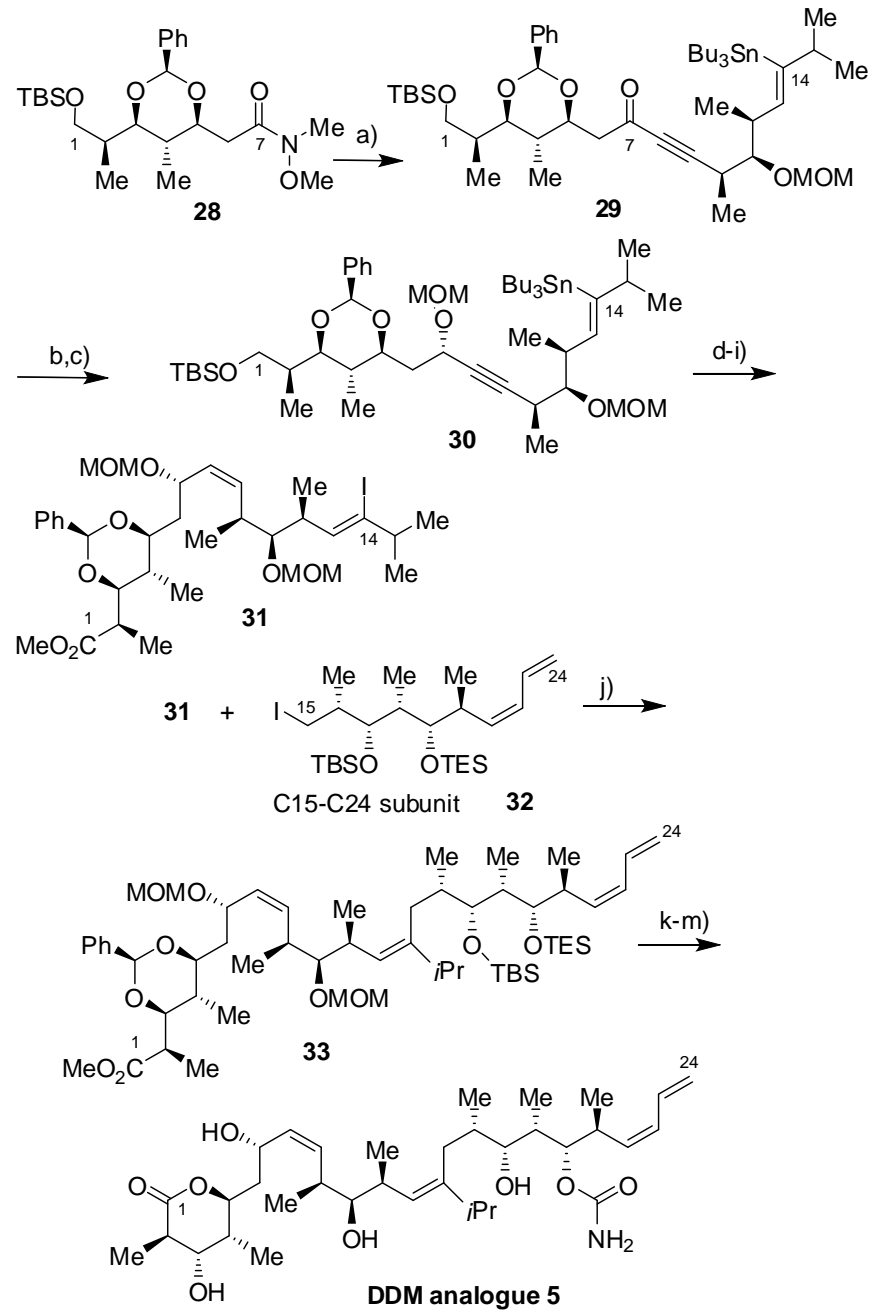

Scheme 10. Synthesis of analogue 5. a) $\mathbf{2 7}, n \mathrm{BuLi} / \mathrm{Et}_{2} \mathrm{O}, \mathrm{THF},-40{ }^{\circ} \mathrm{C}, 50 \mathrm{~min}$, then $\mathbf{2 8}$, $40{ }^{\circ} \mathrm{C}->0{ }^{\circ} \mathrm{C}, 1 \mathrm{~h}, 86 \%$; b) (S)-(-)-2-Methyl-CBS-oxazaborolidine, $\mathrm{BH}_{3} . \mathrm{Me}_{2} \mathrm{~S}$, THF, $30{ }^{\circ} \mathrm{C}, 2$ h, 89\%, dr 98:2. c) MOMCl, TBAI, Hunig's base, $\mathrm{CH}_{2} \mathrm{Cl}_{2}, \mathrm{RT}, 12$ h, 97\%; d) HF/Py, Py/THF, RT, 4 h, 87\%; e) TEMPO (10 mol\%), BAIB, $\mathrm{CH}_{2} \mathrm{Cl}_{2}, \mathrm{RT}, 3 \mathrm{~h}$; f) $\mathrm{NaClO}_{2}, \mathrm{NaH}_{2} \mathrm{PO}_{4}, \quad$ 2-methyl-but-2-ene, $t$-BuOH/H$\left./ \mathrm{H}_{2} \mathrm{O}, \mathrm{RT}, 1 \mathrm{~h} ; \mathrm{g}\right) \mathrm{TMSCHN}_{2}$, $\mathrm{C}_{6} \mathrm{H}_{6} / \mathrm{MeOH}, \mathrm{RT}, 15 \mathrm{~min}, 65 \%$ over 3 steps; h) $\mathrm{H}_{2}$, $\mathrm{PtO}_{2}$ (30 mol\%), AcOEt, RT, 12 h; i) $\mathrm{I}_{2}, \mathrm{CH}_{2} \mathrm{Cl}_{2}, 0{ }^{\circ} \mathrm{C}, 10 \mathrm{~min}, 76 \%$ over 2 steps; j) 32, $t \mathrm{BuLi}, \mathrm{Et}_{2} \mathrm{O},-78{ }^{\circ} \mathrm{C}, 5 \mathrm{~min}, B-$ methoxy-9-BBN, THF, $-78{ }^{\circ} \mathrm{C} \rightarrow \mathrm{RT}$, then 31, $\mathrm{Cs}_{2} \mathrm{CO}_{3}, \mathrm{PdCl}_{2} \mathrm{dppf}, \mathrm{AsPh}_{3}, \mathrm{DMF}, \mathrm{H}_{2} \mathrm{O}$, $16 \mathrm{~h}, 10 \%$; k) PTSA, $\mathrm{MeOH}, 0{ }^{\circ} \mathrm{C}, 1 \mathrm{~h}, 72 \%$; l) $\mathrm{Cl}_{3} \mathrm{CC}(\mathrm{O}) \mathrm{NCO}, \mathrm{CH}_{2} \mathrm{Cl}_{2}$, RT, $15 \mathrm{~min}$, then $\mathrm{K}_{2} \mathrm{CO}_{3}, \mathrm{MeOH}, \mathrm{RT}, 1.15 \mathrm{~h}, 40 \%$; m) $\mathrm{HCl} 4 \mathrm{~N}$, THF, RT, $72 \mathrm{~h}, 50 \%$. CBS= CoreyBakshi-Shibata, MOM=methoxymethyl, TBAI=tetra- $n$-butylammonium iodide, $\mathrm{Py}=$ pyridine, $\quad \mathrm{TEMPO}=2,2,6,6$-tetramethyl-1-piperidinyloxy free radical, TMS=trimethylsilyl, $\quad \mathrm{BBN}=$ borabicyclo[3,3,1]nonane, $\quad \mathrm{dppf}=($ diphenylphosphino)ferrocene, BAIB=[bis(acetoxy)iodo $]$ benzene.

The synthesis of the simplified DDM analogue $\mathbf{6}$ bearing a phenolic group instead of the $\delta$-lactone was much faster. It started with the preparation of amide $\mathbf{3 5}$ from commercial 3hydroxyphenylacetic acid $\mathbf{3 4}$ in two steps and 66\% yield (Scheme 11). Subsequent coupling of the C8-C14 alkyne 36 previously prepared in the laboratory, ${ }^{[8 \mathrm{~m}-\mathrm{n}]}$ with amide $\mathbf{3 5}$ delivered adduct $\mathbf{3 7}$ after reduction by $(S)$-CBS reagent ${ }^{[24]}$ and protection of the newly generated hydroxy function at $\mathrm{C} 7$. Hydrogenation and iodine-tin exchange then led to vinyliodide 38. While the formation of this vinyliodide 38 proceeded smoothly, significant problems were encountered during Suzuki cross-coupling reaction between vinyliodide 38 and alkyliodide 32 . The required adduct 39 was obtained in a rather low $17 \%$ yield, the main isolated product being the cyclohexene derivative $\mathbf{4 0}$ which certainly arose from an intramolecular Heck coupling reaction. ${ }^{[25]}$ 
The same final 3-step sequence (deprotection of the C1-C24 fragment and carbamate formation at $\mathrm{C} 19$ ) delivered analogue $\mathbf{6}$.

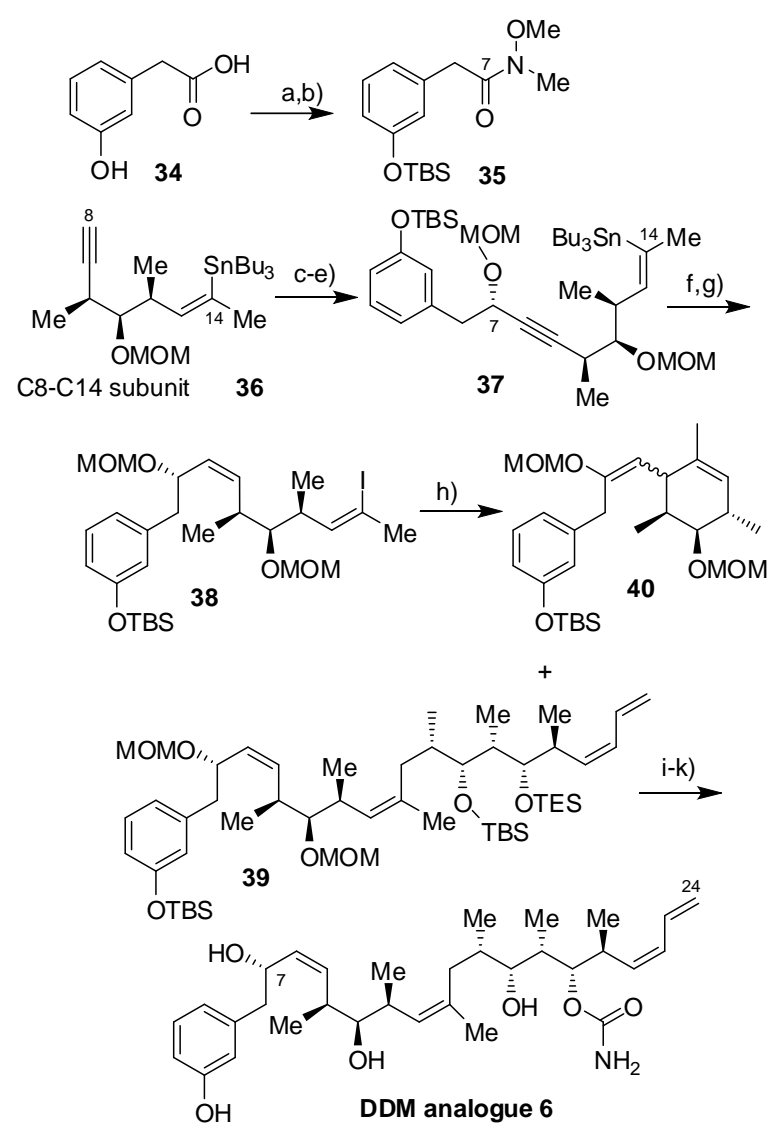

Scheme 11. Synthesis of analogue 6. a) TBSCl, imid, DMF, RT, 4 days; b) $\mathrm{HN}\left(\mathrm{CH}_{3}\right) \mathrm{OCH}_{3} . \mathrm{HCl}$, Hunig's base, EDCI.HCl, $\mathrm{HOBt}, \mathrm{CH}_{2} \mathrm{Cl}_{2}, \mathrm{RT}, 24 \mathrm{~h}, 66 \%$ over 2 steps; c) 36, $n \mathrm{BuLi} / \mathrm{Et}_{2} \mathrm{O}$, THF, $-40{ }^{\circ} \mathrm{C}, 50 \mathrm{~min}$, then $35,-40{ }^{\circ} \mathrm{C}->0{ }^{\circ} \mathrm{C}, 1 \mathrm{~h}, 63 \%$; d) $(S)$ (-)-2-Methyl-CBS-oxazaborolidine, $\mathrm{BH}_{3} \cdot \mathrm{Me}_{2} \mathrm{~S}$, THF, $-30{ }^{\circ} \mathrm{C}, 2 \mathrm{~h}, 81 \%$, dr $98: 2$; e) MOMCl, TBAI, DMAP, Hunig's base, $\mathrm{CH}_{2} \mathrm{Cl}_{2}, \mathrm{RT}, 12 \mathrm{~h}, 90 \%$; f) $\mathrm{H}_{2}, \mathrm{PtO}_{2}(30 \mathrm{~mol} \%$ ), AcOEt, RT, 12 h; g) $\mathrm{I}_{2}, \mathrm{CH}_{2} \mathrm{Cl}_{2}, 0{ }^{\circ} \mathrm{C}, 10 \mathrm{~min}, 76 \%$ over 2 steps; h) 32, $t \mathrm{BuLi}, \mathrm{Et}_{2} \mathrm{O}$, $78{ }^{\circ} \mathrm{C}, 5 \mathrm{~min}, B$-methoxy-9-BBN, THF, $-78{ }^{\circ} \mathrm{C} \rightarrow \mathrm{RT}$, then $38, \mathrm{Cs}_{2} \mathrm{CO}_{3}, \mathrm{PdCl}_{2} \mathrm{dppf}$ $\mathrm{AsPh}_{3}, \mathrm{DMF}, \mathrm{H}_{2} \mathrm{O}, 16 \mathrm{~h}, 3917 \%$ and $4020 \%$; i) 39, PTSA, $\mathrm{MeOH}, 0{ }^{\circ} \mathrm{C}, 1 \mathrm{~h}, 58 \%$; j) $\mathrm{Cl}_{3} \mathrm{CC}(\mathrm{O}) \mathrm{NCO}, \mathrm{CH}_{2} \mathrm{Cl}_{2}, \mathrm{RT}, 15 \mathrm{~min}$, then $\mathrm{K}_{2} \mathrm{CO}_{3}, \mathrm{MeOH}, \mathrm{RT}, 1.15 \mathrm{~h}, 58 \%$; $) \mathrm{HCl} 4 \mathrm{~N}$, THF, RT, 24 h, 88\%. Imid=imidazole, Hunig's base=diisopropylethylamine, EDCI=1ethyl-3-[3-dimethylamino)propyl]carbodiimide, $\mathrm{HOBt}=1$-hydroxybenzotriazole, $\mathrm{CBS}=$ Corey-Bakshi-Shibata, $\mathrm{MOM}=$ methoxymethyl, $\mathrm{DMAP}=$ dimethylaminopyridine, TBAI=tetra- $n$-butylammonium iodide, $\quad \mathrm{BBN}=$ borabicyclo[3,3,1]nonane, $\mathrm{dppf}=($ diphenylphosphino)ferrocene.

Biological evaluation: The five DDM analogues $2,3,4,5$ and 6 were finally screened for cellular activity in comparison to DDM 1 (previously synthesized in the laboratory). Cytotoxicity asssays were performed on three different cell lines. All analogues were effective in the nanomolar range comparable to DDM 1 [IC $50(\mathrm{nM})$ HCT116 and MDA-MB-231]. C24 gem-di-Me analogue 2 and C14-isopropyl analogue 5 were the most potent and both essentially equipotent to DDM (entries 1, 2 and 3, Table 1). They were followed in this order by phenolic 6 and C22-Ph 3 analogues (entries 5 and 6, Table 1). The C22-benzyl analogue 4 was the less potent (entry 4, Table 1).
Table 1. Biological evaluation of synthesized analogues 2-6. ${ }^{[a],[b]}$

\begin{tabular}{|c|c|c|c|c|}
\hline Entry & Compound & $\begin{array}{l}\mathrm{IC}_{50} \quad(\mathrm{nM}) \\
\mathrm{HCT} 116^{[\mathrm{a}]}\end{array}$ & $\begin{array}{l}\mathrm{IC}_{50}(\mathrm{nM}) \\
\text { MDA- } \\
\text { MB231 }\end{array}$ & $\begin{array}{l}\mathrm{IC}_{50}(\mathrm{nM}) \\
\mathrm{MDA}-\mathrm{A} 1^{[\mathrm{c}]}\end{array}$ \\
\hline 1 & DDM 1 & $5.0^{\mathrm{l}}$ & 15.6 & 105.8 \\
\hline 2 & C-24-gem-dimethyle 2 & 1.3 & 3.7 & 155 \\
\hline 3 & C-22-phenyle 3 & 19 & 110 & 4494 \\
\hline 4 & C-22-benzyle 4 & 321 & 1009 & 8709 \\
\hline 5 & C-14-isopropyle 5 & 2.3 & 17.5 & 2200 \\
\hline 6 & Phenol 6 & $16^{]}$ & 66 & 4836 \\
\hline
\end{tabular}

[a] In vitro cytotoxic activities were determined on triplicate samples in WST- 8 cell proliferation assays after 4 days of incubation. [b] Cells lines used: human colon cancer epithelial cell line HCT116, human breast cancer cell lines MDA-MB-231 (wild type) and MDA-A1 (anthracycline resistant).

The present data reveal that a lipophilic C24 gem-di-Me group or a sterically demanding C14-isopropyl substituent is very welltolerated and confers extremely good biological activity. This last result suggests the possibility that the C14-isopropyl substituent may increase the "U" shape bioactive conformation. The phenolic analogue 6 retains good potency considering the structure simplification and may be of utility in the design of straightforward analogues.

\section{Conclusion}

The underlying synthesis blueprint of DDM $\mathbf{1}$ allowed for the convergent preparation of five original analogues $2,3,4,5$ and 6 of DDM 1, each of them exhibiting potent cytotoxicity.

The first requirement was to keep the bioactive $U$ shaped conformation of DDM, therefore modelling studies were achieved before starting the synthesis. Three types of variation were envisioned depending on our synthetic possibilities: 1/ modifying the diene which is a lipophilic part of the compound with a gem-diMe group at the $\mathrm{C} 24$ position, phenyl or benzyl group at C22, 2/ replacing the $\mathrm{C} 14$ methyl group by a more sterically demanding alkyl group in order to reinforce the $\mathrm{U}$ shaped bioative conformation and replacing the $\delta$-lactone by a phenol moiety. If the third variation did efficiently shorten the synthesis of the $\mathrm{C} 1-\mathrm{C} 7$ fragment, the first two modifications were readily accessible through two key reactions of our synthesis of DDM. The first one is a robust and original nickel catalyzed cross-coupling reaction between an enecarbamate and the corresponding magnesium derivative, and the second one is a dyotropic rearrangement performed on a methyldihydrofuran with the corresponding isopropylcuprate. Noteworthy, in both cases, the selectivities were excellent.

Cytotoxicity assays were performed for these five analogues on three different cell lines. All analogues were active in the nanomolar range, especially the C24-gem-di-Me and the C14-iPr analogues 2 and 5 both equipotent to DDM. The phenolic analogue 6 retained a 
very significant and encouraging in vitro activity considering the structure simplification.

Investigation work towards novel simplified DDM analogues is ongoing in the laboratory.

\section{Experimental Section}

All reactions were carried out in oven or flame-dried glassware under an argon atmosphere employing standard techniques in handling air-sensitive materials. Al solvents were employing reagent grade. Tetrahydrofurane (THF) and diethyl ether $\left(\mathrm{Et}_{2} \mathrm{O}\right)$ were freshly distilled from sodium/benzophenone under argon immediately prio to use. Dichloromethane (DCM), cyclohexane and pentane were freshly distilled ove calcium hydride. All other reagents were used as supplied. Reactions were magnetically stirred and monitored by thin layer chromatography with $0.20 \mathrm{~mm}$ SDS $60 \mathrm{~F} 254$ precoated silica gel plates. Visualization was accomplished with UV light then treatment with a $10 \%$ ethanolic phosphomolybdic acid solution followed with heating. Flash chromatography was performed with silica gel 60 (particle size $0.040-0.063 \mathrm{~mm}$ ) supplied by SDS. Yield refers to chromatography and spectroscopically pure compounds, unless otherwise noted. ${ }^{1} \mathrm{H}$ NMR spectra were recorded using an internal deuterium lock at ambient temperature on a JEOL JNM-ECX 270 or $400 \mathrm{MHz}$ spectrometer. Internals references of $\delta_{\mathrm{H}} 7.26$ and 1.96 were used respectively for $\mathrm{CDCl}_{3}$ and $\mathrm{CD}_{3} \mathrm{CN}$. Data are represented as follows: chemical shift (in ppm), multiplicity (s = single, $\mathrm{d}=$ doublet, $\mathrm{t}=$ triplet, $\mathrm{q}=$ quartet $)$, integration, coupling constant $(\mathrm{J} / \mathrm{Hz}) .{ }^{13} \mathrm{C}$ NMR spectra were recorded on a Jeol 67.5 or $100.5 \mathrm{MHz}$ spectrometer. Internals references of $\delta_{\mathrm{C}} 77.16$ and 118.26 were used respectively for $\mathrm{CDCl}_{3}$ and $\mathrm{CD}_{3} \mathrm{CN}$ Infrared spectra were recorded on a Nicolet Impact-400 and wavelength $(v)$ is given in $\mathrm{cm}^{-1}$. Mass spectra were recorded on a GC/MS coupling unit with a MSD 5973 spectrometer and a Hewlett-Packard HP-GC 6890 chromatograph. Ionization was obtained either by electronic impact (EI) or chemical ionization with methane (CI, $\mathrm{CH}_{4}$ ). Mass spectral data are reported as $\mathrm{m} / \mathrm{z}$. Optical rotations were recorded on a Jasco P-1010 digital polarimeter at $589 \mathrm{~nm}$ and reported as follows: $[\alpha]_{\mathrm{D}}^{20}$, concentration (c in $\mathrm{g} / 100 \mathrm{~mL}$ ) and solvent. Elemental analysis were performed on a CHN 240 PerkinElmer instrument by the Service de Microanalyses, Centre d'Etudes Pharmaceutiques, Chatenay-Malabry, F-92296. High-resolution mass-spectra were obtained on a ThermoElectron MAT-95 spectrometer in the ICMMO, Mass Spectrometry Laboratory, Orsay University, F-91 405 Orsay. IUPAC nomenclature was used for all compounds.

(2Z,4Z,6S,7S,8R,9S,10S)-9-(tert-Butyldimethylsilyloxy)-11-(4-methoxybenzyloxy)7-(triethylsilyloxy)-1,5,7,9-tetramethyl undeca-2,4-diene (13): A solution of 2 methylpropenylmagnesium bromide ( $0.5 \mathrm{M}$ in THF, $43 \mathrm{~mL}, 21.6 \mathrm{mmol}, 10$ equiv) was added to a solution of carbamate $\mathbf{1 1}\left(1.5 \mathrm{~g}, 2.16 \mathrm{mmol}, 1.0\right.$ equiv) and $\mathrm{Ni}(\mathrm{acac})_{2}(55 \mathrm{mg}$ $0.22 \mathrm{mmol}, 0.1$ equiv) in $\mathrm{Et}_{2} \mathrm{O}(43 \mathrm{~mL})$ at $-5^{\circ} \mathrm{C} / 0^{\circ} \mathrm{C}$. The resulting mixture was stirred for $16 \mathrm{~h}$ at $0^{\circ} \mathrm{C}$. An aqueous saturated $\mathrm{NH}_{4} \mathrm{Cl}$ solution was then added, and the solution was extracted with $\mathrm{Et}_{2} \mathrm{O}$. The organic layers were washed with brine, dried ove $\mathrm{MgSO}_{4}$, filtered and the solvent removed under reduced pressure. The residue was purified by chromatography on silica gel (cyclohexane/ $\mathrm{Et}_{2} \mathrm{O} 100: 0$ to 80:20) to give $1.22 \mathrm{~g}$ (94\% yield) of compound 13. 13: $[\alpha]_{\mathrm{D}}^{20}=+5.91\left(c=1.72, \mathrm{CHCl}_{3}\right) ;{ }^{1} \mathrm{H}$ NMR $\left(400.0 \mathrm{MHz}, \mathrm{CDCl}_{3}\right) \delta=7.24(\mathrm{~d}, J=8.7 \mathrm{~Hz}, 2 \mathrm{H}), 6.86(\mathrm{~d}, J=8.7 \mathrm{~Hz}, 2 \mathrm{H}), 6.13(\mathrm{dd}, J=$ $11.5,11.0 \mathrm{~Hz}, 1 \mathrm{H}), 6.03(\mathrm{~d}, J=11.5 \mathrm{~Hz}, 1 \mathrm{H}), 5.33(\mathrm{dd}, J=11.0,10.1 \mathrm{~Hz}, 1 \mathrm{H}), 4.41(\mathrm{~d}$ $J=11.5 \mathrm{~Hz}, 1 \mathrm{H}), 4.35(\mathrm{~d}, J=11.5 \mathrm{~Hz}, 1 \mathrm{H}), 3.80\left(\mathrm{~s}, 3 \mathrm{H}, \mathrm{CH}_{3}\right), 3.78(\mathrm{dd}, J=5.5,3.7 \mathrm{~Hz}$ $1 \mathrm{H}), 3.51(\mathrm{dd}, J=5.0,4.6 \mathrm{~Hz}, 1 \mathrm{H}), 3.36(\mathrm{dd}, J=8.7,5.9 \mathrm{~Hz}, 1 \mathrm{H}), 3.12(\mathrm{dd}, J=8.7,8.2$ $\mathrm{Hz}, 1 \mathrm{H}), 2.80(\mathrm{~m}, 1 \mathrm{H}), 1.94(\mathrm{~m}, 1 \mathrm{H}), 1.78\left(\mathrm{~s}, 3 \mathrm{H}, \mathrm{CH}_{3}\right), 1.74\left(\mathrm{~s}, 3 \mathrm{H}, \mathrm{CH}_{3}\right), 1.68-1.62$ $(\mathrm{m}, 1 \mathrm{H}), 0.97\left(\mathrm{~d}, J=6.9 \mathrm{~Hz}, 3 \mathrm{H}, \mathrm{CH}_{3}\right), 0.94\left(\mathrm{t}, J=7.8 \mathrm{~Hz}, 9 \mathrm{H}, 3 \mathrm{CH}_{3}\right), 0.89(\mathrm{~s}, 9 \mathrm{H}$ $\left.3 \mathrm{CH}_{3}\right), 0.87\left(\mathrm{~d}, J=6.9 \mathrm{~Hz}, 3 \mathrm{H}, \mathrm{CH}_{3}\right), 0.84\left(\mathrm{~d}, J=6.9 \mathrm{~Hz}, 3 \mathrm{H}, \mathrm{CH}_{3}\right), 0.60(\mathrm{q}, J=7.8 \mathrm{~Hz}$, $6 \mathrm{H}), 0.05\left(\mathrm{~s}, 6 \mathrm{H}, 2 \mathrm{CH}_{3}\right) ;{ }^{13} \mathrm{C} \mathrm{NMR}\left(100.5 \mathrm{MHz}, \mathrm{CDCl}_{3}\right) \delta=158.9$ (C), 135.1 (C), 132.5 (C), $130.8(\mathrm{CH}), 129.2(2 \mathrm{CH}), 124.4(\mathrm{CH}), 120.6(\mathrm{CH}), 113.6(2 \mathrm{CH}), 77.0(\mathrm{CH}), 73.4$ $\left(\mathrm{CH}_{2}, \mathrm{CH}\right), 72.5\left(\mathrm{CH}_{2}\right), 55.2\left(\mathrm{CH}_{3}\right), 40.1(\mathrm{CH}), 38.0(\mathrm{CH}), 36.2(\mathrm{CH}), 26.9\left(\mathrm{CH}_{3}\right), 26.2$ $\left(3 \mathrm{CH}_{3}\right), 18.5\left(\mathrm{C}, \mathrm{CH}_{3}\right), 18.0\left(\mathrm{CH}_{3}\right), 12.1\left(\mathrm{CH}_{3}\right), 11.6\left(\mathrm{CH}_{3}\right), 7.2\left(3 \mathrm{CH}_{3}\right), 5.6\left(3 \mathrm{CH}_{2}\right),-3.3$ $\left(\mathrm{CH}_{3}\right),-3.9\left(\mathrm{CH}_{3}\right)$;. IR (Film) $v=2957,2931,2877,2856,1574,1462,1249,1092$ $1040,1006 \mathrm{~cm}^{-1}$; elemental analysis calcd $(\%)$ for $\mathrm{C}_{35} \mathrm{H}_{64} \mathrm{O}_{4} \mathrm{Si}_{2}: \mathrm{C} 69.48, \mathrm{H} 10.66$ found: C $69.27, \mathrm{H} 10.59$.

(2Z,4Z,6S,7S,8R,9S,10S)-9-(tert-Butyldimethylsilyloxy)-11-iodo-7-(triethylsilyloxy)1,5,7,9-tetramethyl undeca-2,4-diene 18: 2,3-dichloro-5,6-dicyano-1,4-benzoquinone (DDQ, $648 \mathrm{mg}, 2.85 \mathrm{mmol}, 1.1$ equiv) was added to a solution of compound 13 (1.57 g $2.6 \mathrm{mmol}, 1.0$ equiv) in $\mathrm{CH}_{2} \mathrm{Cl}_{2}(52 \mathrm{~mL}) / \mathrm{H}_{2} \mathrm{O}(2.6 \mathrm{~mL})$ at $0{ }^{\circ} \mathrm{C}$. The mixture was stirred for $10 \mathrm{~min}$ at $0^{\circ} \mathrm{C}$, warmed to $20^{\circ} \mathrm{C}$ and stirred for $3 \mathrm{~h} 30$. The mixture was quenched with a saturated aqueous $\mathrm{NaHCO}_{3}$ solution, diluted with $\mathrm{Et}_{2} \mathrm{O}$, washed with water and brine. The combined organic layers were dried over $\mathrm{MgSO}_{4}$, filtered and the solvent was removed under reduced pressure. The crude residue was purified by chromatography on silica gel (cyclohexane/AcOEt 98:2 to 80:20) to give the expected alcohol $(2 Z, 4 Z, 6 S, 7 S, 8 R, 9 S, 10 S)$-9-(tert-butyldimethylsilyloxy)-11-hydroxy-7-(triethyl- silyloxy)-1,5,7,9-tetramethyl undeca-2,4-diene (1.04 g, 83\% yield). $[\alpha]_{\mathrm{D}}^{20}=+4.6(c=$ $\left.2.24, \mathrm{CHCl}_{3}\right) ;{ }^{1} \mathrm{H} \mathrm{NMR}\left(400.0 \mathrm{MHz}, \mathrm{CDCl}_{3}\right) \delta=6.16(\mathrm{dd}, J=11.4,11.0 \mathrm{~Hz}, 1 \mathrm{H}), 6.02$ $(\mathrm{d}, J=11.4 \mathrm{~Hz}, 1 \mathrm{H}), 5.45(\mathrm{dd}, J=11.0,10.5 \mathrm{~Hz}, 1 \mathrm{H}), 3.67(\mathrm{t}, J=4.1 \mathrm{~Hz}, 1 \mathrm{H}), 3.59$ $3.47(\mathrm{~m}, 2 \mathrm{H}), 3.45-3.38(\mathrm{~m}, 1 \mathrm{H}), 2.85(\mathrm{~m}, 1 \mathrm{H}), 1.82\left(\mathrm{~s}, 3 \mathrm{H}, \mathrm{CH}_{3}\right), 1.74\left(\mathrm{~s}, 3 \mathrm{H}, \mathrm{CH}_{3}\right)$, 1.70-1.60 (m, 3H), $1.03\left(\mathrm{~d}, J=7.3 \mathrm{~Hz}, 3 \mathrm{H}, \mathrm{CH}_{3}\right), 0.99\left(\mathrm{t}, J=7.8 \mathrm{~Hz}, 9 \mathrm{H}, 3 \mathrm{CH}_{3}\right), 0.94$ $\left(\mathrm{d}, J=6.9 \mathrm{~Hz}, 3 \mathrm{H}, \mathrm{CH}_{3}\right), 0.92\left(\mathrm{~s}, 9 \mathrm{H}, 3 \mathrm{CH}_{3}\right), 0.82\left(\mathrm{~d}, J=6.9 \mathrm{~Hz}, 3 \mathrm{H}, \mathrm{CH}_{3}\right), 0.65(\mathrm{q}, J=$ $\left.7.8 \mathrm{~Hz}, 6 \mathrm{H}, 3 \mathrm{CH}_{2}\right), 0.11\left(\mathrm{~s}, 3 \mathrm{H}, \mathrm{CH}_{3}\right), 0.10\left(\mathrm{~s}, 3 \mathrm{H}, \mathrm{CH}_{3}\right) ;{ }^{13} \mathrm{C} \mathrm{NMR}\left(100.5 \mathrm{MHz}, \mathrm{CDCl}_{3}\right)$ $\delta=135.9(\mathrm{C}), 131.0(\mathrm{CH}), 124.4(\mathrm{CH}), 120.2(\mathrm{CH}), 78.1(\mathrm{CH}), 73.5(\mathrm{CH}), 66.0\left(\mathrm{CH}_{2}\right)$, $40.7(\mathrm{CH}), 40.4(\mathrm{CH}), 35.4(\mathrm{CH}), 26.9\left(\mathrm{CH}_{3}\right), 26.3\left(3 \mathrm{CH}_{3}\right), 19.0\left(\mathrm{CH}_{3}\right), 18.4(\mathrm{C}), 18.1$ $\left(\mathrm{CH}_{3}\right), 12.5\left(\mathrm{CH}_{3}\right), 11.8\left(\mathrm{CH}_{3}\right), 7.2\left(3 \mathrm{CH}_{3}\right), 5.6\left(3 \mathrm{CH}_{2}\right),-3.5\left(\mathrm{CH}_{3}\right),-3.7\left(\mathrm{CH}_{3}\right)$; IR (Film) $v=3410,2957,2929,2878,2857,1461,1251,1098,1076,1006,833,772,736$ $\mathrm{cm}^{-1}$.

A solution of iodine $\left(1.07 \mathrm{~g}, 4.21 \mathrm{mmol}, 1.5\right.$ equiv) in $\mathrm{Et}_{2} \mathrm{O}(10 \mathrm{~mL})$ was slowly added to a solution of the above alcohol $(1.36 \mathrm{~g}, 2.81 \mathrm{mmol}, 1.0$ equiv), triphenylphosphine $\left(\mathrm{PPh}_{3}, 1.4 \mathrm{~g}, 5.34 \mathrm{mmol}, 1.9\right.$ equiv) and imidazole ( $363 \mathrm{mg}, 5.34 \mathrm{mmol}, 1.9$ equiv) in a benzene $(10 \mathrm{~mL}) / \mathrm{Et}_{2} \mathrm{O}$ mixture $(20 \mathrm{~mL})$ at $0^{\circ} \mathrm{C}$. After stirring for $2 \mathrm{~h}$ at $20^{\circ} \mathrm{C}$, a $1 \mathrm{M}$ $\mathrm{Na}_{2} \mathrm{~S}_{2} \mathrm{O}_{3}$ solution was added and the reaction mixture was extracted with $\mathrm{Et}_{2} \mathrm{O}$. The organic layers were washed with brine, dried over $\mathrm{MgSO}_{4}$, filtered and the solvent was removed under reduced pressure. The residue was purified by chromatography on silica gel (cyclohexane/Et $2 \mathrm{O} 100: 0$ to $80: 20)$ to give $738 \mathrm{mg}$ (61\% yield) of the title compound 18. 18: $[\alpha]_{\mathrm{D}}^{20}=+10.7\left(c=1.03, \mathrm{CHCl}_{3}\right) ; .{ }^{1} \mathrm{H}$ NMR $\left(400.0 \mathrm{MHz}, \mathrm{CDCl}_{3}\right) \delta$ $6.17(\mathrm{dd}, J=11.4,11.0 \mathrm{~Hz}, 1 \mathrm{H}), 6.01(\mathrm{~d}, J=11.4 \mathrm{~Hz}, 1 \mathrm{H}), 5.38(\mathrm{dd}, J=11.0,10.5 \mathrm{~Hz}$, $1 \mathrm{H}), 3.58(\mathrm{dd}, J=4.6,4.1 \mathrm{~Hz}, 1 \mathrm{H}), 3.50(\mathrm{dd}, J=6.4,3.2 \mathrm{~Hz}, 1 \mathrm{H}), 3.30(\mathrm{dd}, J=9.6,4.6$ $\mathrm{Hz}, 1 \mathrm{H}), 2.94(\mathrm{dd}, J=9.6,9.2 \mathrm{~Hz}, 1 \mathrm{H}), 2.81(\mathrm{~m}, 1 \mathrm{H}), 1.97$ (dqdd, $J=9.2,6.4,4.6,3.2$ $\mathrm{Hz} 1 \mathrm{H}), 1.81\left(\mathrm{~s}, 3 \mathrm{H}, \mathrm{CH}_{3}\right), 1.75\left(\mathrm{~s}, 3 \mathrm{H}, \mathrm{CH}_{3}\right), 1.64(\mathrm{~m}, 1 \mathrm{H}), 1.00(\mathrm{~d}, J=6.4 \mathrm{~Hz}, 3 \mathrm{H}$, $\left.\mathrm{CH}_{3}\right), 0.98\left(\mathrm{t}, J=7.8 \mathrm{~Hz}, 9 \mathrm{H}, 3 \mathrm{CH}_{3}\right), 0.96\left(\mathrm{~d}, J=6.4 \mathrm{~Hz}, 3 \mathrm{H}, \mathrm{CH}_{3}\right), 0.91\left(\mathrm{~s}, 9 \mathrm{H}, 3 \mathrm{CH}_{3}\right)$, $0.89\left(\mathrm{~d}, J=6.9 \mathrm{~Hz}, 3 \mathrm{H}, \mathrm{CH}_{3}\right), 0.64\left(\mathrm{q}, J=7.8 \mathrm{~Hz}, 6 \mathrm{H}, 3 \mathrm{CH}_{2}\right), 0.08\left(\mathrm{~s}, 6 \mathrm{H}, 2 \mathrm{CH}_{3}\right) ;{ }^{13} \mathrm{C}$ NMR (100.5 MHz, $\left.\mathrm{CDCl}_{3}\right) \delta 135.7(\mathrm{C}), 130.9(\mathrm{CH}), 124.6(\mathrm{CH}), 120.5(\mathrm{CH}), 77.8$ $(\mathrm{CH}), 75.0(\mathrm{CH}), 42.1(\mathrm{CH}), 40.7(\mathrm{CH}), 35.6(\mathrm{CH}), 26.9\left(\mathrm{CH}_{3}\right), 26.4\left(3 \mathrm{CH}_{3}\right), 18.8$ $\left(\mathrm{CH}_{3}\right), 18.4\left(\mathrm{CH}_{3}\right), 18.1(\mathrm{C}),, 15.2\left(\mathrm{CH}_{3}\right), 13.7\left(\mathrm{CH}_{2}\right), 12.2\left(\mathrm{CH}_{3}\right), 7.2\left(3 \mathrm{CH}_{3}\right), 5.6$ $\left(3 \mathrm{CH}_{2}\right),-3.6\left(2 \mathrm{CH}_{3}\right)$; IR (Film) $v=3015,2958,2930,2878,2857,1462,1215,1097$, $1030,1007,836,669 \mathrm{~cm}^{-1}$; elemental analysis calcd $(\%)$ for $\mathrm{C}_{27} \mathrm{H}_{55} \mathrm{IO}_{2} \mathrm{Si}_{2}$ : C $54.52, \mathrm{H}$, 9.32; found: C 55.09, H, 9.66 .

\section{$[2 S, 4 R(1 R), 5 S, 6 S(2 S, 3 Z, 5 S, 6 R, 7 S, 8 Z, 11 S, 12 R, 13 S, 14 S, 15 S, 16 Z)]-4-(2-$}

Methoxycarbonyl-1-methyl ethyl-1-yl)-6-\{12-(tert-butyldimethylsilyloxy)$\mathbf{5 , 7 , 9 , 1 1 , 1 3 , 1 5 , 1 9 - h e p t a m e t h y l - 2 , 6 - b i s [ ( m e t h o x y m e t h y l ) o x y ] - 1 4 - ( t r i e t h y l s i l y l o x y ) - ~}$ icosa-3,8,16,18-tetraen-1-yl\}-5-methyl-2-phenyl-1,3-dioxinan 20: $t \mathrm{BuLi}(1.5 \mathrm{M}$ in pentane, $395 \mu \mathrm{L}, 0.59 \mathrm{mmol}, 3.8$ equiv) was rapidly added to a solution of the alkyliodide 18 (166 mg, $0.28 \mathrm{mmol}, 1.8$ equiv) in $\mathrm{Et}_{2} \mathrm{O}(4 \mathrm{~mL})$ at $-80^{\circ} \mathrm{C} ; 2$ min later were added 9-MeOBBN ( $1 M$ in hexane, $670 \mu \mathrm{L}, 0.67 \mathrm{mmol}, 4.3$ equiv) then THF (4 $\mathrm{mL}$ ). The resulting mixture was stirred $10 \mathrm{~min}$ at $-78^{\circ} \mathrm{C}$ and allowed to warm to $20^{\circ} \mathrm{C}$ during $1 \mathrm{~h} 15$; an aqueous $3.5 M \mathrm{Cs}_{2} \mathrm{CO}_{3}$ solution was then added $(243 \mu \mathrm{L}, 0.85 \mathrm{mmol}$, 5.5 equiv), followed by the addition of the vinyliodide $1^{[8 \mathrm{~m}-\mathrm{n}]}(105 \mathrm{mg}, 0.15 \mathrm{mmol}, 1.0$ equiv) in DMF ( $4 \mathrm{~mL})$. Finally $\mathrm{PdCl}_{2} \mathrm{dppf}(13 \mathrm{mg}, 0.015 \mathrm{mmol}, 0.10$ equiv) and triphenylarsine $(6 \mathrm{mg}, 0.019 \mathrm{mmol}, 0.12$ equiv) were added, and the resulting dark solution was stirred at $20^{\circ} \mathrm{C}$ for $16 \mathrm{~h}$. After extraction with $\mathrm{Et}_{2} \mathrm{O}$, the organic layers were washed with brine, dried over $\mathrm{MgSO}_{4}$, filtered and the solvent was removed under reduced pressure. The residue was purified by chromatography on silica gel (cyclohexane/Et ${ }_{2} \mathrm{O} 85: 15$ to 50:50) to give the title compound 20 (71 mg, 51\% yield). 20: $[\alpha]_{\mathrm{D}}^{20}=+16.1\left(c=0.60, \mathrm{CHCl}_{3}\right) ;{ }^{1} \mathrm{H}$ NMR $\left(400.0 \mathrm{MHz}, \mathrm{CDCl}_{3}\right) \delta=7.47-7.43(\mathrm{~m}$, $2 \mathrm{H}, \mathrm{H}-\mathrm{Ar}), 7.35-7.31(\mathrm{~m}, 3 \mathrm{H}), 6.16(\mathrm{dd}, J=11.4,10.5 \mathrm{~Hz}, 1 \mathrm{H}), 6.03(\mathrm{~d}, J=11.4 \mathrm{~Hz}$ $1 \mathrm{H}), 5.58(\mathrm{~s}, 1 \mathrm{H}), 5.54(\mathrm{t}, J=10.5 \mathrm{~Hz}, 1 \mathrm{H}), 5.38(\mathrm{dd}, J=10.5,10.1 \mathrm{~Hz}, 1 \mathrm{H}), 5.22(\mathrm{dd}, J$ $=10.5,9.6 \mathrm{~Hz}, 1 \mathrm{H}), 4.98(\mathrm{~d}, J=10.1 \mathrm{~Hz}, 1 \mathrm{H}), 4.84(\mathrm{dd}, J=10.5,9.6 \mathrm{~Hz}, 1 \mathrm{H}), 4.71(\mathrm{~d}$, $J=6.9 \mathrm{~Hz}, 1 \mathrm{H}), 4.53(\mathrm{~s}, 2 \mathrm{H}), 4.51(\mathrm{~d}, J=6.9 \mathrm{~Hz}, 1 \mathrm{H}), 4.05(\mathrm{dd}, J=10.1,3.2 \mathrm{~Hz}, 1 \mathrm{H})$, $3.82(\mathrm{dd}, J=10.1,8.7 \mathrm{~Hz}, 1 \mathrm{H}), 3.74\left(\mathrm{~s}, 3 \mathrm{H}, \mathrm{CH}_{3}\right), 3.54(\mathrm{dd}, J=6.4,3.7 \mathrm{~Hz}, 1 \mathrm{H}), 3.47$ (dd, $J=4.6,4.1 \mathrm{~Hz}, 1 \mathrm{H}), 3.33$ (s, $\left.3 \mathrm{H}, \mathrm{CH}_{3}\right), 3.32\left(\mathrm{~s}, 3 \mathrm{H}, \mathrm{CH}_{3}\right), 3.09$ (dd, $J=5.9,5.5 \mathrm{~Hz}$, $1 \mathrm{H}), 2.90-2.80(\mathrm{~m}, 3 \mathrm{H}), 2.53-2.49(\mathrm{~m}, 1 \mathrm{H}), 1.80\left(\mathrm{~s}, 3 \mathrm{H}, \mathrm{CH}_{3}\right), 1.75\left(\mathrm{~s}, 3 \mathrm{H}, \mathrm{CH}_{3}\right), 1.67$ (tq, $J=10.1,6.4 \mathrm{~Hz}, 1 \mathrm{H}), 2.51-2.41(\mathrm{~m}, 6 \mathrm{H}), 1.54\left(\mathrm{~s}, 3 \mathrm{H}, \mathrm{CH}_{3}\right), 1.24(\mathrm{~d}, J=6.9 \mathrm{~Hz}$, $\left.3 \mathrm{H}, \mathrm{CH}_{3}\right), 0.99\left(\mathrm{t}, J=7.8 \mathrm{~Hz}, 3 \mathrm{CH}_{3}\right), 1.05-0.87\left(\mathrm{~m}, 6 \mathrm{CH}_{3}\right), 0.93\left(\mathrm{~s}, 3 \mathrm{CH}_{3}\right), 0.65(\mathrm{q}, J=$ $\left.7.8 \mathrm{~Hz}, 3 \mathrm{CH}_{2}\right), 0.08\left(\mathrm{~s}, 3 \mathrm{H}, \mathrm{CH}_{3}\right) 0.07\left(\mathrm{~s}, 3 \mathrm{H}, \mathrm{CH}_{3}\right) ;{ }^{13} \mathrm{C} \mathrm{NMR}\left(100.5 \mathrm{MHz}, \mathrm{CDCl}_{3}\right) \delta=$ $174.8(\mathrm{C}), 138.8(\mathrm{C}), 136.9(\mathrm{C}), 135.3(\mathrm{C}), 132.4(\mathrm{CH}), 131.2(\mathrm{CH}), 130.3(\mathrm{CH}), 128.9$ $(\mathrm{CH}), 128.2(\mathrm{CH}), 127.9(2 \mathrm{CH}), 125.8(2 \mathrm{CH}), 124.4(\mathrm{CH}), 120.5(\mathrm{CH}), 99.6(\mathrm{CH}), 97.8$ $\left(\mathrm{CH}_{2},\right), 93.2\left(\mathrm{CH}_{2}\right), 86.9(\mathrm{CH}), 82.2(\mathrm{CH}), 77.9(\mathrm{CH}), 77.7(\mathrm{CH}), 77.0(\mathrm{CH}), 66.4(\mathrm{CH})$, $56.0\left(\mathrm{CH}_{3}\right), 55.2\left(\mathrm{CH}_{3}\right), 51.9\left(\mathrm{CH}_{3}\right), 41.1,40.2,39.0,36.5,35.8,35.7,35.3,35.0,34.8$ (7CH), $27.1\left(\mathrm{CH}_{3}\right), 26.9\left(3 \mathrm{CH}_{3}\right), 18.7(\mathrm{C}), 18.6,18.1,17.3,16.6,13.9,11.7,11.5,9.3$ $\left(9 \mathrm{CH}_{3}\right), 7.2\left(3 \mathrm{CH}_{3}\right), 5.7\left(3 \mathrm{CH}_{2}\right),-3.1\left(\mathrm{CH}_{3}\right),-3.3\left(\mathrm{CH}_{3}\right)$; IR (Film) $v=3383,2957$, 2932, 2879, 2857, 1461, 1453, 1396, 1152, 1093, $1045 \mathrm{~cm}^{-1}$; HRMS (ESI): $m / z$ : calcd for $\mathrm{C}_{58} \mathrm{H}_{102} \mathrm{O}_{10} \mathrm{NaSi}_{2}$ : 1037.6909 [M+Na]; found: 1037.6913 .

24-Dimethyl discodermolide 2: $p$-toluene sulfonic acid $(7 \mathrm{mg}, 0.035 \mathrm{mmol}, 0.28$ equiv) was added to a solution of compound $20(130 \mathrm{mg}, 0.13 \mathrm{mmol}, 1.0$ equiv) in $\mathrm{MeOH}(15 \mathrm{~mL})$ at $0^{\circ} \mathrm{C}$. After stirring for $1 \mathrm{~h}$ at $0^{\circ} \mathrm{C}$, triethylamine was added to the reaction mixture ( 0.3 equiv) and the solvent was removed under reduced pressure. The residue was purified by chromatography on silica gel (cyclohexane/AcOEt, 95:5 to 70:30) to give the expected alcohol $[2 S, 4 R(1 R), 5 S, 6 S(2 S, 3 Z, 5 S, 6 R, 7 S, 8 Z, 11 S, 12 R, 13 S, 14 S, 15 S, 16 Z)]-4-(2-m e t h o x y-$ carbonyl-1-methyl ethyl-1-yl)-6-\{12-(tert-butyldimethylsilyloxy)-5,7,9,11,13,15,19- 
heptamethyl-14-hydroxy-2,6-bis[(methoxymethyl)oxy]- icosa-3,8,16,18-tetraen-1-yl $\}$ 5-methyl-2-phenyl-1,3-dioxinan (73 mg, 70\% yield). $[\alpha]_{\mathrm{D}}^{20}=+13.9\left(c=1.48, \mathrm{CHCl}_{3}\right)$; ${ }^{1} \mathrm{H}$ NMR $\left(400.0 \mathrm{MHz}, \mathrm{CDCl}_{3}\right) \delta$ 7.48-7.42 (m, 2H), 7.35-7.28 (m, 3H), $6.34(\mathrm{dd}, J=$ $11.5,11.0 \mathrm{~Hz}, 1 \mathrm{H}), 6.07(\mathrm{~d}, J=11.5 \mathrm{~Hz}, 1 \mathrm{H}), 5.58(\mathrm{~s}, 1 \mathrm{H}), 5.55(\mathrm{dd}, J=11.0,10.1 \mathrm{~Hz}$, $1 \mathrm{H}), 5.20(\mathrm{dd}, J=11.0,10.1 \mathrm{~Hz}, 1 \mathrm{H}), 5.18(\mathrm{dd}, J=11.0,9.6 \mathrm{~Hz}, 1 \mathrm{H}), 4.99(\mathrm{~d}, J=10$. $\mathrm{Hz}, 1 \mathrm{H}), 4.84(\mathrm{dd}, J=9.6,9.2 \mathrm{~Hz}, 1 \mathrm{H}), 4.71(\mathrm{~d}, J=6.9 \mathrm{~Hz}, 1 \mathrm{H}), 4.54(\mathrm{~s}, 2 \mathrm{H}), 4.50(\mathrm{~d}, J$ $=6.9 \mathrm{~Hz}, 1 \mathrm{H}), 4.05(\mathrm{dd}, J=10.1,3.2 \mathrm{~Hz}, 1 \mathrm{H}), 3.82(\mathrm{dd}, J=10.1,9.6 \mathrm{~Hz}, 1 \mathrm{H}), 3.73(\mathrm{~s}$ $\left.3 \mathrm{H}, \mathrm{CH}_{3}\right), 3.63(\mathrm{dd}, J=6.4,2.7 \mathrm{~Hz}, 1 \mathrm{H}), 3.33\left(\mathrm{~s}, 6 \mathrm{H}, 2 \mathrm{CH}_{3}\right), 3.35-3.30(\mathrm{~m}, 2 \mathrm{H}), 3.07$ (dd, $J=5.9,5.5 \mathrm{~Hz}, 1 \mathrm{H}), 2.85-2.75(\mathrm{~m}, 3 \mathrm{H}), 2.55(\mathrm{dqd}, J=10.1,6.9,5.9 \mathrm{~Hz}, 1 \mathrm{H}), 2.21$ $(\mathrm{t}, J=12.4 \mathrm{~Hz}, 1 \mathrm{H}), 2.00-1.94(\mathrm{~m}, 1 \mathrm{H}), 1.94-1.86(\mathrm{~m}, 1 \mathrm{H}), 1.81\left(\mathrm{~s}, 3 \mathrm{H}, \mathrm{CH}_{3}\right), 1.76(\mathrm{~s}$, $\left.3 \mathrm{H}, \mathrm{CH}_{3}\right), 1.68-1.61(\mathrm{~m}, 5 \mathrm{H}), 1.61\left(\mathrm{~s}, 3 \mathrm{H}, \mathrm{CH}_{3}\right), 1.22\left(\mathrm{~d}, J=7.3 \mathrm{~Hz}, 3 \mathrm{H}, \mathrm{CH}_{3}\right), 1.01(\mathrm{~d}$ $\left.J=6.9 \mathrm{~Hz}, 3 \mathrm{H}, \mathrm{CH}_{3}\right), 0.98\left(\mathrm{~d}, J=6.9 \mathrm{~Hz}, 3 \mathrm{H}, \mathrm{CH}_{3}\right), 0.97\left(\mathrm{~d}, J=6.9 \mathrm{~Hz}, 3 \mathrm{H}, \mathrm{CH}_{3}\right)$ $0.96\left(\mathrm{~s}, 9 \mathrm{H}, 3 \mathrm{CH}_{3}\right), 0.94\left(\mathrm{~d}, J=6.9 \mathrm{~Hz}, 3 \mathrm{H}, \mathrm{CH}_{3}\right), 0.92\left(\mathrm{~d}, J=6.9 \mathrm{~Hz}, 3 \mathrm{H}, \mathrm{CH}_{3}\right), 0.85$ $\left(\mathrm{d}, J=6.9 \mathrm{~Hz}, 3 \mathrm{H}, \mathrm{CH}_{3}\right), 0.08\left(\mathrm{~s}, 3 \mathrm{H}, \mathrm{CH}_{3}\right) .0 .07\left(\mathrm{~s}, 3 \mathrm{H}, \mathrm{CH}_{3}\right) ;{ }^{13} \mathrm{C} \mathrm{NMR}(100.5 \mathrm{MHz}$ $\left.\mathrm{CDCl}_{3}\right) \delta 174.8(\mathrm{C}), 138.8(\mathrm{C}), 136.9(\mathrm{CH}), 136.8(\mathrm{C}), 132.7(\mathrm{C}), 131.2(\mathrm{CH}), 130.2$ $(\mathrm{CH}), 129.0(\mathrm{CH}), 128.2(\mathrm{CH}), 127.9(2 \mathrm{CH}), 126.8(\mathrm{CH}), 125.8(2 \mathrm{CH}), 120.0(\mathrm{CH})$ $99.6(\mathrm{CH}), 97.8\left(\mathrm{CH}_{2}\right), 93.2\left(\mathrm{CH}_{2}\right), 86.8(\mathrm{CH}), 82.3(\mathrm{CH}), 79.0(\mathrm{CH}), 77.7(\mathrm{CH}), 75.6$ $(\mathrm{CH}), 66.3(\mathrm{CH}), 56.0\left(\mathrm{CH}_{3}\right), 55.2\left(\mathrm{CH}_{3}\right), 51.9\left(\mathrm{CH}_{3}\right), 41.0(\mathrm{CH}), 39.1\left(\mathrm{CH}_{2}\right), 37.9$ $(\mathrm{CH}), 36.8\left(\mathrm{CH}_{2}\right), 36.0(\mathrm{CH}), 35.8(\mathrm{CH}), 35.3(\mathrm{CH}), 34.5(\mathrm{CH}), 34.4\left(\mathrm{CH}_{3}\right), 27.1\left(\mathrm{CH}_{3}\right)$ $26.3\left(\mathrm{CH}_{3}\right), 26.2\left(3 \mathrm{CH}_{3}\right), 23.3\left(\mathrm{CH}_{3}\right), 18.7(\mathrm{C}), 17.5\left(\mathrm{CH}_{3}\right), 17.1\left(\mathrm{CH}_{3}\right), 16.4\left(\mathrm{CH}_{3}\right), 13.1$ $\left(\mathrm{CH}_{3}\right), 11.7\left(\mathrm{CH}_{3}\right), 9.5\left(\mathrm{CH}_{3}\right), 9.3\left(\mathrm{CH}_{3}\right),-3.2\left(\mathrm{CH}_{3}\right),-3.6\left(\mathrm{CH}_{3}\right)$. IR $($ Film $) v=3382$ 2969, 2930, 2839, 2857, 1743, 1460, 1453, 1152, 1110, 1092, 1045, $772 \mathrm{~cm}^{-1}$; HRMS (ESI): $m / z$ : calcd for $\mathrm{C}_{52} \mathrm{H}_{88} \mathrm{O}_{10} \mathrm{NaSi}[M+\mathrm{Na}$ ]: 923.6044 ; found: 923.6045 .

Trichloroacetylisocyanate $(10 \mu \mathrm{l}, 0.085 \mathrm{mmol}, 1.05$ equiv) was added to a solution of the above alcohol $\left(73 \mathrm{mg}, 0.08 \mathrm{mmol}, 1.0\right.$ equiv) in $\mathrm{CH}_{2} \mathrm{Cl}_{2}(6 \mathrm{~mL})$. After stirring for 15 min at $20^{\circ} \mathrm{C}$, the resulting mixture was concentrated in vacuo and the residue taken up in $\mathrm{MeOH}(8 \mathrm{~mL}) . \mathrm{K}_{2} \mathrm{CO}_{3}(61 \mathrm{mg}, 0.44 \mathrm{mmol}, 5.5$ equiv) was added and the resulting solution was stirred $1 \mathrm{~h} 15$, then concentrated in vacuo and extracted with AcOEt. The organic layers were washed with water, brine, dried over $\mathrm{MgSO}_{4}$, filtered and the solvent removed under reduced pressure. The residue was purified by chromatography on silica gel (cyclohexane/AcOEt 90:10 to 50:50) to give the title carbamate $[2 S, 4 R(1 R), 5 S, 6 S(2 S, 3 Z, 5 S, 6 R, 7 S, 8 Z, 11 S, 12 R, 13 S, 14 S, 15 S, 16 Z)]-4-(2-$

methoxycarbonyl-1-methyl ethyl-1-yl)-6-\{12-(tert-butyldimethylsilyloxy)-14 (carbamoyloxy)-5,7,9,11,13,15,19-heptamethyl-14-(carbamoyloxy)-2,6-

bis[(methoxymethyl)oxy]- icosa-3,8,16,18-tetraen-1-yl $\}-5$-methyl-2-phenyl-1,3 dioxinan $(59 \mathrm{mg}, 78 \%$ yield $)$ as a pale oil. $[\alpha]_{\mathrm{D}}^{20}=+30.3\left(c=1.18, \mathrm{CHCl}_{3}\right) ;{ }^{1} \mathrm{H} \mathrm{NMR}$ $\left(400.0 \mathrm{MHz}, \mathrm{CDCl}_{3}\right) \delta=7.49-7.43(\mathrm{~m}, 2 \mathrm{H}, \mathrm{H}-\mathrm{Ar}), 7.36-7.28(\mathrm{~m}, 3 \mathrm{H}), 6.20$ (dd, $J=$ $11.4,11.0 \mathrm{~Hz}, 1 \mathrm{H}), 6.04(\mathrm{~d}, J=11.4 \mathrm{~Hz}, 1 \mathrm{H}), 5.58(\mathrm{~s}, 1 \mathrm{H}), 5.53(\mathrm{dd}, J=11.0,10.1 \mathrm{~Hz}$ $1 \mathrm{H}), 5.25(\mathrm{dd}, J=10.5,10.1 \mathrm{~Hz}, 1 \mathrm{H}), 5.22(\mathrm{dd}, J=11.0,10.1 \mathrm{~Hz}, 1 \mathrm{H}), 4.97(\mathrm{~d}, J=10$. $\mathrm{Hz}, 1 \mathrm{H}), 4.79-4.70(\mathrm{~m}, 1 \mathrm{H}), 4.83(\mathrm{dd}, J=10.5,9.6 \mathrm{~Hz}, 1 \mathrm{H}), 4.71(\mathrm{~d}, J=6.9 \mathrm{~Hz}, 1 \mathrm{H})$ $4.73-4.70(\mathrm{~m}, 1 \mathrm{H}), 4.54(\mathrm{~s}, 2 \mathrm{H}), 4.50(\mathrm{~d}, J=6.9 \mathrm{~Hz}, 1 \mathrm{H}), 4.52-4.49(\mathrm{~m}, 1 \mathrm{H}), 4.05(\mathrm{dd}, J$ $=10.1,3.2 \mathrm{~Hz}, 1 \mathrm{H}), 3.82(\mathrm{dd}, J=10.1,9.2 \mathrm{~Hz}, 1 \mathrm{H}), 3.73\left(\mathrm{~s}, 3 \mathrm{H}, \mathrm{CH}_{3}\right), 3.45(\mathrm{dd}, J=4.6$ $4.2 \mathrm{~Hz}, 1 \mathrm{H}), 3.33\left(\mathrm{~s}, 6 \mathrm{H}, 2 \mathrm{CH}_{3}\right), 3.06(\mathrm{dd}, J=5.9,5.5 \mathrm{~Hz}, 1 \mathrm{H}), 2.98(\mathrm{dqm}, J=10.1,6.4$ $\mathrm{Hz}, 1 \mathrm{H}), 2.85-2.76(\mathrm{dq}, J=6.9,3.2 \mathrm{~Hz}, 1 \mathrm{H}), 2.85-2.76(\mathrm{~m}, 1 \mathrm{H}), 2.55-2.45(\mathrm{~m}, 1 \mathrm{H})$ 2.10-1.82 (m, $6 \mathrm{H}), 1.82\left(\mathrm{~s}, 3 \mathrm{H}, \mathrm{CH}_{3}\right), 1.76\left(\mathrm{~s}, 3 \mathrm{H}, \mathrm{CH}_{3}\right), 1.66(\mathrm{tq}, J=10.1,6.9 \mathrm{~Hz}, 1 \mathrm{H})$ $1.57\left(\mathrm{~s}, 3 \mathrm{H}, \mathrm{CH}_{3}\right), 1.23\left(\mathrm{~d}, J=6.9 \mathrm{~Hz}, 3 \mathrm{H}, \mathrm{CH}_{3}\right), 0.99\left(\mathrm{~d}, J=6.9 \mathrm{~Hz}, 3 \mathrm{H}, \mathrm{CH}_{3}\right), 0.98(\mathrm{~d}$, $\left.J=6.9 \mathrm{~Hz}, 3 \mathrm{H}, \mathrm{CH}_{3}\right), 0.96\left(\mathrm{~s}, 9 \mathrm{H}, 3 \mathrm{CH}_{3}\right), 0.93\left(\mathrm{~d}, J=6.9 \mathrm{~Hz}, 3 \mathrm{H}, \mathrm{CH}_{3}\right), 0.89(\mathrm{~d}, J=6.9$ $\left.\mathrm{Hz}, 3 \mathrm{H}, \mathrm{CH}_{3}\right), 0.87\left(\mathrm{~d}, J=6.9 \mathrm{~Hz}, 3 \mathrm{H}, \mathrm{CH}_{3}\right), 0.71\left(\mathrm{~d}, J=6.9 \mathrm{~Hz}, 3 \mathrm{H}, \mathrm{CH}_{3}\right), 0.10(\mathrm{~s}, 3 \mathrm{H}$ $\left.\mathrm{CH}_{3}\right) .0 .09$ (s, $\left.3 \mathrm{H}, \mathrm{CH}_{3}\right) ;{ }^{13} \mathrm{C} \mathrm{NMR}\left(100.5 \mathrm{MHz}, \mathrm{CDCl}_{3}\right) \delta=174.8(\mathrm{C}), 157.0(\mathrm{C}), 138.7$ (C), $136.8(\mathrm{CH}), 136.0(\mathrm{C}), 132.4(\mathrm{C}), 130.6(\mathrm{CH}), 130.1(2 \mathrm{CH}), 128.9(\mathrm{CH}), 128.2$ $(\mathrm{CH}), 127.8(2 \mathrm{CH}), 125.8(2 \mathrm{CH}), 125.1(\mathrm{CH}), 99.5(\mathrm{CH}), 97.7\left(\mathrm{CH}_{2}\right), 93.1\left(\mathrm{CH}_{2}\right), 86.9$ $(\mathrm{CH}), 82.1(\mathrm{CH}), 79.1(\mathrm{CH}), 77.6(\mathrm{CH}), 77.0(\mathrm{CH}), 66.3(\mathrm{CH}), 56.0\left(\mathrm{CH}_{3}\right), 55.2\left(\mathrm{CH}_{3}\right)$ $51.9\left(\mathrm{CH}_{3}\right), 41.1(\mathrm{CH}), 39.0,37.9,36.1,35.8,35.2,35.1,34.4,34.0\left(6 \mathrm{CH}, 2 \mathrm{CH}_{2}\right), 26.8$ $\left(3 \mathrm{CH}_{3}\right), 26.3\left(\mathrm{CH}_{3}\right), 23.0\left(\mathrm{CH}_{3}\right), 18.4\left(\mathrm{CH}_{3}\right), 18.0(\mathrm{C}), 17.6\left(\mathrm{CH}_{3}\right), 17.3\left(\mathrm{CH}_{3}\right), 16.5$ $\left(\mathrm{CH}_{3}\right), 13.8\left(\mathrm{CH}_{3}\right), 11.6\left(\mathrm{CH}_{3}\right), 10.1\left(\mathrm{CH}_{3}\right), 9.3\left(\mathrm{CH}_{3}\right),-3.4\left(\mathrm{CH}_{3}\right),-3.6\left(\mathrm{CH}_{3}\right) . \mathrm{IR}(\mathrm{Film})$ $v=33282,3315,3304,3215,2983,2956,2930,2901,2880,1726,1090,1045 \mathrm{~cm}^{-1}$

$\mathrm{HCl}(4 \mathrm{~N}, 6 \mathrm{~mL})$ was added to a solution of the above carbamate $(58 \mathrm{mg}, 0.06 \mathrm{mmol}$, 1.0 equiv) in THF $(6 \mathrm{~mL})$. The resulting mixture was stirred $72 \mathrm{~h}$ at $20^{\circ} \mathrm{C}$ then added with solid $\mathrm{NaHCO}_{3}$ and extracted 3 times with $\mathrm{AcOEt}$. The organic layers were washed with water, brine, dried over $\mathrm{MgSO}_{4}$, filtered and the solvent was removed under reduced pressure. The residue was purified by chromatography on silica gel $\left(\mathrm{CH}_{2} \mathrm{Cl}_{2} / \mathrm{MeOH} 95: 5\right.$ to $\left.90: 10\right)$ to give the title compound, DDM analogue $2(18 \mathrm{mg}$ $47 \%$ yield $)$ as an oil. $2:[\alpha]_{\mathrm{D}}^{20}=+22.0(c=1.8, \mathrm{MeOH}) ;{ }^{1} \mathrm{H} \mathrm{NMR}\left(400.0 \mathrm{MHz}, \mathrm{CDCl}_{3}\right)$ $\delta=6.19(\mathrm{dd}, J=11.2,11.0 \mathrm{~Hz}, 1 \mathrm{H}), 6.03(\mathrm{~d}, J=11.2 \mathrm{~Hz}, 1 \mathrm{H}), 5.50(\mathrm{dd}, J=11.4,7.8$ $\mathrm{Hz}, 1 \mathrm{H}), 5.43(\mathrm{dd}, J=11.4,9.6 \mathrm{~Hz}, 1 \mathrm{H}), 5.23(\mathrm{dd}, J=11.0,10.5 \mathrm{~Hz}, 1 \mathrm{H}), 5.13(\mathrm{~d}, J=$ $10.1 \mathrm{~Hz}, 1 \mathrm{H}), 4.78-4.65(\mathrm{~m}, 4 \mathrm{H}), 4.62(\mathrm{t}, J=10.1 \mathrm{~Hz}, 1 \mathrm{H}), 3.71(\mathrm{dd}, J=4.1,3.2 \mathrm{~Hz}$ $1 \mathrm{H}), 3.29(\mathrm{dd}, J=5.0,4.6 \mathrm{~Hz}, 1 \mathrm{H}), 3.19(\mathrm{dd}, J=5.9,5.5 \mathrm{~Hz}, 1 \mathrm{H}), 2.98(\mathrm{dqm}, J=10.5$ $6.9 \mathrm{~Hz}, 1 \mathrm{H}), 2.81-2.73(\mathrm{~m}, 2 \mathrm{H}), 2.70(\mathrm{qd}, J=7.3,4.1 \mathrm{~Hz}, 1 \mathrm{H}), 2.72-2.68(\mathrm{~m}, 1 \mathrm{H}), 2.55-$ $2.45(\mathrm{~m}, 3 \mathrm{H}, \mathrm{H}-12), 1.99-1.64(\mathrm{~m}, 7 \mathrm{H}), 1.81\left(\mathrm{~s}, 3 \mathrm{H}, \mathrm{CH}_{3}\right), 1.75\left(\mathrm{~s}, 3 \mathrm{H}, \mathrm{CH}_{3}\right), 1.64(\mathrm{~s}$ $\left.3 \mathrm{H}, \mathrm{CH}_{3}\right), 1.29\left(\mathrm{~d}, J=7.3 \mathrm{~Hz}, 3 \mathrm{H}, \mathrm{CH}_{3}\right), 1.06\left(\mathrm{~d}, J=6.9 \mathrm{~Hz}, 3 \mathrm{H}, \mathrm{CH}_{3}\right), 1.01(\mathrm{~d}, J=6.9$ $\left.\mathrm{Hz}, 3 \mathrm{H}, \mathrm{CH}_{3}\right), 1.00\left(\mathrm{~d}, J=6.9 \mathrm{~Hz}, 3 \mathrm{H}, \mathrm{CH}_{3}\right), 096(2 \mathrm{~d}, J=7.3 \mathrm{~Hz}, 6 \mathrm{H}), 0.94(\mathrm{~d}, J=6.4$ $\left.\mathrm{Hz}, 3 \mathrm{H}, \mathrm{CH}_{3}\right) ;{ }^{13} \mathrm{C}$ NMR $\left(100.5 \mathrm{MHz}, \mathrm{CDCl}_{3}\right) \delta 174.8(\mathrm{C}), 158.5(\mathrm{C}), 136.8(\mathrm{C}), 133.9$ $(\mathrm{CH}), 133.7(\mathrm{CH}), 130.9(\mathrm{CH}), 130.4(\mathrm{CH}), 125.9(\mathrm{C}), 121.1(\mathrm{CH}), 118.3(\mathrm{CH}), 79.7$ $(2 \mathrm{CH}), 77.3(\mathrm{CH}), 75.8(\mathrm{CH}), 73.1(\mathrm{CH}), 63.2(\mathrm{CH}), 43.9(\mathrm{CH}), 42.0,38.4,37.3,36.7$, $36.3,36.1,34.3,34.1\left(6 \mathrm{CH}, 2 \mathrm{CH}_{2}\right), 26.3\left(2 \mathrm{CH}_{3}\right), 23.3\left(\mathrm{CH}_{3}\right), 19.8,18.4,18.0,16.0$ 15.7, 13.0, 9.2 $\left(7 \mathrm{CH}_{3}\right) ; \mathrm{IR}(\mathrm{Film}) \mathrm{v}=3382,2962,2929,2870,2856,2360,2340,1726$
1682, 1454, 1395, 1032, $668 \mathrm{~cm}^{-1}$; HRMS (ESI): $\mathrm{m} / z$ : calcd for $\mathrm{C}_{35} \mathrm{H}_{59} \mathrm{NO}_{8} \mathrm{NaSi}$ : $644.4138[M+\mathrm{Na}]$; found: 644.4142 .

22-Phenyl discodermolide 3: $p$-toluene sulfonic acid ( $1.7 \mathrm{mg}, 0.009 \mathrm{mmol}, 0.28$ equiv) was added to a solution of compound 22 ( $40 \mathrm{mg}, 0.032 \mathrm{mmol}, 1.0$ equiv) in $\mathrm{MeOH}$ (4 $\mathrm{mL}$ ) at $0^{\circ} \mathrm{C}$. After stirring for $1 \mathrm{~h}$ at $0^{\circ} \mathrm{C}$, triethylamine was added to the reaction mixture ( 0.3 equiv) and the solvent was removed under reduced pressure. The residue was purified by chromatography on silica gel (cyclohexane/AcOEt, 95:5 to 60:40) to give the expected alcohol $(20 \mathrm{mg}, 69 \%$ yield $) .[\alpha]_{\mathrm{D}}^{20}=+19.1\left(c=0.4, \mathrm{CHCl}_{3}\right) ;{ }^{1} \mathrm{H}$ NMR $\left(400.0 \mathrm{MHz}, \mathrm{CDCl}_{3}\right): \delta=7.48-7.44(\mathrm{~m}, 2 \mathrm{H}), 7.39-7.23(\mathrm{~m}, 8 \mathrm{H}), 6.59(\mathrm{~d}, \mathrm{~J}=11.4 \mathrm{~Hz}$, $1 \mathrm{H}), 5.61-5.54(\mathrm{~m}, 2 \mathrm{H}), 5.59(\mathrm{~s}, 1 \mathrm{H}), 5.23(\mathrm{t}, J=10.1 \mathrm{~Hz}, 1 \mathrm{H}), 4.99(\mathrm{~d}, J=10.1 \mathrm{~Hz}$, $1 \mathrm{H}), 4.84(\mathrm{dd}, J=10.1,9.2 \mathrm{~Hz}, 1 \mathrm{H}), 4.72(\mathrm{~d}, J=6.9 \mathrm{~Hz}, 1 \mathrm{H}), 4.56(\mathrm{~s}, 2 \mathrm{H}), 4.50(\mathrm{~d}, J=$ $6.9 \mathrm{~Hz}, 1 \mathrm{H}), 4.06(\mathrm{dd}, J=10.1,3.2 \mathrm{~Hz}, 1 \mathrm{H}), 3.82(\mathrm{dd}, J=9.6,9.2 \mathrm{~Hz}, 1 \mathrm{H}), 3.74(\mathrm{~s}, 3 \mathrm{H}$, $\left.\mathrm{CH}_{3}\right), 3.49(\mathrm{dd}, \mathrm{J}=5.0,3.7 \mathrm{~Hz}, 1 \mathrm{H}), 3.35-3.31(\mathrm{ddd}, \mathrm{J}=7.8,3.7,3.2 \mathrm{~Hz}, 1 \mathrm{H}), 3.34(\mathrm{~s}$, $\left.6 \mathrm{H}, 2 \mathrm{CH}_{3}\right), 3,11(\mathrm{t}, J=5.5 \mathrm{~Hz}, 1 \mathrm{H}), 3.02(\mathrm{dqd}, J=7.3,6.4,3.7 \mathrm{~Hz}, 1 \mathrm{H}), 2.88-2.76(\mathrm{~m}$, $2 \mathrm{H}), 2.56(\mathrm{dqd}, J=10.1,6.9,5.5 \mathrm{~Hz}, 1 \mathrm{H}), 2.13(\mathrm{t}, J=12.4 \mathrm{~Hz}, 1 \mathrm{H}), 1.98(\mathrm{~m}, 1 \mathrm{H})$, $1.88-1.57(\mathrm{~m}, 6 \mathrm{H}), 1.56\left(\mathrm{~s}, 3 \mathrm{H}, \mathrm{CH}_{3}\right), 1.22\left(\mathrm{~d}, J=7.3 \mathrm{~Hz}, 3 \mathrm{H}, \mathrm{CH}_{3}\right), 1.03(\mathrm{~d}, J=6.4 \mathrm{~Hz}$ $\left.3 \mathrm{H}, \mathrm{CH}_{3}\right), 1.01\left(\mathrm{~d}, J=6.4 \mathrm{~Hz}, 3 \mathrm{H}, \mathrm{CH}_{3}\right), 0.93\left(\mathrm{~d}, J=6.9 \mathrm{~Hz}, 3 \mathrm{H}, \mathrm{CH}_{3}\right), 0.90(\mathrm{~d}, J=6.9$ $\left.\mathrm{Hz}, 3 \mathrm{H}, \mathrm{CH}_{3}\right), 0.90\left(\mathrm{~s}, 9 \mathrm{H}, 3 \mathrm{CH}_{3}\right), 0.87\left(\mathrm{~d}, J=6.9 \mathrm{~Hz}, 3 \mathrm{H}, \mathrm{CH}_{3}\right), 0.69(\mathrm{~d}, J=6.9 \mathrm{~Hz}$, $\left.3 \mathrm{H}, \mathrm{CH}_{3}\right), 0.00$ (s, $\left.3 \mathrm{H}, \mathrm{CH}_{3}\right),-0.05\left(\mathrm{~s}, 3 \mathrm{H}, \mathrm{CH}_{3}\right) ;{ }^{13} \mathrm{C} \mathrm{NMR}\left(100.5 \mathrm{MHz}, \mathrm{CDCl}_{3}\right): \delta=$ $174.8(\mathrm{C}), 138.8(\mathrm{C}), 137.1(\mathrm{C}), 136.8(\mathrm{CH}), 134.7(\mathrm{CH}), 132.7(\mathrm{C}), 130.8(\mathrm{CH}), 130.2$ $(\mathrm{CH}), 129.0(\mathrm{CH}), 128.6(2 \mathrm{CH}), 128.3(2 \mathrm{CH}), 128.2(\mathrm{CH}), 127.9(2 \mathrm{CH}), 126.9(\mathrm{CH})$ $125.8(2 \mathrm{CH}), 99.6(\mathrm{CH}), 97.8\left(\mathrm{CH}_{2}\right), 93.1\left(\mathrm{CH}_{2}\right), 86.8(\mathrm{CH}), 82.2(\mathrm{CH}), 78.7(\mathrm{CH}), 77.7$ $(\mathrm{CH}), 76.7(\mathrm{CH}), 66.3(\mathrm{CH}), 56.0\left(\mathrm{CH}_{3}\right), 55.2\left(\mathrm{CH}_{3}\right), 51.9\left(\mathrm{CH}_{3}\right), 41.0(\mathrm{CH}), 39.1$ $\left(\mathrm{CH}_{2}\right), 38.1(\mathrm{CH}), 36.4\left(\mathrm{CH}_{2}\right), 35.9(\mathrm{CH}), 35.8(\mathrm{CH}), 35.3(\mathrm{CH}), 34.6(\mathrm{CH}), 34.5(\mathrm{CH})$ $26.2\left(3 \mathrm{CH}_{3}\right), 23.3\left(\mathrm{CH}_{3}\right), 18.4(\mathrm{C}), 17.5\left(2 \mathrm{CH}_{3}\right), 16.4\left(\mathrm{CH}_{3}\right), 13.7\left(\mathrm{CH}_{3}\right), 11.6\left(\mathrm{CH}_{3}\right), 9.4$ $\left(\mathrm{CH}_{3}\right), 9.3\left(\mathrm{CH}_{3}\right),-3.3\left(\mathrm{CH}_{3}\right),-3.6\left(\mathrm{CH}_{3}\right)$; IR $\left(\right.$ Film) $v_{\max }=3440,3377,2960,2929$, $1461,1453,1435,1151,1092,1036 \mathrm{~cm}^{-1}$; HRMS (ESI): $\mathrm{m} / z$ calcd for $\mathrm{C}_{55} \mathrm{H}_{90} \mathrm{O}_{10} \mathrm{NaSi}$ $961.6201[\mathrm{M}+\mathrm{Na}]$; found: 961.6208

Trichloroacetylisocyanate ( $2.7 \mu \mathrm{l}, 0.023 \mathrm{mmol}, 1.05$ equiv) was added to a solution of the preceding alcohol ( $20 \mathrm{mg}, 0.022 \mathrm{mmol}, 1.0$ equiv) in $\mathrm{CH}_{2} \mathrm{Cl}_{2}(1.7 \mathrm{~mL})$. After stirring for $15 \mathrm{~min}$ at $20^{\circ} \mathrm{C}$, the resulting mixture was concentrated in vacuo and the residue taken up in $\mathrm{MeOH}(2.2 \mathrm{~mL}) . \mathrm{K}_{2} \mathrm{CO}_{3}(17 \mathrm{mg}, 0.12 \mathrm{mmol}, 5.5$ equiv) was added and the resulting solution was stirred $1 \mathrm{~h} 15$ then concentrated in vacuo and extracted with AcOEt. The organic layers were washed with water, brine, dried over $\mathrm{MgSO}_{4}$, filtered and the solvent removed under reduced pressure. The residue was purified by chromatography on silica gel (cyclohexane/AcOEt 90:10 to 50:50) to give the title carbamate $(12 \mathrm{mg}, 58 \%$ yield $)$ as a pale oil. $[\alpha]_{\mathrm{D}}^{20}=+33.0\left(c=1.2, \mathrm{CHCl}_{3}\right) ;{ }^{1} \mathrm{H} \mathrm{NMR}$ $\left(400.0 \mathrm{MHz}, \mathrm{CDCl}_{3}\right) \delta=7.49-7.44(\mathrm{~m}, 2 \mathrm{H}), 7.37-7.22(\mathrm{~m}, 8 \mathrm{H}), 6.48(\mathrm{~d}, J=11.9 \mathrm{~Hz}$ $1 \mathrm{H}), 5.62(\mathrm{dd}, J=11.9,11.0 \mathrm{~Hz}, 1 \mathrm{H}), 5.60(\mathrm{t}, J=10.1 \mathrm{~Hz}, 1 \mathrm{H}), 5.58(\mathrm{~s}, 1 \mathrm{H}), 5.24(\mathrm{t}, J=$ $10.1 \mathrm{~Hz}, 1 \mathrm{H}), 4.96(\mathrm{~d}, J=10.1 \mathrm{~Hz}, 1 \mathrm{H}), 4.84(\mathrm{dd}, J=10.1,9.6 \mathrm{~Hz}, 1 \mathrm{H}), 4.76(\mathrm{dd}, J=$ $6.4,5.9 \mathrm{~Hz}, 1 \mathrm{H}), 4.72(\mathrm{~d}, J=6.9 \mathrm{~Hz}, 1 \mathrm{H}), 4.62-4.57\left(\mathrm{~m}, 2 \mathrm{H}, \mathrm{NH}_{2}\right), 4.56\left(\mathrm{~s}, 2 \mathrm{H}, \mathrm{CH}_{2}\right)$ $4.51(\mathrm{~d}, J=6.9 \mathrm{~Hz}, 1 \mathrm{H}), 4.05(\mathrm{dd}, J=11.7,3.2 \mathrm{~Hz}, 1 \mathrm{H}), 3.83(\mathrm{t}, J=9.2 \mathrm{~Hz}, 1 \mathrm{H}), 3.73$ $\left(\mathrm{s}, 3 \mathrm{H}, \mathrm{CH}_{3}\right), 3.33\left(\mathrm{~s}, 6 \mathrm{H}, 2 \mathrm{CH}_{3}\right), 3.21-3.13(\mathrm{~m}, 2 \mathrm{H}), 3.08(\mathrm{dd}, J=5.9,5.5 \mathrm{~Hz}, 1 \mathrm{H})$ 2.85-2.78 (m, 2H), $2.54(\mathrm{dqd}, J=10.1,6.4,5.5 \mathrm{~Hz}, 1 \mathrm{H}), 1.98-1.87(\mathrm{~m}, 2 \mathrm{H}), 1.85(\mathrm{~m}$, $1 \mathrm{H}), 1.78-1.60(\mathrm{~m}, 4 \mathrm{H}), 1.54\left(\mathrm{~s}, 3 \mathrm{H}, \mathrm{CH}_{3}\right), 1.22\left(\mathrm{~d}, J=7.3 \mathrm{~Hz}, 3 \mathrm{H}, \mathrm{CH}_{3}\right), 1.11(\mathrm{~d}, J=$ $\left.6.9 \mathrm{~Hz}, 3 \mathrm{H}, \mathrm{CH}_{3}\right), 1.02\left(\mathrm{~d}, J=6.9 \mathrm{~Hz}, 3 \mathrm{H}, \mathrm{CH}_{3}\right), 0.92\left(\mathrm{~d}, J=6.4 \mathrm{~Hz}, 3 \mathrm{H}, \mathrm{CH}_{3}\right), 0.90(\mathrm{~d}$ $\left.J=7.3 \mathrm{~Hz}, 3 \mathrm{H}, \mathrm{CH}_{3}\right), 0.88\left(\mathrm{~d}, J=6.4 \mathrm{~Hz}, 3 \mathrm{H}, \mathrm{CH}_{3}\right), 0.88\left(\mathrm{~s}, 9 \mathrm{H}, 3 \mathrm{CH}_{3}\right), 0.56(\mathrm{~d}, J=6.9$ $\left.\mathrm{Hz}, 3 \mathrm{H}, \mathrm{CH}_{3}\right), 0.01\left(\mathrm{~s}, 3 \mathrm{H}, \mathrm{CH}_{3}\right),-0.12\left(\mathrm{~s}, 3 \mathrm{H}, \mathrm{CH}_{3}\right) ;{ }^{13} \mathrm{C} \mathrm{NMR}\left(100.5 \mathrm{MHz}, \mathrm{CDCl}_{3}\right) \delta=$ 174.8 (C), $156.9(\mathrm{C}), 138.7(\mathrm{C}), 137.3(\mathrm{C}), 136.6(\mathrm{CH}), 133.5(\mathrm{CH}), 132.5(\mathrm{C}), 130.1$ $(\mathrm{CH}), 129.5(\mathrm{CH}), 129.1(\mathrm{CH}), 128.4(2 \mathrm{CH}), 128.3(2 \mathrm{CH}), 128.2(\mathrm{CH}), 127.9(2 \mathrm{CH})$, $126.8(\mathrm{CH}), 125.8(2 \mathrm{CH}), 99.6(\mathrm{CH}), 97.9\left(\mathrm{CH}_{2}\right), 93.2\left(\mathrm{CH}_{2}\right), 87.0(\mathrm{CH}), 82.2(\mathrm{CH})$ $79.1(\mathrm{CH}), 77.7(\mathrm{CH}), 77.0(\mathrm{CH}), 66.3(\mathrm{CH}), 56.0\left(\mathrm{CH}_{3}\right), 55.2\left(\mathrm{CH}_{3}\right), 51.9\left(\mathrm{CH}_{3}\right), 41.1$ $(\mathrm{CH}), 39.0\left(\mathrm{CH}_{2}\right), 37.9(\mathrm{CH}), 36.0\left(\mathrm{CH}_{2}\right), 35.9(\mathrm{CH}), 35.3(\mathrm{CH}), 34.8(\mathrm{CH}), 34.7(\mathrm{CH})$, $34.2(\mathrm{CH}), 26.1\left(3 \mathrm{CH}_{3}\right), 23.0\left(\mathrm{CH}_{3}\right), 18.5(\mathrm{C}), 17.7\left(\mathrm{CH}_{3}\right), 17.4\left(\mathrm{CH}_{3}\right), 16.7\left(\mathrm{CH}_{3}\right), 14.1$ $\left(\mathrm{CH}_{3}\right), 11.6\left(\mathrm{CH}_{3}\right), 9.9\left(\mathrm{CH}_{3}\right), 9.4\left(\mathrm{CH}_{3}\right),-3.5\left(2 \mathrm{CH}_{3}\right)$; IR (Film) $v_{\max }=3376,2961$, 2930, 1728, 1460, 1147, 1094, 1035, $757 \mathrm{~cm}^{-1}$; HRMS (ESI): $\mathrm{m} / \mathrm{z}$ calcd for $\mathrm{C}_{56} \mathrm{H}_{91} \mathrm{NO}_{11} \mathrm{NaSi}$ : 1004.6259 [M+Na]; found: 1004.6250 .

$\mathrm{HCl}(4 \mathrm{~N}, 1.2 \mathrm{~mL})$ was added to a solution of the preceding carbamate $(12 \mathrm{mg}, 0.012$ mmol, 1.0 equiv) in THF $(1.2 \mathrm{~mL})$ The resulting mixture was stirred $72 \mathrm{~h}$ at $20^{\circ} \mathrm{C}$ then added with solid $\mathrm{NaHCO}_{3}$ and extracted 3 times with AcOEt. The organic layers were washed with water, brine, dried over $\mathrm{MgSO}_{4}$, filtered and the solvent was removed under reduced pressure. The residue was purified by chromatography on silica gel $\left(\mathrm{CH}_{2} \mathrm{Cl}_{2} / \mathrm{MeOH}\right.$ 100:0 to 70:30) to give the title compound 3 (7 mg, 91\% yield). $[\alpha]_{\mathrm{D}}^{20}$ $=+3.2(c=0.7, \mathrm{MeOH}) ;{ }^{1} \mathrm{H}$ NMR $\left(400.0 \mathrm{MHz}, \mathrm{CD}_{3} \mathrm{CN}\right) \delta=7.34-7.25(\mathrm{~m}, 4 \mathrm{H}), 7.25$ $7.18(\mathrm{~m}, 1 \mathrm{H}), 6.50(\mathrm{~d}, J=11.9 \mathrm{~Hz}, 1 \mathrm{H}), 5.74(\mathrm{dd}, J=10.5,10.1 \mathrm{~Hz}, 1 \mathrm{H}), 5.64(\mathrm{dd}, J=$ $11.9,11.4 \mathrm{~Hz}, 1 \mathrm{H}), 5.49(\mathrm{t}, J=10.1 \mathrm{~Hz}, 1 \mathrm{H}), 5.15-5.05(\mathrm{~m}, 1 \mathrm{H}), 4.90(\mathrm{~d}, J=10.1 \mathrm{~Hz}$ $1 \mathrm{H}), 4.64(\mathrm{dd}, J=9.2,3.2 \mathrm{~Hz}, 1 \mathrm{H}), 4.46-4.38(\mathrm{~m}, 4 \mathrm{H}), 3.59(\mathrm{t}, J=4.6 \mathrm{~Hz}, 1 \mathrm{H}), 3.56-$ $3.50(\mathrm{~m}, 1 \mathrm{H}), 3.19-3.12(\mathrm{~m}, 1 \mathrm{H}), 3.10-3.08(\mathrm{~m}, 1 \mathrm{H}), 2.71-2.61(\mathrm{~m}, 1 \mathrm{H}), 2.50(\mathrm{qd}, J=$ 7.3, $4.6 \mathrm{~Hz}, 1 \mathrm{H}), 2.31-2.20$ (dqm, $J=10.1,6.4 \mathrm{~Hz}, 1 \mathrm{H}), 1.81-1.40(\mathrm{~m}, 10 \mathrm{H}, 6 \mathrm{CH}$, $\left.2 \mathrm{CH}_{2}\right), 1.53\left(\mathrm{~s}, 3 \mathrm{H}, \mathrm{CH}_{3}\right), 1.14\left(\mathrm{~d}, J=7.3 \mathrm{~Hz}, 3 \mathrm{H}, \mathrm{CH}_{3}\right), 1.08\left(\mathrm{~d}, J=6.9 \mathrm{~Hz}, 3 \mathrm{H}, \mathrm{CH}_{3}\right)$, $1.02\left(\mathrm{~d}, J=7.3 \mathrm{~Hz}, 3 \mathrm{H}, \mathrm{CH}_{3}\right), 0.98\left(\mathrm{~d}, J=6.9 \mathrm{~Hz}, 3 \mathrm{H}, \mathrm{CH}_{3}\right), 0.90(\mathrm{~d}, J=6.4 \mathrm{~Hz}, 3 \mathrm{H}$ $\left.\mathrm{CH}_{3}\right), 0.66\left(\mathrm{~d}, J=6.9 \mathrm{~Hz}, 3 \mathrm{H}, \mathrm{CH}_{3}\right), 0.34\left(\mathrm{~d}, J=6.4 \mathrm{~Hz}, 3 \mathrm{H}, \mathrm{CH}_{3}\right) .{ }^{13} \mathrm{C}$ NMR $(100.5$ $\left.\mathrm{MHz}, \mathrm{CD}_{3} \mathrm{CN}\right) \delta=174.7(\mathrm{C}), 158.4(\mathrm{C}), 138.3(\mathrm{C}), 134.2(\mathrm{CH}), 133.9(\mathrm{CH}), 133.8(\mathrm{C})$, $130.9(\mathrm{CH}), 130.3(\mathrm{CH}), 129.4(\mathrm{CH}), 129.3(3 \mathrm{CH}), 122.7(2 \mathrm{CH}), 79.8(\mathrm{CH}), 79.7(\mathrm{CH})$ $77.2(\mathrm{CH}), 75.4(\mathrm{CH}), 73.1(\mathrm{CH}), 63.1(\mathrm{CH}), 43.9(\mathrm{CH}), 42.1\left(\mathrm{CH}_{2}\right), 38.5(\mathrm{CH}), 37.7$ $(\mathrm{CH}), 36.8\left(\mathrm{CH}, \mathrm{CH}_{2}\right), 35.8(\mathrm{CH}), 34.2(\mathrm{CH}), 34.1(\mathrm{CH}), 23.6\left(\mathrm{CH}_{3}\right), 20.0\left(\mathrm{CH}_{3}\right), 18.2$ 
$\left(2 \mathrm{CH}_{3}\right), 15.8\left(\mathrm{CH}_{3}\right), 15.7\left(\mathrm{CH}_{3}\right), 13.0\left(\mathrm{CH}_{3}\right), 9.1\left(\mathrm{CH}_{3}\right) ; \mathrm{IR}($ Film $) v_{\max }=3364,2961$ 2930, 2868, 1706, 1456, 1396, 1387, 1034, 737, $702 \mathrm{~cm}^{-1}$; HRMS (ESI): $\mathrm{m} / \mathrm{z}$ calcd for $\mathrm{C}_{37} \mathrm{H}_{57} \mathrm{NO}_{8} \mathrm{Na}$ : 666.3982 [M+Na]; found: 666.3990 .

22-Benzyl discodermolide 4: $p$-toluene sulfonic acid ( $7 \mathrm{mg}, 0.037 \mathrm{mmol}, 0.28$ equiv) was added to a solution of compound $24(140 \mathrm{mg}, 0.13 \mathrm{mmol}, 1.0$ equiv) in $\mathrm{MeOH}$ (15 $\mathrm{mL})$ at $0^{\circ} \mathrm{C}$. After stirring for $1 \mathrm{~h}$ at $0^{\circ} \mathrm{C}$, triethylamine was added to the reaction mixture ( 0.3 equiv) and the solvent was removed under reduced pressure. The residue was purified by chromatography on silica gel (cyclohexane/AcOEt, 95:5 to 60:40) to give the expected alcohol $(99 \mathrm{mg}, 80 \%$ yield $) .{ }^{1} \mathrm{H}$ NMR $\left(400.0 \mathrm{MHz}, \mathrm{CDCl}_{3}\right) \delta=7.50$ $7.43(\mathrm{~m}, 2 \mathrm{H}), 7.35-7.29(\mathrm{~m}, 6 \mathrm{H}), 7.23-7.17(\mathrm{~m}, 2 \mathrm{H}), 5.59(\mathrm{~s}, 1 \mathrm{H}), 5.59-5.50(\mathrm{~m}, 3 \mathrm{H})$ $5.22(\mathrm{dd}, J=10.1,9.2 \mathrm{~Hz}, 1 \mathrm{H}), 5.04(\mathrm{~d}, J=9.2 \mathrm{~Hz}, 1 \mathrm{H}), 4.84(\mathrm{dd}, J=11.9,9.2 \mathrm{~Hz}$ $1 \mathrm{H}), 4.71(\mathrm{~d}, J=6.4 \mathrm{~Hz}, 1 \mathrm{H}), 4.55(\mathrm{~s}, 2 \mathrm{H}), 4.51(\mathrm{~d}, J=6.4 \mathrm{~Hz}, 1 \mathrm{H}), 4.40-4.35(\mathrm{~m}, 1 \mathrm{H})$, $4.16(\mathrm{dd}, J=5.9,5.5 \mathrm{~Hz}, 1 \mathrm{H}), 4.06(\mathrm{dd}, J=10.1,3.2 \mathrm{~Hz}, 1 \mathrm{H}), 3.83(\mathrm{~m}, 1 \mathrm{H}), 3.74(\mathrm{~s}$ $\left.3 \mathrm{H}, \mathrm{CH}_{3}\right), 3.53-3.43\left(\mathrm{~m}, 3 \mathrm{H}, \mathrm{CH}, \mathrm{CH}_{2}\right), 3.33\left(\mathrm{~s}, 6 \mathrm{H}, 2 \mathrm{CH}_{3}\right), 3.09$ (dd $, J=5.9,5.5 \mathrm{~Hz}$ $1 \mathrm{H}), 2.99-2.79(\mathrm{~m}, 3 \mathrm{H}), 2.64-2.54(\mathrm{~m}, 1 \mathrm{H}), 2.18(\mathrm{dd}, J=12.3,11.9 \mathrm{~Hz}, 1 \mathrm{H}), 1.99(\mathrm{~m}$ $1 \mathrm{H}), 1.90-1.78(\mathrm{~m}, 3 \mathrm{H}), 1.70-1.60(\mathrm{~m}, 2 \mathrm{H}), 1.60\left(\mathrm{~s}, 3 \mathrm{H}, \mathrm{CH}_{3}\right), 1.25(\mathrm{~d}, J=6.9 \mathrm{~Hz}, 3 \mathrm{H}$ $\left.\mathrm{CH}_{3}\right), 0.97\left(\mathrm{~d}, J=6.4 \mathrm{~Hz}, 3 \mathrm{H}, \mathrm{CH}_{3}\right), 0.94\left(\mathrm{~s}, 3 \mathrm{CH}_{3}\right), 0.97-0.90\left(\mathrm{~m}, 9 \mathrm{H}, 3 \mathrm{CH}_{3}\right), 0.88(\mathrm{~d}$ $\left.J=6.9 \mathrm{~Hz}, 3 \mathrm{H}, \mathrm{CH}_{3}\right), 0.74\left(\mathrm{~d}, J=6.9 \mathrm{~Hz}, 3 \mathrm{H}, \mathrm{CH}_{3}\right), 0.10\left(\mathrm{~s}, 3 \mathrm{H}, \mathrm{CH}_{3}\right), 0.06(\mathrm{~s}, 3 \mathrm{H}$ $\left.\mathrm{CH}_{3}\right) ;{ }^{13} \mathrm{C}$ NMR $\left(100.5 \mathrm{MHz}, \mathrm{CDCl}_{3}\right) \delta=174.6(\mathrm{C}), 140.9(\mathrm{C}), 138.6(\mathrm{C}), 136.9(\mathrm{CH})$ $133.4(\mathrm{CH}), 132.2(\mathrm{C}), 130.2(\mathrm{CH}), 128.7(\mathrm{CH}), 128.2(2 \mathrm{CH}), 128.1(2 \mathrm{CH}), 128.0(\mathrm{CH})$ $127.8(2 \mathrm{CH}), 127.7(2 \mathrm{CH}), 125.5(2 \mathrm{CH}), 99.4(\mathrm{CH}), 97.5\left(\mathrm{CH}_{2}\right), 93.0\left(\mathrm{CH}_{2}\right), 86.5(\mathrm{CH})$ $82.0(\mathrm{CH}), 77.6(\mathrm{CH}), 77.0(\mathrm{CH}), 74.7(\mathrm{CH}), 66.2(\mathrm{CH}), 55.8\left(\mathrm{CH}_{3}\right), 55.0\left(\mathrm{CH}_{3}\right), 51.7$ $\left(\mathrm{CH}_{3}\right), 40.9(\mathrm{CH}), 38.9\left(\mathrm{CH}_{2}\right), 38.1\left(\mathrm{CH}_{2}\right), 36.8(\mathrm{CH}), 35.7(\mathrm{CH}), 35.2(\mathrm{CH}), 34.3(\mathrm{CH})$ $34.0(\mathrm{CH}), 33.8\left(\mathrm{CH}_{2}\right), 31.4(\mathrm{CH}), 26.0\left(3 \mathrm{CH}_{3}\right), 21.7\left(\mathrm{CH}_{3}\right), 18.3(\mathrm{C}), 17.8\left(\mathrm{CH}_{3}\right), 17.1$ $\left(\mathrm{CH}_{3}\right), 16.0\left(\mathrm{CH}_{3}\right), 13.2\left(\mathrm{CH}_{3}\right), 11.5\left(\mathrm{CH}_{3}\right), 9.9\left(\mathrm{CH}_{3}\right), 9.1\left(\mathrm{CH}_{3}\right),-3.3\left(\mathrm{CH}_{3}\right),-3.6$ $\left(\mathrm{CH}_{3}\right)$; IR (Film) $v_{\max }=3889,2928,2897,2956,1746,1690,1452,1410,1154,1090$, $1000,735,699 \mathrm{~cm}^{-1}$

Trichloroacetylisocyanate ( $12.5 \mu \mathrm{l}, 0.106 \mathrm{mmol}, 1.05$ equiv) was added to a solution of preceding alcohol ( $99 \mathrm{mg}, 0.10 \mathrm{mmol}, 1.0$ equiv) in $\mathrm{CH}_{2} \mathrm{Cl}_{2}(8 \mathrm{~mL})$. After stirring for 15 min at $20^{\circ} \mathrm{C}$, the resulting mixture was concentrated in vacuo and the residue taken up in $\mathrm{MeOH}(10 \mathrm{~mL}) . \mathrm{K}_{2} \mathrm{CO}_{3}(81 \mathrm{mg}, 0.58 \mathrm{mmol}, 5.5$ equiv) was added and the resulting solution was stirred $1 \mathrm{~h} 15$ then concentrated in vacuo and extracted with AcOEt. The organic layers were washed with water, brine, dried over $\mathrm{MgSO}_{4}$, filtered and the solvent removed under reduced pressure. The residue was purified by chromatography on silica gel (cyclohexane/AcOEt 90:10 to 50:50) to give the corresponding carbamate $(27 \mathrm{mg}, 27 \%$ yield $)$ as a pale oil. $[\alpha]_{\mathrm{D}}^{20}=+11.3\left(c=0.5, \mathrm{CHCl}_{3}\right) ;{ }^{1} \mathrm{H}$ NMR $(400.0$ $\left.\mathrm{MHz}, \mathrm{CDCl}_{3}\right) \delta=7.52-7.45(\mathrm{~m}, 2 \mathrm{H}), 7.35-7.25(\mathrm{~m}, 6 \mathrm{H}), 7.25-7.15(\mathrm{~m}, 2 \mathrm{H}), 6.64(\mathrm{~m}$ $1 \mathrm{H}), 6.32(\mathrm{~m}, 1 \mathrm{H}), 5.62(\mathrm{ddd}, J=10.5,7.8,7.3 \mathrm{~Hz}, 1 \mathrm{H}),, 5.58(\mathrm{~s}, 1 \mathrm{H}), 5.53(\mathrm{t}, J=10.5$ $\mathrm{Hz}, 1 \mathrm{H}), 5.42(\mathrm{dd}, J=10.5,10.1 \mathrm{~Hz}, 1 \mathrm{H}), 5.21(\mathrm{dd}, J=10.5,10.1 \mathrm{~Hz}, 1 \mathrm{H}), 5.00(\mathrm{~d}, J=$ $9.6 \mathrm{~Hz}, 1 \mathrm{H}), 4.82(\mathrm{t}, J=10.1 \mathrm{~Hz}, 1 \mathrm{H}), 4.75-4.70(\mathrm{~m}, 1 \mathrm{H}), 4.70(\mathrm{~d}, J=6.4 \mathrm{~Hz}, 1 \mathrm{H}), 4.53$ $(\mathrm{s}, 2 \mathrm{H}), 4.49$ (d, $J=6.4 \mathrm{~Hz}, 1 \mathrm{H}), 4.05(\mathrm{dd}, J=10.1,3.2 \mathrm{~Hz}, 1 \mathrm{H}), 3.82(\mathrm{t}, J=9.6 \mathrm{~Hz}$ $1 \mathrm{H}), 3.73\left(\mathrm{~s}, 3 \mathrm{H}, \mathrm{CH}_{3}\right), 3.48-3.43(\mathrm{~m}, 1 \mathrm{H}), 3.38-3.30(\mathrm{~m}, 2 \mathrm{H}), 3.32\left(\mathrm{~s}, 6 \mathrm{H}, 2 \mathrm{CH}_{3}\right), 3.07$ $(\mathrm{t}, J=5.5 \mathrm{~Hz}, 1 \mathrm{H}), 2.96(\mathrm{dqd}, J=10.1,6.9,2.7 \mathrm{~Hz}, 1 \mathrm{H}), 2.87-2.75(\mathrm{qd}, J=6.9,3.2 \mathrm{~Hz}$ $1 \mathrm{H}), 2.87-2.75(\mathrm{dqd}, J=10.5,6.9,5.5 \mathrm{~Hz}, 1 \mathrm{H}), 2.54(\mathrm{dqd}, J=9.6,7.3,5.5 \mathrm{~Hz}, 1 \mathrm{H})$ $2.16(\mathrm{dd}, J=12.5,12.4 \mathrm{~Hz}, 1 \mathrm{H}), 2.00-1.80(\mathrm{~m}, 4 \mathrm{H}), 1.79-1.60(\mathrm{~m}, 2 \mathrm{H}), 1.59(\mathrm{~s}, 3 \mathrm{H}$ $\left.\mathrm{CH}_{3}\right), 1.23\left(\mathrm{~d}, J=6.9 \mathrm{~Hz}, 3 \mathrm{H}, \mathrm{CH}_{3}\right), 1.00\left(\mathrm{~d}, J=6.9 \mathrm{~Hz}, 3 \mathrm{H}, \mathrm{CH}_{3}\right), 0.99(\mathrm{~d}, J=6.9 \mathrm{~Hz}$ $\left.3 \mathrm{H}, \mathrm{CH}_{3}\right), 0.96\left(\mathrm{~d}, J=6.9 \mathrm{~Hz}, 3 \mathrm{H}, \mathrm{CH}_{3}\right), 0.92\left(\mathrm{~s}, 9 \mathrm{H}, 3 \mathrm{CH}_{3}\right), 0.91(\mathrm{~d}, J=7.3 \mathrm{~Hz}, 3 \mathrm{H}$ $\left.\mathrm{CH}_{3}\right), 0.87\left(\mathrm{~d}, J=6.4 \mathrm{~Hz}, 3 \mathrm{H}, \mathrm{CH}_{3}\right), 0.73\left(\mathrm{~d}, J=6.4 \mathrm{~Hz}, 3 \mathrm{H}, \mathrm{CH}_{3}\right), 0.11\left(, 3 \mathrm{H}, \mathrm{CH}_{3}\right)$ $0.05\left(\mathrm{~s}, 3 \mathrm{H}, \mathrm{CH}_{3}\right) ;{ }^{13} \mathrm{C}$ NMR $\left(100.5 \mathrm{MHz}, \mathrm{CDCl}_{3}\right) \delta=174.8(\mathrm{C}), 163.5(\mathrm{C}), 157.0(\mathrm{C})$ $138.7(\mathrm{C}), 136.8(\mathrm{CH}), 132.3(\mathrm{CH}), 132.1(\mathrm{C}), 130.3(\mathrm{CH}), 128.9(\mathrm{CH}), 128.6(\mathrm{CH})$ $128.4(2 \mathrm{CH}), 128.3(2 \mathrm{CH}), 128.2(\mathrm{CH}), 127.8(2 \mathrm{CH}), 125.9(\mathrm{CH}), 125.7(2 \mathrm{CH}), 99.6$ $(\mathrm{CH}), 97.7\left(\mathrm{CH}_{2}\right), 93.2\left(\mathrm{CH}_{2}\right), 86.8(\mathrm{CH}), 82.2(\mathrm{CH}), 78.7(\mathrm{CH} 5), 77.7(\mathrm{CH}), 77.3(\mathrm{CH})$ $66.3(\mathrm{CH}), 55.9\left(\mathrm{CH}_{3}\right), 55.2\left(\mathrm{CH}_{3}\right), 51.8\left(\mathrm{CH}_{3}\right), 41.1(\mathrm{CH}), 39.0\left(\mathrm{CH}_{2}\right), 37.6(\mathrm{CH}), 35.9$ $(\mathrm{CH}), 36.4(\mathrm{CH}), 35.8(\mathrm{CH}), 35.3\left(\mathrm{CH}_{2}\right), 34.3(\mathrm{CH}), 34.1(\mathrm{CH}), 33.7\left(\mathrm{CH}_{2}\right), 26$. $\left(3 \mathrm{CH}_{3}\right), 23.0\left(\mathrm{CH}_{3}\right), 18.4(\mathrm{C}), 17.6\left(\mathrm{CH}_{3}\right), 17.3\left(\mathrm{CH}_{3}\right), 16.4\left(\mathrm{CH}_{3}\right), 13.2\left(\mathrm{CH}_{3}\right), 11.6$ $\left(\mathrm{CH}_{3}\right), 10.2\left(\mathrm{CH}_{3}\right), 9.3\left(\mathrm{CH}_{3}\right),-3.7\left(\mathrm{CH}_{3}\right),-3.3\left(\mathrm{CH}_{3}\right)$; IR (Film) $v_{\max }=3354,2957$ 2930, 2889, 2856, 1726, 1600, 1459, 1439, 1375, 1146, 1110, 1093, $1032 \mathrm{~cm}^{-1}$; HRMS (ESI): $\mathrm{m} / z$ calcd for $\mathrm{C}_{56} \mathrm{H}_{89} \mathrm{NO}_{11} \mathrm{NaSi}$ : 1002.6103 [M+Na]; found: 1002.6097 .

$\mathrm{HCl}(4 \mathrm{~N}, 2.7 \mathrm{~mL})$ was added to a solution of preceding carbamate $(27 \mathrm{mg}, 0.027 \mathrm{mmol}$, 1.0 equiv) in THF $(2.7 \mathrm{~mL})$ The resulting mixture was stirred $72 \mathrm{~h}$ at $20^{\circ} \mathrm{C}$ then added with solid $\mathrm{NaHCO}_{3}$ and extracted 3 times with AcOEt. The organic layers were washed with water, brine, dried over $\mathrm{MgSO}_{4}$, filtered and the solvent was removed under reduced pressure. The residue was purified by chromatography on silica gel $\left(\mathrm{CH}_{2} \mathrm{Cl}_{2} / \mathrm{MeOH} 95: 5\right.$ to 60:40) to give the title 22-Benzyl discodermolide 4 (10 mg $56 \%$ yield $) .[\alpha]_{\mathrm{D}}^{20}=+4.6(c=1.0, \mathrm{MeOH}) ;{ }^{1} \mathrm{H}$ NMR $\left(400.0 \mathrm{MHz}, \mathrm{CDCl}_{3}\right) \delta=7.33$ $7.14(\mathrm{~m}, 5 \mathrm{H}), 5.66-5.58(\mathrm{~m}, 1 \mathrm{H}), 5.51(\mathrm{dd}, J=11.0,7.8 \mathrm{~Hz}, 1 \mathrm{H}), 5.45-5.34(\mathrm{~m}, 2 \mathrm{H})$ $5.16(\mathrm{~d}, J=9.6 \mathrm{~Hz}, 1 \mathrm{H}), 4.78-4.67(\mathrm{~m}, 3 \mathrm{H}), 4.64-59(\mathrm{~m}, 2 \mathrm{H}), 3.75-3.67(\mathrm{~m}, 2 \mathrm{H}), 3.44$ $(\mathrm{dd}, J=15.5,7.8 \mathrm{~Hz}, 1 \mathrm{H}), 3.38(\mathrm{dd}, J=15.5,8.7 \mathrm{~Hz}, 1 \mathrm{H}), 3.28(\mathrm{dd}, J=5.9,3.7 \mathrm{~Hz}$ $1 \mathrm{H}), 3.19(\mathrm{dd}, J=6.4,4.6 \mathrm{~Hz}, 1 \mathrm{H}), 3.00-2.91(\mathrm{~m}, 1 \mathrm{H}), 2.83-2.75(\mathrm{~m}, 1 \mathrm{H}), 2.74-2.68(\mathrm{~m}$ $1 \mathrm{H}), 2.66-2.58(\mathrm{~m}, 1 \mathrm{H}), 2.58-2.45(\mathrm{~m}, 1 \mathrm{H}), 2.03-1.80\left(\mathrm{~m}, 9 \mathrm{H}, 5 \mathrm{CH}, 2 \mathrm{CH}_{2}\right), 1.65(\mathrm{~s}, 3 \mathrm{H}$ $\left.\mathrm{CH}_{3}\right), 1.30\left(\mathrm{~d}, J=7.3 \mathrm{~Hz}, 3 \mathrm{H}, \mathrm{CH}_{3}\right), 1.08\left(\mathrm{~d}, J=6.9 \mathrm{~Hz}, 3 \mathrm{H}, \mathrm{CH}_{3}\right), 1.04-0.95(\mathrm{~m}, 12 \mathrm{H}$ $\left.4 \mathrm{CH}_{3}\right), 0.83\left(\mathrm{~d}, J=5.5 \mathrm{~Hz}, 3 \mathrm{H}, \mathrm{CH}_{3}\right) ;{ }^{13} \mathrm{C} \mathrm{NMR}\left(100.5 \mathrm{MHz}, \mathrm{CD}_{3} \mathrm{CN}\right) \delta=173.7(\mathrm{C})$ $157.2(\mathrm{C}), 141.1(\mathrm{C}), 133.0(\mathrm{CH}), 132.9(\mathrm{CH}), 131.5(\mathrm{C}), 130.3(\mathrm{CH}), 128.9(\mathrm{CH})$ $128.6(2 \mathrm{CH}), 128.4(2 \mathrm{CH}), 126.0(\mathrm{CH}), 117.0(\mathrm{CH}), 78.8(\mathrm{CH}), 78.4(\mathrm{CH}), 76.8(\mathrm{CH})$, $75.4(\mathrm{CH}), 72.3(\mathrm{CH}), 62.7(\mathrm{CH}), 43.1(\mathrm{CH}), 41.4\left(\mathrm{CH}_{2}\right), 37.6(\mathrm{CH}), 36.1(\mathrm{CH}), 35.6$ $(\mathrm{CH}), 35.5\left(\mathrm{CH}, \mathrm{CH}_{2}\right), 33.6,\left(\mathrm{CH}_{2}\right), 33.4(\mathrm{CH}), 32.7(\mathrm{CH}), 22.5\left(\mathrm{CH}_{3}\right), 18.6\left(\mathrm{CH}_{3}\right), 17.4$
$\left(\mathrm{CH}_{3}\right), 16.4\left(\mathrm{CH}_{3}\right), 14.8\left(\mathrm{CH}_{3}\right), 14.3\left(\mathrm{CH}_{3}\right), 12.1\left(\mathrm{CH}_{3}\right), 8.4\left(\mathrm{CH}_{3}\right)$; IR (Film) $v_{\max }=$ 3384, 2984, 2932, 2877, 2859, 1712, 1698, 1454, 1390, 1387, 1285, 1100, 1031, 739 $700 \mathrm{~cm}^{-1}$; HRMS (ESI): $\mathrm{m} / z$ calcd for $\mathrm{C}_{38} \mathrm{H}_{59} \mathrm{O}_{8} \mathrm{NaN}$ : $680.4138[M+\mathrm{Na}]$; found: 680.4133 .

14-Isopropyl discodermolide 5: $p$-toluene sulfonic acid $(2 \mathrm{mg}, 0.008 \mathrm{mmol}, 0.28$ equiv) was added to a solution of compound $\mathbf{3 3}(30 \mathrm{mg}, 0.029 \mathrm{mmol}, 1.0$ equiv) in $\mathrm{MeOH}(4 \mathrm{~mL})$ at $0^{\circ} \mathrm{C}$. After stirring for $1 \mathrm{~h}$ at $0^{\circ} \mathrm{C}$, triethylamine was added to the reaction mixture ( 0.3 equiv) and the solvent removed under reduced pressure. The residue was purified by chromatography on silica gel (cyclohexane/AcOEt 95:5 to $70: 30)$ to give expected alcohol $(19 \mathrm{mg}, 72 \%$ yield $) .[\alpha]_{\mathrm{D}}^{20}=+8.4\left(c=0.38, \mathrm{CHCl}_{3}\right)$; ${ }^{1} \mathrm{H}$ NMR $\left(400.0 \mathrm{MHz}, \mathrm{CDCl}_{3}\right) \delta=7.50-7.42(\mathrm{~m}, 2 \mathrm{H}), 7.38-7.27(\mathrm{~m}, 3 \mathrm{H}), 6.63$ (ddd, $J=$ $16.9,11.0,10.5 \mathrm{~Hz}, 1 \mathrm{H}), 6.16(\mathrm{dd}, J=11.0,10.5 \mathrm{~Hz}, 1 \mathrm{H}), 5.59(\mathrm{~s}, 1 \mathrm{H}), 5.53(\mathrm{dd}, J=$ $10.5,10.1 \mathrm{~Hz}, 1 \mathrm{H}), 5.33(\mathrm{t}, J=10.5 \mathrm{~Hz}, 1 \mathrm{H}), 5.27-5.23(\mathrm{~m}, 1 \mathrm{H}), 5.20(\mathrm{~d}, J=16.9 \mathrm{~Hz}$ $1 \mathrm{H}), 5.16(\mathrm{~d}, J=10.5 \mathrm{~Hz}, 1 \mathrm{H}), 5.05(\mathrm{~d}, J=9.6 \mathrm{~Hz}, 1 \mathrm{H}), 4.85(\mathrm{dd}, J=10.1,9.6 \mathrm{~Hz}, 1 \mathrm{H})$, $4.72(\mathrm{~d}, J=6.9 \mathrm{~Hz}, 1 \mathrm{H}), 4.50\left(\mathrm{~s}, 2 \mathrm{H}, \mathrm{CH}_{2}\right), 4.49(\mathrm{~d}, J=6.9 \mathrm{~Hz}, 1 \mathrm{H}), 4.06(\mathrm{dd}, J=10.1$, $2.7 \mathrm{~Hz}, 1 \mathrm{H}), 3.84(\mathrm{dd}, J=10.1,9.2 \mathrm{~Hz}, 1 \mathrm{H}), 3.73\left(\mathrm{~s}, 3 \mathrm{H}, \mathrm{CH}_{3}\right), 3.62(\mathrm{dd}, J=5.9,3.2$ $\mathrm{Hz}, 1 \mathrm{H}), 3.35-3.32(\mathrm{~m}, 1 \mathrm{H}), 3.34\left(\mathrm{~s}, 3 \mathrm{H}, \mathrm{CH}_{3}\right), 3.31\left(\mathrm{~s}, 3 \mathrm{H}, \mathrm{CH}_{3}\right), 3.08(\mathrm{t}, J=5.5 \mathrm{~Hz}$, $1 \mathrm{H}), 2.87-2.78(\mathrm{~m}, 3 \mathrm{H}), 2.65-2.53(\mathrm{~m}, 1 \mathrm{H}), 2.19-2.06(\mathrm{~m}, 2 \mathrm{H}), 1.95(\mathrm{dd}, J=14.2,12.4$ $\mathrm{Hz}, 1 \mathrm{H}), 1.90-1.79(\mathrm{~m}, 2 \mathrm{H}), 1.72-1.60(\mathrm{~m}, 3 \mathrm{H}), 1.44(\mathrm{~s}, 1 \mathrm{H}), 1.23$ (d, $J=6.9 \mathrm{~Hz}, 3 \mathrm{H}$ $\left.\mathrm{CH}_{3}\right), 1.02-0.87\left(\mathrm{~m}, 12 \mathrm{H}, 6 \mathrm{CH}_{3}\right), 0.93\left(\mathrm{~s}, 9 \mathrm{H}, 3 \mathrm{CH}_{3}\right), 0.88\left(\mathrm{~d}, J=6.9 \mathrm{~Hz}, 3 \mathrm{H}, \mathrm{CH}_{3}\right)$, $0.75\left(\mathrm{~d}, J=6.9 \mathrm{~Hz}, 3 \mathrm{H}_{1} \mathrm{CH}_{3}\right), 0.10\left(\mathrm{~s}, 6 \mathrm{H}, 2 \mathrm{CH}_{3}\right) ;{ }^{13} \mathrm{C} \mathrm{NMR}\left(100.5 \mathrm{MHz}, \mathrm{CDCl}_{3}\right) \delta=$ $175.1(\mathrm{C}), 142.5(\mathrm{C}), 139.0(\mathrm{C}), 138.0(\mathrm{CH}), 134.9(\mathrm{CH}), 132.3(\mathrm{CH}), 131.4(\mathrm{CH})$, $129.0(\mathrm{CH}), 128.5(\mathrm{CH}), 128.2(2 \mathrm{CH}), 126.1(2 \mathrm{CH}), 127.2(\mathrm{CH}), 118.8\left(\mathrm{CH}_{2}\right), 99.9$ $(\mathrm{CH}), 98.0\left(\mathrm{CH}_{2}\right), 93.4\left(\mathrm{CH}_{2}\right), 87.0(\mathrm{CH}), 82.5(\mathrm{CH}), 79.2(\mathrm{CH}), 77.6(\mathrm{CH}), 76.3(\mathrm{CH})$ $66.5(\mathrm{CH}), 56.3\left(\mathrm{CH}_{3}\right), 55.5\left(\mathrm{CH}_{3}\right), 52.2\left(\mathrm{CH}_{3}\right), 41.1(\mathrm{CH}), 39.3\left(\mathrm{CH}_{2}\right), 38.3(\mathrm{CH}), 36.5$ $(\mathrm{CH}), 35.6\left(\mathrm{CH}_{2}\right), 35.5(\mathrm{CH}), 35.1(\mathrm{CH}), 34.4(\mathrm{CH}), 33.9(\mathrm{CH}), 32.3(\mathrm{CH}), 26.5\left(3 \mathrm{CH}_{3}\right)$, $18.5(\mathrm{C}), 22.9\left(\mathrm{CH}_{3}\right), 22.4\left(\mathrm{CH}_{3}\right), 18.7\left(\mathrm{CH}_{3}\right), 17.5\left(\mathrm{CH}_{3}\right), 16.1\left(\mathrm{CH}_{3}\right), 13.9\left(\mathrm{CH}_{3}\right)$, $11.9\left(\mathrm{CH}_{3}\right), 9.7\left(\mathrm{CH}_{3}\right), 9.5\left(\mathrm{CH}_{3}\right),-2.9\left(\mathrm{CH}_{3}\right),-3.4\left(\mathrm{CH}_{3}\right)$; IR (Film) $v_{\max }=3055,2956$, 2931, 2909, 1742, 1736, 1460, 1453, 1433, 1377, 1146, 1093, 1013, 836, $772 \mathrm{~cm}^{-1}$.

Trichloroacetylisocyanate ( $2.6 \mu \mathrm{l}, 0.022 \mathrm{mmol}, 1.05$ equiv) was added to a solution of preceding alcohol (19 mg, $0.021 \mathrm{mmol}, 1.0$ equiv) in $\mathrm{CH}_{2} \mathrm{Cl}_{2}(1.7 \mathrm{~mL})$. After stirring for $15 \mathrm{~min}$ at $20^{\circ} \mathrm{C}$, the resulting mixture was concentrated in vacuo and the residue taken up in $\mathrm{MeOH}(2.1 \mathrm{~mL}), \mathrm{K}_{2} \mathrm{CO}_{3}(16 \mathrm{mg}, 0.45 \mathrm{mmol}, 5.5$ equiv) was added and the resulting solution was stirred $1 \mathrm{~h} 15$ then concentrated in vacuo and extracted with AcOEt. The organic layers were washed with water, brine, dried over $\mathrm{MgSO}_{4}$, filtered and the solvent removed under reduced pressure. The residue was purified by chromatography on silica gel (cyclohexane/AcOEt 90:10 to 50:50) to give the title carbamate $(8 \mathrm{mg}, 40 \%$ yield $)$ as a pale oil. $[\alpha]_{\mathrm{D}}^{20}=+20.7\left(c=0.80, \mathrm{CHCl}_{3}\right) ;{ }^{1} \mathrm{H} \mathrm{NMR}$ $\left(400.0 \mathrm{MHz}, \mathrm{CDCl}_{3}\right) \delta=7.50-7.42(\mathrm{~m}, 2 \mathrm{H}), 7.37-7.27(\mathrm{~m}, 3 \mathrm{H}), 6.60(\mathrm{ddd}, J=16.5$, $11.0,10.5 \mathrm{~Hz}, 1 \mathrm{H}), 6.04(\mathrm{t}, J=11.0 \mathrm{~Hz}, 1 \mathrm{H}), 5.58(\mathrm{~s}, 1 \mathrm{H}), 5.53(\mathrm{t}, J=10.5 \mathrm{~Hz}, 1 \mathrm{H}, \mathrm{H}-9$, $\mathrm{m}, 1 \mathrm{H}), 5.39(\mathrm{dd}, J=11.0,10.5 \mathrm{~Hz}, 1 \mathrm{H}), 5.25-5.11(\mathrm{~m}, 4 \mathrm{H}), 5.03(\mathrm{~d}, J=10.1 \mathrm{~Hz}, 1 \mathrm{H})$ $4.85(\mathrm{dd}, J=10.1,8.7 \mathrm{~Hz}, 1 \mathrm{H}), 4.71(\mathrm{~d}, J=6.4 \mathrm{~Hz}, 1 \mathrm{H}), 4.71-4.67(\mathrm{~m}, 1 \mathrm{H}), 4.51(\mathrm{~s}, 2 \mathrm{H}$, $\left.\mathrm{CH}_{2}\right), 4.50(\mathrm{~d}, J=6.4 \mathrm{~Hz}, 1 \mathrm{H}), 4.05(\mathrm{dd}, J=11.0,2.7 \mathrm{~Hz}, 1 \mathrm{H}), 3.84(\mathrm{dd}, J=10.1,9.6$ $\mathrm{Hz}, 1 \mathrm{H}), 3.73$ (s, $\left.3 \mathrm{H}, \mathrm{CH}_{3}\right), 3.43(\mathrm{dd}, J=4.6,4.1 \mathrm{~Hz}, 1 \mathrm{H}), 3.32\left(\mathrm{~s}, 3 \mathrm{H}, \mathrm{CH}_{3}\right), 3.30$ (s, $\left.3 \mathrm{H}, \mathrm{CH}_{3}\right), 3.05(\mathrm{t}, J=5.5 \mathrm{~Hz}, 1 \mathrm{H}), 3.03-2.96(\mathrm{~m}, 1 \mathrm{H}), 2.87-2.78(\mathrm{~m}, 2 \mathrm{H}), 2.58(\mathrm{dqd}, J=$ $10.1,6.9,5.5 \mathrm{~Hz}, 1 \mathrm{H}), 2.12$ (hept, $J=6.4 \mathrm{~Hz}), 2.03-1.67\left(\mathrm{~m}, 7 \mathrm{H}, 2 \mathrm{CH}_{2}, 3 \mathrm{CH}\right), 1.23(\mathrm{~d}, J$ $\left.=7.3 \mathrm{~Hz}, 3 \mathrm{H}, \mathrm{CH}_{3}\right), 1.00\left(\mathrm{~d}, J=6.9 \mathrm{~Hz}, 3 \mathrm{H}, \mathrm{CH}_{3}\right), 0.99\left(\mathrm{~d}, J=6.9 \mathrm{~Hz}, 3 \mathrm{H}, \mathrm{CH}_{3}\right), 0.96-$ $0.90\left(\mathrm{~m}, 9 \mathrm{H}, 3 \mathrm{CH}_{3}\right), 0.93\left(\mathrm{~s}, 9 \mathrm{H}, 3 \mathrm{CH}_{3}\right), 0.89\left(\mathrm{~d}, J=6.9 \mathrm{~Hz}, 3 \mathrm{H}, \mathrm{CH}_{3}\right), 0.88(\mathrm{~d}, J=6.9$ $\left.\mathrm{Hz}, 3 \mathrm{H}, \mathrm{CH}_{3}\right), 0.73$ (d, $\left.J=6.9 \mathrm{~Hz}, 3 \mathrm{H}, \mathrm{CH}_{3}\right), 0.11\left(\mathrm{~s}, 3 \mathrm{H}, \mathrm{CH}_{3}\right), 0.08\left(\mathrm{~s}, 3 \mathrm{H}, \mathrm{CH}_{3}\right) ;{ }^{13} \mathrm{C}$ NMR (100.5 MHz, $\left.\mathrm{CDCl}_{3}\right) \delta=174.8(\mathrm{C}), 157.1(\mathrm{C}), 141.7(\mathrm{C}), 138.7(\mathrm{CH}), 137.7(\mathrm{C})$, $133.5(\mathrm{CH}), 132.0(\mathrm{CH}), 129.8(\mathrm{CH}), 128.7(\mathrm{CH}), 128.3(\mathrm{CH}), 128.2(\mathrm{CH}), 127.9$ (2CH), $125.8(2 \mathrm{CH}), 117.9\left(\mathrm{CH}_{2}\right), 99.7(\mathrm{CH}), 97.7\left(\mathrm{CH}_{2}\right), 93.1\left(\mathrm{CH}_{2}\right), 86.8(\mathrm{CH}), 82.2$ $(\mathrm{CH}), 78.8(\mathrm{CH}), 77.7(\mathrm{CH}), 77.0(\mathrm{CH}), 66.3(\mathrm{CH}), 56.0\left(\mathrm{CH}_{3}\right), 55.2\left(\mathrm{CH}_{3}\right), 51.9\left(\mathrm{CH}_{3}\right)$, $41.2,39.0,37.9,35.9,35.8,35.4,34.4,33.6,31.6\left(9 \mathrm{CH}, 2 \mathrm{CH}_{2}, \mathrm{C}-2, \mathrm{C}-4, \mathrm{C}-6, \mathrm{C}-10, \mathrm{C}-\right.$ 12, C-15, C-16, C-18, C-20, $\left.\mathrm{CH}\left(\mathrm{CH}_{3}\right)_{2}\right), 26.2\left(3 \mathrm{CH}_{3}\right), 18.5(\mathrm{C}), 22.6\left(\mathrm{CH}_{3}\right), 21.9\left(\mathrm{CH}_{3}\right)$, $17.5\left(\mathrm{CH}_{3}\right), 17.1\left(\mathrm{CH}_{3}\right), 15.9\left(\mathrm{CH}_{3}\right), 13.7\left(\mathrm{CH}_{3}\right), 11.7\left(\mathrm{CH}_{3}\right), 9.4\left(\mathrm{CH}_{3}\right), 9.3\left(7 \mathrm{CH}_{3}\right),-3.3$ $\left(\mathrm{CH}_{3}\right),-3.8\left(\mathrm{CH}_{3}\right)$; IR $\left(\right.$ Film) $v_{\max }=3440,3355,2998,2933,1730,1721,1460,1450$ 1409, 1395, 1094, $1034 \mathrm{~cm}^{-1}$; HRMS (ESI): $\mathrm{m} / z$ calcd for $\mathrm{C}_{53} \mathrm{H}_{89} \mathrm{O}_{11} \mathrm{NNaSi}$ : 966.6103 $[M+\mathrm{Na}]$; found: 966.6097 .

To a solution of preceding carbamate $(8 \mathrm{mg}, 0.008 \mathrm{mmol}, 1.0$ equiv) in THF ( $0.9 \mathrm{~mL})$ was added $\mathrm{HCl}(4 \mathrm{~N}, 0.9 \mathrm{~mL})$. The resulting mixture was stirred $72 \mathrm{~h}$ at $20^{\circ} \mathrm{C}$ then added with solid $\mathrm{NaHCO}_{3}$ and extracted 3 times with AcOEt. The organic layers were washed with water, brine, dried over $\mathrm{MgSO}_{4}$, filtered and the solvent was removed under reduced pressure. The residue was purified by chromatography on silica gel $\left(\mathrm{CH}_{2} \mathrm{Cl}_{2} / \mathrm{MeOH} 95: 5\right.$ to $\left.70: 30\right)$ to give 14-Isopropyl discodermolide 5 (2 $\mathrm{mg}, 50 \%$ yield). ${ }^{1} \mathrm{H}$ NMR $\left(400.0 \mathrm{MHz}, \mathrm{CDCl}_{3}\right) \delta=6.64$ (ddd, $\left.J=17.4,10.5,10.1 \mathrm{~Hz}, 1 \mathrm{H}\right), 6.05$ $(\mathrm{dd}, J=11.0,10.5 \mathrm{~Hz}, 1 \mathrm{H}), 5.55(\mathrm{dd}, J=11.0,7.8 \mathrm{~Hz}, 1 \mathrm{H}), 5.45(\mathrm{dd}, J=12.4,11.0 \mathrm{~Hz}$, $1 \mathrm{H}), 5.37(\mathrm{dd}, J=11.0,10.1 \mathrm{~Hz}, 1 \mathrm{H}), 5.25(\mathrm{~d}, J=17.4 \mathrm{~Hz}, 1 \mathrm{H}), 5.20(\mathrm{~d}, J=10.1 \mathrm{~Hz}$, $1 \mathrm{H}), 5.14(\mathrm{~d}, J=10.5 \mathrm{~Hz}, 1 \mathrm{H}), 4.80-4.76(\mathrm{~m}, 1 \mathrm{H}), 4.72(\mathrm{dd}, J=6.9,4.1 \mathrm{~Hz}, 1 \mathrm{H}), 4.70$ $4.59(\mathrm{~m}, 4 \mathrm{H}), 3.80-3.72(\mathrm{~m}, 2 \mathrm{H}), 3.30(\mathrm{t}, J=5.0 \mathrm{~Hz}, 1 \mathrm{H}), 3.21(\mathrm{dd}, J=7.3,4.6 \mathrm{~Hz}, 1 \mathrm{H})$, $3.06-2.98(\mathrm{~m}, 1 \mathrm{H}), 2.88-2.80(\mathrm{~m}, 1 \mathrm{H}), 2.75-2.62(\mathrm{~m}, 2 \mathrm{H}), 2.16$ (hept, $J=7.8 \mathrm{~Hz}, 1 \mathrm{H})$ 2.00-1.85 (m, 9H, 5CH, 2CH $), 1.33\left(\mathrm{~d}, J=7.3 \mathrm{~Hz}, 3 \mathrm{H}, \mathrm{CH}_{3}\right), 1.09(\mathrm{~d}, J=6.9 \mathrm{~Hz}, 3 \mathrm{H}$, $\left.\mathrm{CH}_{3}\right), 1.06\left(\mathrm{~d}, J=7.3 \mathrm{~Hz}, 3 \mathrm{H}, \mathrm{CH}_{3}\right), 1.05\left(\mathrm{~d}, J 6.0 \mathrm{~Hz}, 3 \mathrm{H}, \mathrm{CH}_{3}\right), 1.03(\mathrm{~d}, J=6.9 \mathrm{~Hz}$, $\left.3 \mathrm{H}, \mathrm{CH}_{3}\right), 1.01\left(\mathrm{~d}, J=6.9 \mathrm{~Hz}, 6 \mathrm{H}, 2 \mathrm{CH}_{3}\right), 0.96\left(\mathrm{~d}, J=6.4 \mathrm{~Hz}, 3 \mathrm{H}, \mathrm{CH}_{3}\right), 0.85(\mathrm{~d}, J=$ $6.0 \mathrm{~Hz}, 3 \mathrm{H}, \mathrm{CH}_{3}$ ); HRMS (ESI): $\mathrm{m} / z$ calcd for $\mathrm{C}_{35} \mathrm{H}_{59} \mathrm{O}_{8} \mathrm{NNa}$ : $644.4138[M+\mathrm{Na}]$; found: 644.4133 . 
Phenol discodermolide 6: Compound 39 ( $16 \mathrm{mg}, 0.017 \mathrm{mmol}, 1.0$ equiv) was diluted in $\mathrm{MeOH}(2 \mathrm{~mL})$ at $0^{\circ} \mathrm{C}$ and $p$-toluene sulfonic acid $(0.9 \mathrm{mg}, 0.0047 \mathrm{mmol}, 0.28$ equiv) was added. After stirring for $1 \mathrm{~h}$ at $0^{\circ} \mathrm{C}$, triethylamine was added to the reaction mixture ( 0.3 equiv) and the solvent removed under reduced pressure. The residue was purified by chromatography on silica gel (cyclohexane/ $\mathrm{Et}_{2} \mathrm{O} 95: 5$ to $60: 40$ ) to give the expected alcohol $(8 \mathrm{mg}, 58 \%$ yield $) .[\alpha]_{\mathrm{D}}^{20}=+20.8\left(c=0.8, \mathrm{CHCl}_{3}\right) ;{ }^{1} \mathrm{H}$ NMR $(400.0 \mathrm{MHz}$, $\left.\mathrm{CDCl}_{3}\right) \delta=7.13(\mathrm{t}, J=7.8 \mathrm{~Hz}, 1 \mathrm{H}), 6.84(\mathrm{~d}, J=7.8 \mathrm{~Hz}, 1 \mathrm{H}), 6.76(\mathrm{~s}, 1 \mathrm{H}), 6.68(\mathrm{~d}, J=$ $7.8 \mathrm{~Hz}, 1 \mathrm{H}), 6.66(\mathrm{ddd}, J=16.5,11.0,10.5 \mathrm{~Hz}, 1 \mathrm{H}), 6.13(\mathrm{t}, J=11.0 \mathrm{~Hz}, 1 \mathrm{H}), 5.49(\mathrm{dd}$, $J=10.5,10.1 \mathrm{~Hz}, 1 \mathrm{H}), 5.33(\mathrm{dd}, J=11.0,10.1 \mathrm{~Hz}, 1 \mathrm{H}), 5.25(\mathrm{~d}, J=16.5 \mathrm{~Hz}, 1 \mathrm{H}), 5.24$ (t, $J=10.5 \mathrm{~Hz}, 1 \mathrm{H}), 5.16(\mathrm{~d}, J=10.5 \mathrm{~Hz}, 1 \mathrm{H}), 4.89(\mathrm{~d}, J=10.1 \mathrm{~Hz}, 1 \mathrm{H}), 4.61(\mathrm{~s}, 2 \mathrm{H})$, $4.59(\mathrm{~d}, J=6.4 \mathrm{~Hz}, 1 \mathrm{H}), 4.61-4.55(\mathrm{~m}, 1 \mathrm{H}), 4.36(\mathrm{~d}, J=6.4 \mathrm{~Hz}, 1 \mathrm{H}), 3.62(\mathrm{dd}, J=5.5$, $3.2 \mathrm{~Hz}, 1 \mathrm{H}), 3.40\left(\mathrm{~s}, 3 \mathrm{H}, \mathrm{CH}_{3}\right), 3.33$ (ddd, $\left.J=8.7,3.2,2.7 \mathrm{~Hz}, 1 \mathrm{H}\right), 3.16(\mathrm{~d}, J=8.7 \mathrm{~Hz}$, $1 \mathrm{H}), 3.02\left(\mathrm{~s}, 3 \mathrm{H}, \mathrm{CH}_{3}\right), 2.93(\mathrm{dd}, J=6.4,5.0 \mathrm{~Hz}, 1 \mathrm{H}), 2.85-2.76(\mathrm{~m}, 3 \mathrm{H}), 2.75(\mathrm{dd}, J=$ 7.8, $5.0 \mathrm{~Hz}, 1 \mathrm{H}), 2.58-2.52(\mathrm{~m}, 1 \mathrm{H}), 2.21(\mathrm{dd}, J=12.4,11.9 \mathrm{~Hz}, 1 \mathrm{H}), 1.95-1.85(\mathrm{~m}$, $1 \mathrm{H}), 1.82-1.75(\mathrm{~m}, 2 \mathrm{H}), 1.60\left(\mathrm{~s}, 3 \mathrm{H}, \mathrm{CH}_{3}\right), 0.98\left(\mathrm{~s}, 18 \mathrm{H}, 6 \mathrm{CH}_{3}\right), 0.99-0.92\left(\mathrm{~m}, 4 \mathrm{CH}_{3}\right)$, $0.74\left(\mathrm{~d}, J=6.9 \mathrm{~Hz}, \mathrm{CH}_{3}\right), 0.18\left(\mathrm{~s}, 6 \mathrm{H}, 2 \mathrm{CH}_{3}\right), 0.09\left(\mathrm{~s}, 6 \mathrm{H}, 2 \mathrm{CH}_{3}\right) ;{ }^{13} \mathrm{C} \mathrm{NMR}(100.5$ $\left.\mathrm{MHz}, \mathrm{CDCl}_{3}\right) \delta=155.3(\mathrm{C}), 140.2(\mathrm{C}), 137.0(\mathrm{CH}), 134,7(\mathrm{CH}), 132.4(\mathrm{CH}), 132.0$ $(\mathrm{CH}), 131.0(\mathrm{C}), 130.4(\mathrm{CH}), 128.9(\mathrm{CH}), 128.7(\mathrm{CH}), 122.7(\mathrm{CH}), 121.7(\mathrm{CH}), 118.5$ $\left(\mathrm{CH}_{2}\right), 117.7(\mathrm{CH}), 97.7\left(\mathrm{CH}_{2}\right), 93.0\left(\mathrm{CH}_{2}\right), 87.0(\mathrm{CH}), 78.9(\mathrm{CH}), 76.2(\mathrm{CH}), 71.9$ $(\mathrm{CH}), 55.9\left(\mathrm{CH}_{3}\right), 54.9\left(\mathrm{CH}_{3}\right), 42.0\left(\mathrm{CH}_{2}\right), 37.9(\mathrm{CH}), 36.5\left(\mathrm{CH}_{2}\right), 36.3(\mathrm{CH}), 35.6$ $(\mathrm{CH}), 34.6(\mathrm{CH}), 34.4(\mathrm{CH}), 26.6\left(3 \mathrm{CH}_{3}\right), 26.2\left(3 \mathrm{CH}_{3}\right), 23.3\left(\mathrm{CH}_{3}\right), 18.4(2 \mathrm{C}), 18.1$ $\left(\mathrm{CH}_{3}\right), 17.1\left(\mathrm{CH}_{3}\right), 16.9\left(\mathrm{CH}_{3}\right), 13.4\left(\mathrm{CH}_{3}\right), 9.4\left(\mathrm{CH}_{3}\right),-3.2\left(2 \mathrm{CH}_{3}\right),-3.7\left(\mathrm{CH}_{3}\right),-4.4$ $\left(\mathrm{CH}_{3}\right)$; IR (Film) $v_{\max }=3373,2957,2929,2857,1148,1096,1031,1004,838 \mathrm{~cm}^{-1}$.

Trichloroacetylisocyanate $(2.3 \mu \mathrm{l}, 0.019 \mathrm{mmol}, 1.05$ equiv) was added to a solution of preceding alcohol ( $15 \mathrm{mg}, 0.018 \mathrm{mmol}, 1.0$ equiv) in $\mathrm{CH}_{2} \mathrm{Cl}_{2}(1.4 \mathrm{~mL})$ After stirring for $15 \mathrm{~min}$ at $20^{\circ} \mathrm{C}$, the resulting mixture was concentrated in vacuo and the residue was taken up in $\mathrm{MeOH}(1.8 \mathrm{~mL}) . \mathrm{K}_{2} \mathrm{CO}_{3}(14 \mathrm{mg}, 0.10 \mathrm{mmol}$, 5.5 equiv) was added and the resulting solution was stirred for $1 \mathrm{~h} 15$ then concentrated in vacuo and extracted with AcOEt. The organic layers were washed with water, brine, dried over $\mathrm{MgSO}_{4}$, filtered and the solvents were removed under reduced pressure. The residue was purified by chromatography on silica gel (cyclohexane/AcOEt 90:10 to 50:50) to give the title carbamate $(9 \mathrm{mg}, 58 \%$ yield $) .[\alpha]_{\mathrm{D}}^{20}=+31.7\left(c=0.9, \mathrm{CHCl}_{3}\right) ;{ }^{1} \mathrm{H}$ NMR $(400.0 \mathrm{MHz}$ $\left.\mathrm{CDCl}_{3}\right) \delta=7.15(\mathrm{t}, J=7.8 \mathrm{~Hz}, 1 \mathrm{H}), 6.84(\mathrm{~d}, J=7.8 \mathrm{~Hz}, 1 \mathrm{H}), 6.73(\mathrm{~s}, 1 \mathrm{H}), 6.72(\mathrm{~d}, J=$ $7.8 \mathrm{~Hz}, 1 \mathrm{H}), 6.60(\mathrm{ddd}, J=16.5,11.0,10.1 \mathrm{~Hz}, 1 \mathrm{H}), 6.03(\mathrm{dd}, J=11.0,10.5 \mathrm{~Hz}, 1 \mathrm{H})$, $5.48(\mathrm{dd}, J=10.5,10.1 \mathrm{~Hz}, 1 \mathrm{H}), 5.34(\mathrm{dd}, J=10.5,10.1 \mathrm{~Hz}, 1 \mathrm{H}), 5.25-5.22(\mathrm{~m}, 1 \mathrm{H})$, $5.22(\mathrm{~d}, J=16.5 \mathrm{~Hz}, 1 \mathrm{H}), 5.19(\mathrm{dd}, J=10.5,10.1 \mathrm{~Hz}, 1 \mathrm{H}), 5.13(\mathrm{~d}, J=10.1 \mathrm{~Hz}, 1 \mathrm{H})$ $4.73(\mathrm{~d}, J=6.9 \mathrm{~Hz}, 1 \mathrm{H}), 4.73-4.64(\mathrm{~m}, 1 \mathrm{H}), 4.64(\mathrm{~d}, J=6.9 \mathrm{~Hz}, 1 \mathrm{H}), 4.62(\mathrm{~d}, J=6.9$ $\mathrm{Hz}, 1 \mathrm{H}), 4.62-4.53\left(\mathrm{~m}, 3 \mathrm{H}, 1 \mathrm{CH}, 1 \mathrm{CH}_{2}\right), 4.45(\mathrm{~d}, J=6.9 \mathrm{~Hz}, 1 \mathrm{H}), 3.46\left(\mathrm{~s}, 3 \mathrm{H}, \mathrm{CH}_{3}\right)$, $3.48(\mathrm{dd}, J=6.4,3.2 \mathrm{~Hz}, 1 \mathrm{H}), 3.18\left(\mathrm{~s}, 3 \mathrm{H}, \mathrm{CH}_{3}\right), 2.92-2.87(\mathrm{~m}, 2 \mathrm{H}), 2.81-2.73(\mathrm{~m}, 2 \mathrm{H})$ $2.69(\mathrm{dd}, J=13.7,5.9 \mathrm{~Hz}, 1 \mathrm{H}), 2.54(\mathrm{dqm}, J=10.1,6.9 \mathrm{~Hz}, 1 \mathrm{H}), 2.18(\mathrm{t}, J=12.4 \mathrm{~Hz}$, $1 \mathrm{H}), 2.01-1.87(\mathrm{~m}, 2 \mathrm{H}), 1.70-1.66(\mathrm{~m}, 1 \mathrm{H}), 1.58\left(\mathrm{~s}, 3 \mathrm{H}, \mathrm{CH}_{3}\right), 0.99\left(\mathrm{~d}, J=6.9 \mathrm{~Hz}, \mathrm{CH}_{3}\right)$ $0.98\left(\mathrm{~d}, J=6.9 \mathrm{~Hz}, \mathrm{CH}_{3}\right), 0.93\left(\mathrm{~d}, J=6.9 \mathrm{~Hz}, \mathrm{CH}_{3}\right), 0.92\left(\mathrm{~s}, 18 \mathrm{H}, 6 \mathrm{CH}_{3}\right), 0.89(\mathrm{~d}, J=$ $\left.6.9 \mathrm{~Hz}, \mathrm{CH}_{3}\right), 0.71\left(\mathrm{~d}, J=6.9 \mathrm{~Hz}, \mathrm{CH}_{3}\right), 0.08\left(\mathrm{~s}, 6 \mathrm{H}, 2 \mathrm{CH}_{3}\right), 0.07\left(\mathrm{~s}, 6 \mathrm{H}, 2 \mathrm{CH}_{3}\right) ;{ }^{13} \mathrm{C}$ NMR $\left(100.5 \mathrm{MHz}, \mathrm{CDCl}_{3}\right) \delta=157.3(\mathrm{C}), 156.0(\mathrm{C}), 139.9(\mathrm{C}), 137.0(\mathrm{CH}), 134.0$ $(\mathrm{CH}), 132.5(\mathrm{CH}), 132.1(\mathrm{C}), 130.5(\mathrm{CH}), 130.1(\mathrm{CH}), 129.6(\mathrm{CH}), 128.7(\mathrm{CH}), 122.1$ $(\mathrm{CH}), 117.9\left(\mathrm{CH}_{2}\right), 116.2(\mathrm{CH}), 113.7(\mathrm{CH}), 97.3\left(\mathrm{CH}_{2}\right), 93.0\left(\mathrm{CH}_{2}\right), 87.2(\mathrm{CH}), 78.9$ $(\mathrm{CH}), 77.3(\mathrm{CH}), 71.3(\mathrm{CH}), 56.0\left(\mathrm{CH}_{3}\right), 55.2\left(\mathrm{CH}_{3}\right), 41.7\left(\mathrm{CH}_{2}\right), 37.8(\mathrm{CH}), 37.3$ $\left(\mathrm{CH}_{2}\right), 35.5(\mathrm{CH}), 34.9(\mathrm{CH}), 34.4(\mathrm{CH}), 34.3(\mathrm{CH}), 26.2\left(6 \mathrm{CH}_{3}\right), 22.7\left(\mathrm{CH}_{3}\right), 18.5$ (2C), $17.8\left(\mathrm{CH}_{3}\right), 17.3\left(\mathrm{CH}_{3}\right), 17.1\left(\mathrm{CH}_{3}\right), 12.7\left(\mathrm{CH}_{3}\right), 10.1\left(\mathrm{CH}_{3}\right),-3.2\left(2 \mathrm{CH}_{3}\right),-3.3$ $\left(\mathrm{CH}_{3}\right),-3.4\left(\mathrm{CH}_{3}\right)$; IR (Film) $v_{\max }=3353,2960,2930,2885,1720,1711,1455,1096$, $1031 \mathrm{~cm}^{-1}$. HRMS (ESI): $\mathrm{m} / z$ calcd for $\mathrm{C}_{48} \mathrm{H}_{85} \mathrm{O}_{8} \mathrm{NNaSi}_{2}$ : 882.5711 [M+Na]; found: 566.3447

Preceding carbamate $(9 \mathrm{mg}, 0.010 \mathrm{mmol}, 1.0$ equiv) was dissolved in $\mathrm{MeOH}(1 \mathrm{~mL})$ $\mathrm{HCl}(4 \mathrm{~N}, 1 \mathrm{~mL})$ was added and the resulting mixture was stirred for $24 \mathrm{~h}$ at $20^{\circ} \mathrm{C}$ then solid $\mathrm{NaHCO}_{3}$ was added. The reaction mixture was extracted 3 times with AcOEt. The organic layers were washed with water, brine, dried over $\mathrm{MgSO}_{4}$, filtered and the solvent was removed under reduced pressure. The residue was purified by chromatography on silica gel $\left(\mathrm{CH}_{2} \mathrm{Cl}_{2} / \mathrm{MeOH} 95: 5\right.$ to $\left.80: 20\right)$ to give phenol discodermolide 6 (5 mg, 88\% yield). $[\alpha]_{\mathrm{D}}^{20}=+7.54\left(c=0.5, \mathrm{CHCl}_{3}\right) ;{ }^{1} \mathrm{H}$ NMR $(400.0$ $\left.\mathrm{MHz}, \mathrm{CDCl}_{3}\right) \delta=7.16(\mathrm{t}, J=8.2 \mathrm{~Hz}, 1 \mathrm{H}), 6.77-6.70(\mathrm{~m}, 3 \mathrm{H}), 6.61(\mathrm{ddd}, J=16.9,10.5$, $10.1 \mathrm{~Hz}, 1 \mathrm{H}), 6.04(\mathrm{dd}, J=11.0,10.5 \mathrm{~Hz}, 1 \mathrm{H}), 5.52(\mathrm{~d}, J=8.2 \mathrm{~Hz}, 1 \mathrm{H}), 5.33$ (dd, $J=$ $11.0,9.6 \mathrm{~Hz}, 1 \mathrm{H}), 5.23(\mathrm{~d}, J=16.9 \mathrm{~Hz}, 1 \mathrm{H}), 5.21(\mathrm{~d}, J=8.2 \mathrm{~Hz}, 1 \mathrm{H}), 5.13(\mathrm{~d}, J=10.1$ $\mathrm{Hz}, 1 \mathrm{H}), 5.08(\mathrm{~d}, J=10.1 \mathrm{~Hz}, 1 \mathrm{H}), 4.72(\mathrm{dd}, J=9.2,3.2 \mathrm{~Hz}, 1 \mathrm{H}), 4.70-4.62(\mathrm{~m}, 3 \mathrm{H}$ $\left.1 \mathrm{CH}, 1 \mathrm{CH}_{2}\right), 3.40(\mathrm{dd}, J=9.2,2.7 \mathrm{~Hz}, 1 \mathrm{H}), 3.36(\mathrm{dd}, J=5.5,2.7 \mathrm{~Hz}, 1 \mathrm{H}), 3.14(\mathrm{t}, J=$ $5.9 \mathrm{~Hz}, 1 \mathrm{H}), 3.01-2.97(\mathrm{~m}, 1 \mathrm{H}), 2.82-2.63(\mathrm{~m}, 2 \mathrm{H}), 2.56-2.48(\mathrm{~m}, 1 \mathrm{H}), 2.20-2.10(\mathrm{~m}$, $2 \mathrm{H}), 2.00-1.90(\mathrm{~m}, 2 \mathrm{H}), 1.66\left(\mathrm{~s}, 3 \mathrm{H}, \mathrm{CH}_{3}\right), 1.07-0.88\left(\mathrm{~m}, 4 \mathrm{CH}_{3}\right), 0.71(\mathrm{~d}, J=5.5 \mathrm{~Hz}$ $\left.\mathrm{CH}_{3}\right) ;{ }^{13} \mathrm{C}$ NMR $\left(100.5 \mathrm{MHz}, \mathrm{CDCl}_{3}\right) \delta=157.4(\mathrm{C}), 139.4(\mathrm{C}), 135.3(\mathrm{C}), 133.8(\mathrm{CH})$, $133.4(\mathrm{C}), 132.2(\mathrm{CH}), 131.8(\mathrm{CH}), 130.1(\mathrm{CH}), 129.7(\mathrm{CH}), 129.4(\mathrm{CH}), 129.3(\mathrm{CH})$ $121.3(\mathrm{CH}), 118.0\left(\mathrm{CH}_{2}\right), 115.8(\mathrm{CH}), 114.1(\mathrm{CH}), 79.5(\mathrm{CH}), 77.6(\mathrm{CH}), 76.2(\mathrm{CH})$, $68.6(\mathrm{CH}), 44.0\left(\mathrm{CH}_{2}\right), 42.9(\mathrm{CH}), 37.1\left(\mathrm{CH}_{2}\right), 36.5(\mathrm{CH}), 36.2(\mathrm{CH}), 34.7(\mathrm{CH}), 32.0$ (CH), $23.0\left(\mathrm{CH}_{3}\right), 18.9\left(\mathrm{CH}_{3}\right), 17.4\left(\mathrm{CH}_{3}\right), 17.1\left(\mathrm{CH}_{3}\right), 12.1\left(\mathrm{CH}_{3}\right), 9.3\left(\mathrm{CH}_{3}\right) ; \mathrm{IR}(\mathrm{Film})$ $V_{\max }=3360,2350,2341,1620,1434,1396,668 \mathrm{~cm}^{-1}$; HRMS (ESI): $\mathrm{m} / \mathrm{z}$ calcd for $\mathrm{C}_{35} \mathrm{H}_{59} \mathrm{O}_{8} \mathrm{NNa}: 566.3457$ [M+Na]; found: 566.3447 .

\section{Acknowledgements}

We thank Sanofi-Aventis for fellowships for E. d. L. and A. A..

[1] a) S. P. Gunasekera, R. E. Longley, R. A. Isbrucker, J. Nat. Prod. 2002, 65 , 1830-1837; b) S. P. Gunasekera, M. Gunasekera, R. E. Longley, G. K. Schulte, J Org. Chem. 1990, 55, 4912-4915; Correction: J. Org. Chem. 1991, 56, 1346; c) S. P. Gunasekera, G. K. Paul, R. E. Longley, R. A. Isbruker, S. A. Pomponi, J. Nat. Prod. 2002, 65, 1643-1648

[2] a) A. Canales, R. Matesanz, N. M. Gardner, J. M. Andreu, I. Paterson, J. F. Diaz, J. Jimenez-Barbero, Chem. Eur. J. 2008, 14, 7557-7569; b) V. M. SánchezPedregal, K. Kubicek, J. Meiler, I. Lyothier, I. Paterson, T. Carlomagno, Angew. Chem. 2006, 118, 7548-7554; Angew. Chem. Int. Ed. 2006, 45, 7388-7394; c) S. Xia, C. S. Kenesky, P. V. Rucker, A. B. Smith III, G. A. Orr, S. B. Horwitz, Biochemistry 2006, 45, 11762-11775; d) R. M. Bluey, I. Barasoain, E. Jackson, A. Meyer, P. Giannakakou, I. Paterson, S. Mooberry, J. M. Andreu, J. F. Diaz, Chem. Biol. 2005, 12, 1269-1279; e) S. Honore, K. Kamath, D. Braguer, L. Wilson, C. Briand, M. A. Jordan, Mol. Cancer Ther. 2003, 2, 1303-1311; f) L. He, G. A. Orr, S. B. Horwitz, Drug Discovery Today 2001, 6, 1153-1164; g) L. He, H. Y. Chia-Ping, S. B. Horwitz, Mol. Cancer Ther. 2001, 1, 3-10; h) L. A. Martello, M. J. LaMarche, L. He, T. J. Beauchamp, A. B. Smith, III, S. B. Horwitz, Chem. Biol. 2001, 8, 843-855; i) M. Kalesse, ChemBioChem. 2000, 1 , 171-175; j) R. J. Kowalski, P. Giannakakou, S. P. Gunasekera, R. E. Longley, B. W. Day, E. Hamel, Mol. Pharmacol. 1997, 52, 613-622. k) E. ter Haar, R. J. Kowalski, E. Hamel, C. M. Lin, R. E. Longley, S. P. Gunasekera, H. S. Rosenkranz, B. W. Day, Biochemistry 1996, 35, 243-250; 1) R. Balachandran, E. ter Haar, M. J. Welsh, S. G. Grant, B. W. Day, Anti-Cancer Drugs 1998, 6, 6776.

[3] L. E. Klein, B. S. Freeze, A. B. Smith III, S. B. Horwitz, Cell Cycle 2005, 4, 501-507.

[4] a) M. Khrapunovitch-Baine, V. Menon, P. Verdier-Pinard, A. B. Smith III; R. H. Angeletti, A. Fiser, S. B. Horwitz, H. Xiao, Biochemistry 2009, 48, 11664 11677 ; b) G. S. Huang, L. Lopez-Barcons, B. S. Freeze, A. B. Smith III, G. L. Goldberg, S. B. Horwitz, H. M. McDaid, Clin. Cancer Res. 2006, 12, 298-304, b) L. A. Martello, H. M. McDaid, D. L. Regl, C.-P. H. Yang, D. Meng, T. R. R. Pettus, M. D. Kaufman, H. Arimoto, S. J. Danishefsky, A. B. Smith III, S. B. Horwitz, Clin. Cancer Res. 2000, 6, 1978-1987.

[5] A. Mita, C. Lockhart, T. L. Chen, K. Bocinski, J. Curtright, W. Cooper, L. Hammond, M. Rothenberg, E. Rowinsky, S. Sharma, J. Clin. Oncol. 2004, 22 , 133S-133S (14S - ASCO Annual Meeting Proceedings, Post-Meeting Edition), abstract 2025

[6] For instance: a) I. Paterson, G. J. Naylor, N. M. Gardner, E. Guzman, A. E. Wright, Chem. Asian J. 2011, 6, 459-473; b) I. Paterson, G. J. Naylor, T. Fujita, E. Guzman, A. E. Wright, Chem. Commun. 2010, 46, 261-263; c) K. Prantz, J. Mulzer, Chem. Eur. J. 2010, 16, 485-506; d) Y. Fan, E. M. Schreiber, B. W. Day, J. Nat. Prod. 2009, 72, 1748-1754; e) X. Mollat du Jourdain, M. Noshi, P. L. Fuchs, Org. Lett. 2009, 11, 543-545; f) H. Cao, K. A. Parker, Org. Lett. 2008, 10, 1353-1356.

[7] a) A. S. Jogalekar, F. H. Kriel, Q. Shi, B. Cornett, D. Cicero, J. P. Snyder, J. Med. Chem. 2010, 53, 155-165 and references therein; b) L. B. Salum, L. C. Dias, A. D. Andricopulo, QSAR Comb. Sci. 2009, 28, 325-337; c) A. Canales, R. Matesanz, N. M. Gardner, J. M. Andreu, I. Paterson, J. F. Diaz, J. JimenezBarbero, Chem. Eur. J. 2008, 14, 7557-7569; d) A. B. Smith, M. LaMarche, M. Falcone-Hindley, Org. Lett. 2001, 3, 695-698.

[8] DDM total synthesis: a) J. B. Nerenberg, D. T. Hung, P. K. Somers, S. L. Schreiber, J. Am. Chem. Soc. 1993, 115, 12621-12622; b) D. T. Hung, J. B. Nerenberg, S. L. Schreiber, J. Am. Chem. Soc. 1996, 118, 11054-11080; c) A. B. Smith III, Y. Qiu, D. R. Jones, K. Kobayashi, J. Am. Chem. Soc. 1995, 117, 12011-12012; d) A. B. Smith III, T. J. Beauchamp, M. J. LaMarche, M. D. Kaufman, Y. Qiu, H. Arimoto, D. R. Jones, K. Kobayashi, J. Am. Chem. Soc. 2000, 122, 8654-8664, and references therein; e) S. S. Harried, G. Yang, M. A. Strawn, D. C. Myles, J. Org. Chem. 1997, 62, 6098-6099; f) S. S. Harried, C. P. Lee, G. Yang, T. I. H. Lee, D. C Myles, J. Org. Chem. 2003, 68, 6646-6660; g) J. A. Marshall, Z.-H. Lu, B. A. Johns, J. Org. Chem. 1998, 63, 817-823; h) J. A. Marshall, B. A. Johns, J. Org. Chem. 1998, 63, 7885-7892; i) I. Paterson, G. J. Florence, K. Gerlach, J. P. Scott, Angew. Chem. 2000, 112, 385-388; Angew. Chem. Int. Ed. 2000, 39, 377-380; j) I. Paterson, G. J. Florence, Eur. J. Org. Chem. 2003, 2193-2208; k) I. Paterson, I. Lyothier, J. Org. Chem. 2005, 70, 5494-5507, and references therein; 1) A. Arefolov, J. S. Panek, J. Am. Chem. Soc 2005, 127, 5596-5603, and references therein; m) E. de Lemos, F. H. Porée, A. Commerçon, J.-F. Betzer, A. Pancrazi, J. Ardisson, Angew. Chem. 2007, 48, 9509-9600; Angew. Chem. Int. Ed. 2007, 46, 1917-1921; n) E. de Lemos, F. H. Porée, A. Bourin, J. Barbion, E. Agouridas, M.-I. Lannou, A. Commerçon, J.-F. Betzer, A. Pancrazi, J. Ardisson, Chem. Eur. J. 2008, 14, 11092-11112. 
[9] For a preparative scale synthesis of DDM see: a) S. J. Mickel, D. Niederer, R. Daeffler, A. Osmani, E. Kuesters, E. Schmid, K. Schaer, R. Gamboni, W. Chen, E. Loeser, F. R. Kinder, Jr., K. Konigsberger, K. Prasad, T. M. Ramsey, O. Repič, R.-M. Wang, G. Florence, I. Lyothier, I. Paterson, Org. Process Res. Dev. 2004, 8, 122-130, and the four precedent papers; b) S. J. Mickel, R. Daeffler, W. Prikoszovich, Org. Process Res. Dev. 2005, 9, 113-120; c) O. Loiseleur, G. Koch, J. Cercus, F. Schürch, Org. Process Res. Dev. 2005, 9, 259-271.

[10] For recent reviews on DDM synthesis and DDM analogue design, synthesis an biological activity see: a) S. J. Shaw, Mini-Rev. Med. Chem 2008, 8, 276-284, and references therein; b) A. B. Smith III, B. S. Freeze, Tetrahedron 2008, 64 261-298, and references therein; c) G. J. Florence, N. M. Gardner, I. Paterson, Nat. Prod. Rep. 2008, 25, 342-375, and references therein d) I. Paterson, G. J. Florence, Top. Curr. Chem. 2009, 286, 73-119 and references therein.

[11] Design and synthesis of DDM analogues (highlights): a) D. T. Hung, J. B Nerenberg, S. L. Schreiber, Chem. Biol. 1994, 1, 67-71; b) I. Paterson, K. R Gibson, R. M. Oballa, Tetrahedron Lett. 1996, 37, 8585-8588; c) I. Paterson, G J. Florence, K. gerlach, J. P. Scott, N. Sereinig, J. Am. Chem. Soc 2001, 123 9535-9544; d) F. R., Kinder Jr., K. W. Bair, W. Chen, G. J. Florence, C Francavilla, P. Geng, S. Gunasekera, P. T. Lassota, R. Longley, M. Palermo, I. Paterson, S. Pomponi, T. M. Ramsey, L. Rogers, M. Sabio, N. Sereini, E. Sorensen, R. Wang, A. Wright, Presented at American Association for Cance Research $93^{\text {rd }}$ Annual meeting, San Francisco, CA, 2002. Poster 3650; e) F. R. Kinder, WO 2,002,012,220, 2002; f) F. R. Kinder Jr., P. K. Paka, E. M. Loeser WO 2,002,098,843, 2002; g) F. R. Kinder Jr., K. W. Bair, T. M. Ramsey, M. L. Sabio WO 2,003,014,102, 2003; h) S. P. Gunasekera, S. J. Mickel, R. Daeffler, D. Niederer, A. E. Wright, P. Linley, T. Pitts, J. Nat. Prod. 2004, 67, 749-756; i) D. P. Curran, T. Furukawa, Org. Lett. 2002, 4, 2233-2235; j) J. M. Minguez, K A. Giulano, R. balachadran, C. Madijaru, B. W. Day, D. P. Curran, Biorg. Med Chem. 2003, 11, 3335-3357; k) M. A. Burlingame, S. J. Shaw, K. F. Sundermann, D. Zhang, J. Petryka, E. Mendoza, F. Liu, D. C. Myles, M. J. LaMarche, T. Hirose, B. S. Freeze, A. B. Smith III, Bioorg. Med. Chem. Lett 2004, 14, 2335-2338; 1) A. B. Smith III, B. S. Freeze, M. J. LaMarche, T. Hirose, I. Brouard, M. Xian, K. F. Sundermann, S. J. Shaw, M. A. Burlingame, S. B. Horwitz, D. C. Myles, Org. Lett. 2005, 7, 315-318; m) A. B. Smith III, B. S. Freeze, M. J. LaMarche, T. Hirose, I. Brouard, P. V. Rucker, M. Xian, K. F. Sundermann, S. J. Shaw, M. A. Burlingame, S. B. Horwitz, D. C. Myles, Org Lett. 2005, 7, 311-314; n) S. J. Shaw, K. F. Sundermann, M. A. Burlingame, D C. Myles, B. S. Freeze, M. Xian, I. Brouard, A. B. Smith III, J. Am. Chem. Soc 2005, 127, 6532-6533; o) A. B. Smith III, B. S. Freeze, M. J. LaMarche, J. Sager, K. W. Kinzler, B. Vogelstein, Bioorg. Med. Chem. Lett. 2005, 15, 3623 3626; p) S. J. Shaw, H. G. Menzella, D. C. Myles, M. Xian, A. B. Smith III, Org. Biomol. Chem. 2007, 5, 2753-2755.

[12] It has been shown by stochastic conformational analysis (Monte Carlo method, Spartan'04 Win. Software, MMF94aq force field) from RX diffraction DDM structure, that the "U"'-shaped conformers of the three following analogues were the lowest in energy (see Supporting Information).

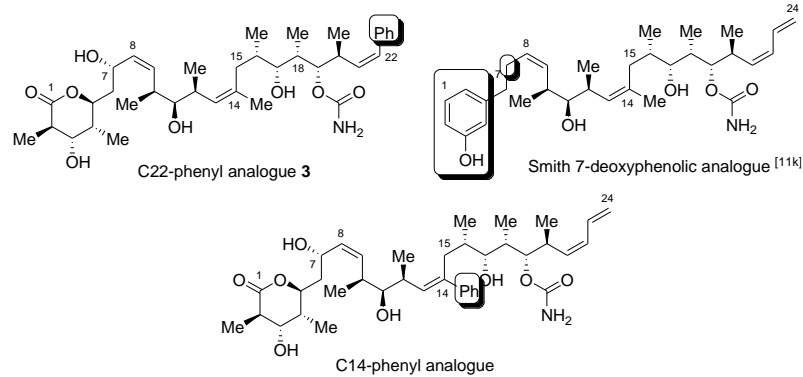

[25] The formation of the cyclohexene 40 through an intramolecular coupling reaction proves the fold of the $\mathrm{C} 8-\mathrm{C} 14$ core

Received: ((will be filled in by the editorial staff))

Revised: ((will be filled in by the editorial staff)) Published online: ((will be filled in by the editorial staff)

[14] a) V. Fargeas, P. Le Ménez, I. Berque, J. Ardisson, A. Pancrazi, Tetrahedron 1996, 52, 6613-6634; b) I. Berque, P. Le Ménez, P. Razon, C. Anies, A Pancrazi, J. Ardisson, A. Neuman, T. Prangé, J.-D. Brion, Synlett 1998, 11321134; c) I. Berque, P. Le Ménez, P. Razon, A. Pancrazi, J. Ardisson, J.-D. Brion, Synlett 1998, 1135-1137; d) I. Berque, P. Le Ménez, P. Razon, J. Mahuteau, J.-P. Férézou, A. Pancrazi, J. Ardisson, J.-D. Brion, J. Org. Chem. 1999, 64, 373-381.

[15] F.-H. Porée, A. Clavel, J.-F. Betzer, A. Pancrazi, J. Ardisson, Tetrahedron Lett. 2003, 44, 7553-7556.

16] Noteworthy, in this particular case, the vinylation reaction of $\mathbf{1 1}$ with vinylmagnesium bromide gave highly variable but mostly low yields. The reaction with solely vinyllithium species without magnesium salt (produced from tetravinyltin and MeLi) allowed the formation of the desired product $\mathbf{1 2}$ in a reproducible high yield.

17] a) P. Kocienski, S. Wadman, K. Cooper, J. Am. Chem. Soc. 1989, 111, 2363 2365; b) P. Kocienski, C. Barber, Pure Appl. Chem. 1990, 62, 1933-1940. c) P. Kocienski in Organic Synthesis via Organometallics, Proceeding of the Fourth Symposium in Aachen, July 15-18 1992; E. Enders, H.-J. Eds; Verlag Wiesbaden: Germany, 1992.

[18] 7-hydroxyphenol analogue 6 was briefly presented only once: W. Chen, K. W. Blair, P. T. Lassota, T. M. Ramsey, E. Sorensen, R. M. Wang, F. R. Kinder Jr, Abstracts of Papers, 224 $4^{\text {th }}$ Meeting of the American Chemical Society, Boston, MA; American Chemical Society: Washington DC, 2002; Abstracts ORGN 790.

[19] J. A. Marshall, G. M. Schaaf, J. Org. Chem. 2003, 68, 7428-7432.

[20] a) B. M. Trost, J. L. Belletire, S. Godleski, P. G. McDougal, J. M. Balkovec, J.J. Baldwin, M. E. Christy, G. S. Ponticello, S. L. Varga, J. P. Springer, J. Org Chem. 1986, 51, 2370-2374; b) J. M. Seco, E. Quiñoá, R. Riguera, Chem. Rev. 2004, 104, 17-117.

21] The assignment of the configuration of the (S) C12 methyl centre of compound 25 was determined in analogy with the corresponding sequence developed for DDM synthesis.

[22] a) E. J. Corey, R. K. Bakshi, S. Shibata, J. Am. Chem. Soc. 1987, 109, 55515553; b) E. J. Corey, C. J. Helal, Angew. Chem. 1998, 110, 2092-2118; Angew. Chem. Int. Ed. 1998, 37, 1986-2012. c) B. M. Trost, J. L. Gunzner, O. Dirat, Y. H. Rhee, J. Am. Chem. Soc. 2002, 124, 10396-10415.

23] In this case, the Suzuki cross-coupling reaction gave a highly disappointing low yield $(10 \%)$. We suspected that the isopropyl group could have deleterious effects for steric reasons. Therefore, we investigated this reaction between model substrates; however, under the same conditions; the desired product was obtained in $61 \%$ yield.

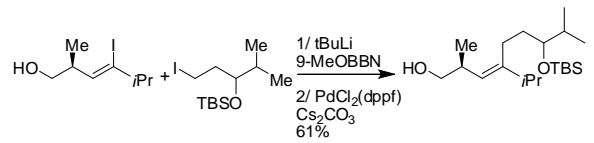

The $\mathrm{C} 7$ centre configuration of the alcohol precursor of $\mathbf{3 7}$ was confirmed through derivatization to the corresponding $(R)$ - and $(S)$ - $\alpha$-methoxyphenylacetic acid (MPA) ester (see experimental part). ${ }^{[20]}$

[13] a) D. Hoppe, Angew. Chem. 1984, 96, 930-946; Angew. Chem, Int. Ed. Engl. 1984, 23, 932-948; b) D. Hoppe, O. Zschage, Angew. Chem. 1989, 101, 67-69; Angew. Chem. Int. Ed. Engl. 1989, 28, 69-71; c) D. Hoppe, O. Zschage, Tetrahedron 1992, 48, 8389-8392. D. Hoppe, T. Hense, D. Hoppe, T. Hense, Angew. Chem. 1997, 109, 2376-2410; Angew. Chem. Int. Ed. 1997, 36, 22822316 